\title{
Too little, too late? Evaluating the European Works Councils Recast Directive
}

Stan De Spiegelaere

Report 138 


\section{Too little, too late? Evaluating the European Works Councils Recast Directive \\ Stan De Spiegelaere}

Report 138

european trade union institute 
Stan De Spiegelaere is a researcher at the European Trade Union Institute, Brussels. Contact: sdespiegelaere@etui.org

The author is grateful for the help and comments of Aline Hoffmann, Romuald Jagodzinski, Irmgard Pas, Jeremy Waddington and the participants of the two workshops on the EWC Recast Directive organized by the ETUI.

Brussels, 2016

๑Publisher: ETUI aisbl, Brussels

All rights reserved

Print: ETUI Printshop, Brussels

D/2016/10.574/23

ISBN: 978-2-87452-410-3 (print version)

ISBN: 978-2-87452-411-0 (electronic version)

The ETUI is financially supported by the European Union. The European Union is not responsible for any use made of the information contained in this publication. 


\section{Contents}

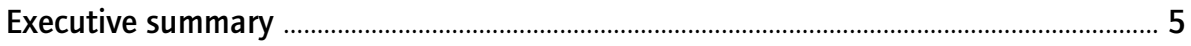

1. More EWCs: too little ................................................................................................. 5

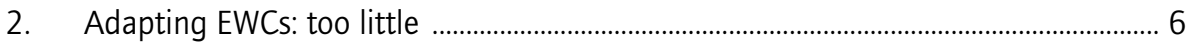

3. Better EWCs: too little, too late .................................................................................. 6

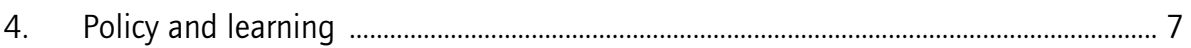

5. Conclusion: too little, too late .......................................................................................... 7

6. The future: more and better ............................................................................................... 8

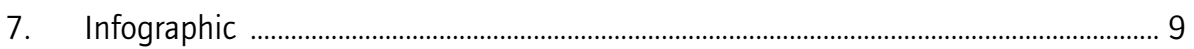

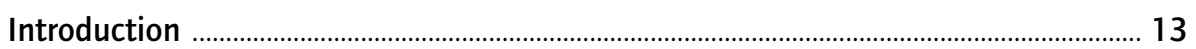

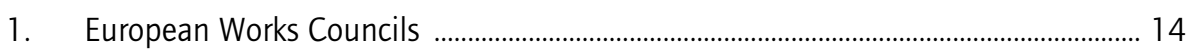

2. The EWC Directives ............................................................................................. 14

3. The evaluation of the Recast Directive …………..................................................... 18

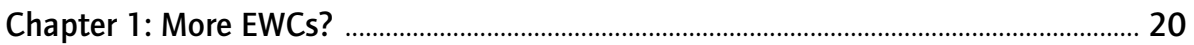

1. The Recast's declared objectives and instruments ..................................................... 21

2. EWC growth rate ............................................................................................................ 22

3. Compliance: are there still sufficient companies? ........................................................... 25

4. Alternatives: are EWCs transforming into alternative legal frameworks? ................ 26

5. Changing company characteristics .............................................................................. 28

6. Other possible explanations ....................................................................................... 29

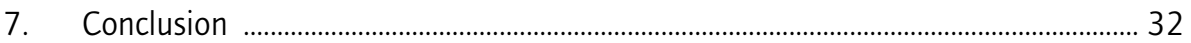

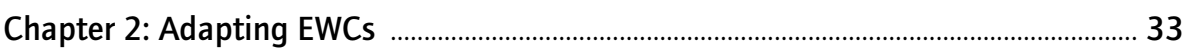

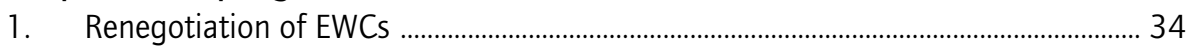

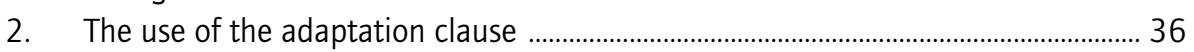

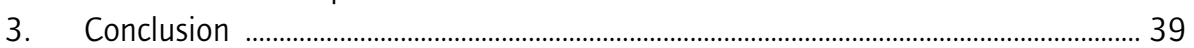

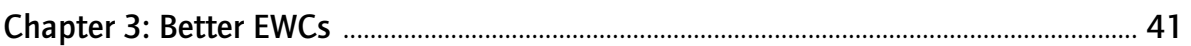

1. Looking at agreements to evaluate the Recast ........................................................... 42

2. EWC Recast Directive - Hypotheses ………………………………………………….... 45

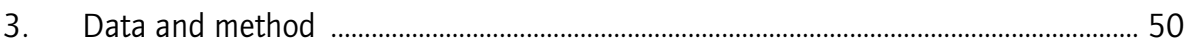

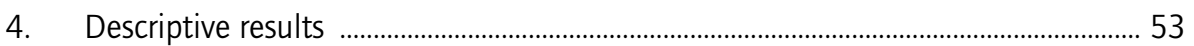

5. Multivariate results .................................................................................................... 55

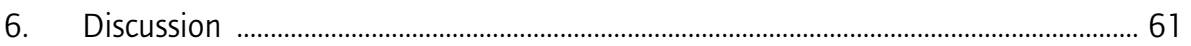

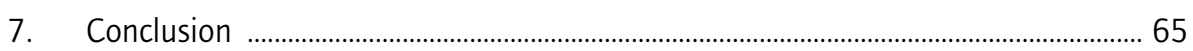




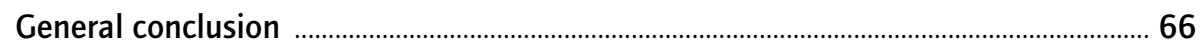

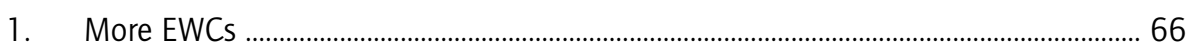

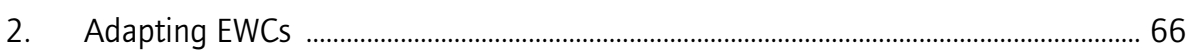

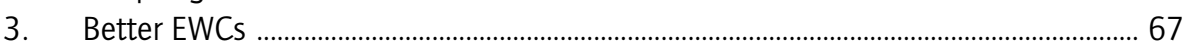

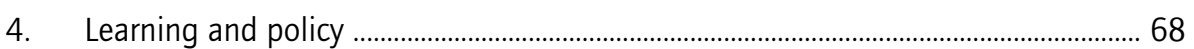

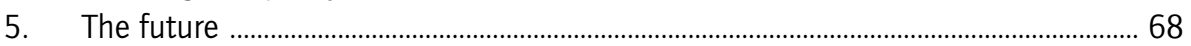

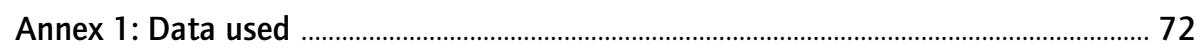

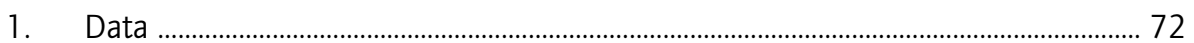

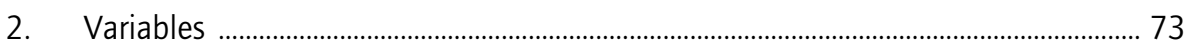

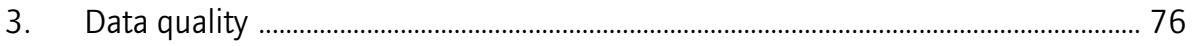

4. Robustness test of the GEE models .............................................................................. 76

Annex 2: EWC agreement content: evolutions and bivariate relations ........................ 77

1. EWC agreement demographics .................................................................................... 77

2. Agreement content and characteristics: bivariate relations ......................................... 82

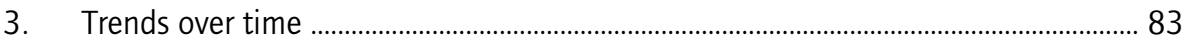

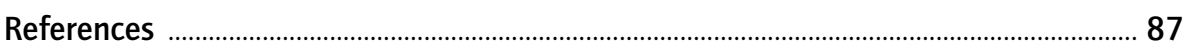




\section{Executive summary}

In 2009, after years of discussion, the European Union adopted the European Works Councils Recast Directive. The principal aims were to increase the amount of European Works Councils (EWCs) and to improve the functioning of the existing and future EWCs. In the Recast, an evaluation of the implementation was envisaged for June 2016.

For the European Trade Union Institute (ETUI), EWCs have always been a priority. From the beginning, the ETUI has monitored their development and now currently runs the most exhaustive database available on EWCs. Making thorough use of this database, this report presents an evaluation of the effectiveness of the Recast Directive in reaching its declared objectives. The conclusions of this report are based on data from more than 1400 EWCs created over the years and the analysis of more than 1000 EWC agreements.

While the Recast Directive was a clear improvement on the original Directive, and contributed to the legal certainty around EWCs in several ways, the overall conclusion of this evaluation is that it was in most respects too little, too late for enabling the establishment of more and better EWCs.

\section{More EWCs: too little}

The Recast was ineffective in boosting the establishment of new EWCs. A lack of incentives seems to be the major explanation.
Based on the results of this research, the Recast Directive was found to be ineffective in stimulating the creation of more EWCs. Both during the second transition period and in the post-Recast period, the amount of newly created EWCs declined and continues to do so. There are still lots of firms that could have an EWC but do not have one yet, so this decline in the growth rate is unlikely to be the result of what this report refers to as a saturated population; neither can it be attributed to the existence of alternative ways of organizing transnational information and consultation.

The legal instruments provided by the Recast to boost the establishment of new EWCs (transition period, information to trade unions and clarification on who should provide the necessary information for the negotiations) have proven ineffective and insufficient. The multiple obstacles faced by employees in creating EWCs are left unaddressed by the current legal framework. 
The Recast led to a minor increase in renegotiations and amendments of existing EWC agreements.

The adaptation clause of the Recast was of limited effectiveness. Obstacles in using this clause remain unaddressed by both the Recast and the national implementation laws.

A large proportion of EWCS (42\%) remain exempt from the rules of the Recast, limiting its potential effect. Many have never renegotiated their agreement. This undermines the ability of regulation to affect the EWC reality.

\section{Adapting EWCs: too little}

Although the Recast aimed to improve the functioning of both existing and future EWCs, it explicitly ruled out an obligation to renegotiate agreements. The figures show that there was a slight increase of renegotiations and amendments in the post-Recast period. This shows that EWCs did see the use in aligning their agreements with the new rules and obligations.

The Recast also provides for an obligation (if so requested by either the employer or employees) to fully renegotiate the EWC agreement in the event of 'significant structural changes' in the company. Such a renegotiation entails the creation of a new Special Negotiation Body (SNB) and thus leads to a brand new EWC. This so-called adaptation clause was expected to serve as a converging factor, as it gives some EWCs the possibility to change their preDirective status. Such a convergence did not materialize. Few EWCs have transformed from pre-Directive into normal Article 6 EWCs.

The ineffectiveness of the adaptation clause is likely caused by various factors which are left unaddressed by the Recast: insufficient knowledge of the existence of this clause, limited legal clarity on what 'significant change of structure' means, other priorities for employee representatives and management in the event of a merger, power dynamics, high perceived costs and low perceived added value.

One of the consequences of the limited effectiveness of the adaptation clause is that a considerable number of EWCs continue to function as pre-Directive EWCs (42\%). Many of these have never renegotiated their agreement. This undermines the ability of any regulation to influence the content of EWC agreements and therefore influence EWC practice.

\section{Better EWCs: too little, too late}

This report studies the contribution of the Recast to creating better EWCs. For this, EWC agreements established before, during and after the Recast are compared, expecting to observe significant differences in their content. The focus was on the presence of the following agreement characteristics which are likely to be stimulated by the Recast: information and consultation definitions, the presence of a select committee, training clauses, definition of the 'transnational competence', a clause on reporting back to employees, access to company premises, preparatory and debriefing meetings, the presence of a trade union representative, and the inclusion of renegotiation and termination clauses.

The results show that a clear Recast effect is observable for only three of these characteristics: information and consultation definitions, definition of the transnational competence and the presence of a clause on reporting back. 
The Recast merely affirmed the already-existing reality of omnipresent select committees and training rights.

The Recast did not effectively boost the inclusion of trade union representatives in EWCS or with the provision of access to company premises. A lack of legal instruments to enforce this objective is the most likely cause.

Learning effects surpassed policy effects.
For all the other variables, a Recast effect could not be identified. In most cases, however, EWCs seem to learn and copy practices from each other, one example being the provision of training. This means that with every passing year, more agreements tend to include these clauses. Throughout this report, this phenomenon is referred to as the learning effect'.

In the case of the select committee, training clauses and preparatory and debriefing meetings, almost all agreements signed just before the Recast already included these clauses. There was therefore only limited room for improvement, explaining why a Recast effect could not be established. On these topics the Recast merely affirmed the fact that in virtually all recent EWC agreements these aspects are already included.

For the inclusion of trade union representatives and giving EWC members access to the company premises, no Recast effect is observed; although there remains great potential for improvement. The vague way in which these objectives were included in the Recast was inefficient at boosting their inclusion in EWC agreements.

\section{Policy and learning}

One of the major explanations for the limited effect of the Recast Directive on the content of EWC agreements is the observed strong learning effects, which leave only limited room for improvement. The fact that in many ways these learning effects surpassed the policy effects, and that policy (by means of the Recast) only managed to catch up with learning, can be explained in two ways.

One the one hand, learning in EWCs was particularly strong. Thanks to the efforts of the European Trade Union Federations in providing coordination for EWCs' negotiation and practice, and the development of specialized training courses, some practices proliferated very quickly.

On the other hand, policy is particularly weak. In many cases, the Recast only stipulates what should be regulated but does not prescribe the content or specific solutions. There is also no administrative monitoring or sanctioning policy organized to enforce compliance. This, together with legislation that merely reflects the most common and accepted practices already in place, reduces the potential for strong policy effects.

\section{Conclusion: too little, too late}

In conclusion, the Recast Directive can be considered as being too little, too late to really lead to more and better EWCs. It was too little to encourage the establishment of new EWCs, as it did not provide instruments to overcome various obstacles in their formation. It similarly provides insufficient levers to make the adaptation clause effective in reality. Several of the Recast interventions to increase the effectiveness of EWCs came too late as they were 
already omnipresent in recently renegotiated agreements. Furthermore, the Recast provided insufficient incentives to promote other more uncommon good practices. More generally, the Recast can be considered as too little because it established some rights, and forces agreements to mention some clauses, but provides little guidance with regards to content and compliance.

\section{The future: more and better}

Future policy intervention should provide real resources and incentives for the creation of more and better EWCs. From this evaluation study we identify six potential areas of progress:

1. Policy which drives pro-active innovation: instead of reflecting commonly accepted practices, policy should stimulate less commonly employed good practices to really upgrade the functioning of the average EWC.

2. Right and levers to use them: establishing a certain right (e.g. renegotiation in case of structural change) without providing the necessary instruments to make this right effective in practice should be avoided. Rights should be combined with effective resources to overcome common obstacles.

3. Focus on capacity building: if policy aims to promote the establishment of more EWCs, it should focus on building up the capacity of the partners to make good use of the EWC, but also ensure their capacity to negotiate an agreement. Here, investment in trade union organizations and local information and consultation institutions is essential.

4. Knowledge and information: other major obstacles in the establishment of more EWCs and the effective use of the rights at hand include limited knowledge of the existing rules and insufficient information on which companies are covered by the Directive (lack of a company registry).

5. Monitoring of formal compliance with EWC agreements could be developed in order to reduce the legal uncertainty arising from diversity in legal arrangements, itself being a consequence of the policy of 'regulated self-regulation.'

6. Clarity in objectives: certain objectives of the Recast (e.g. stimulating trade union involvement) were included implicitly. Naturally, the effectiveness of these policy interventions is limited. If policy aims to stimulate certain practices, these objectives should be clearly included in the legal texts and backed by robust provisions. 


\section{Infographic}

\section{Too little, too late?}

Evaluating the European Works Councils Recast Directive Stan De Spiegelaere - ETUI

\section{The objectives of the Recast}
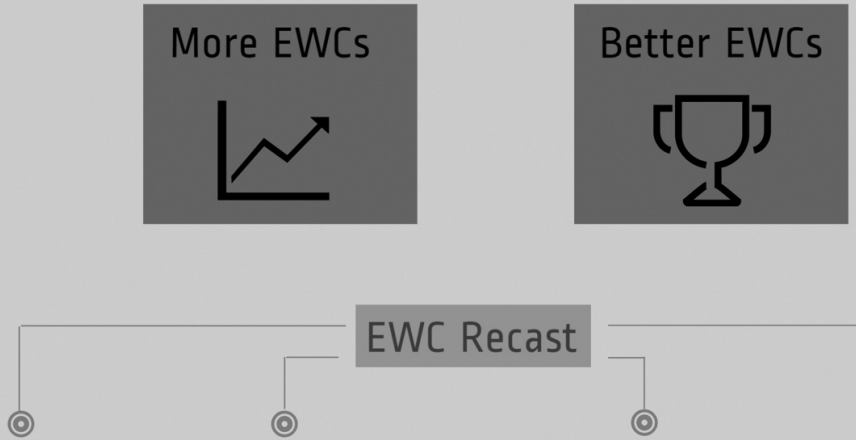

\section{EWC Recast}

Definitions Rights \& obligations

Adaptation clause Trade union role
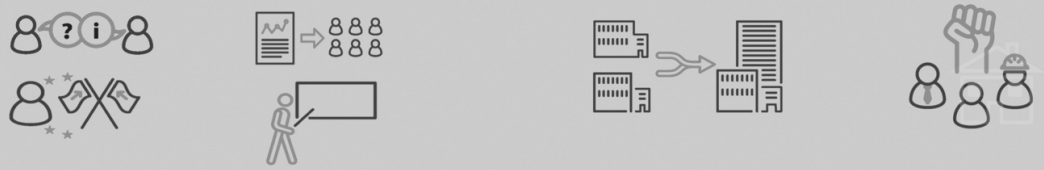

\section{The results}

\section{More EWCs?}
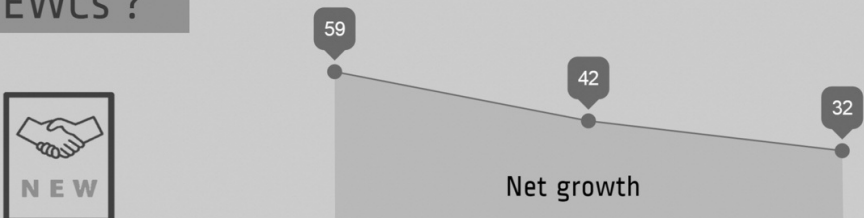

Net growth

2006-2008

2009-2011

$2012-2015$

21 EWCs can be considered as Art 14.1b EWCs. 


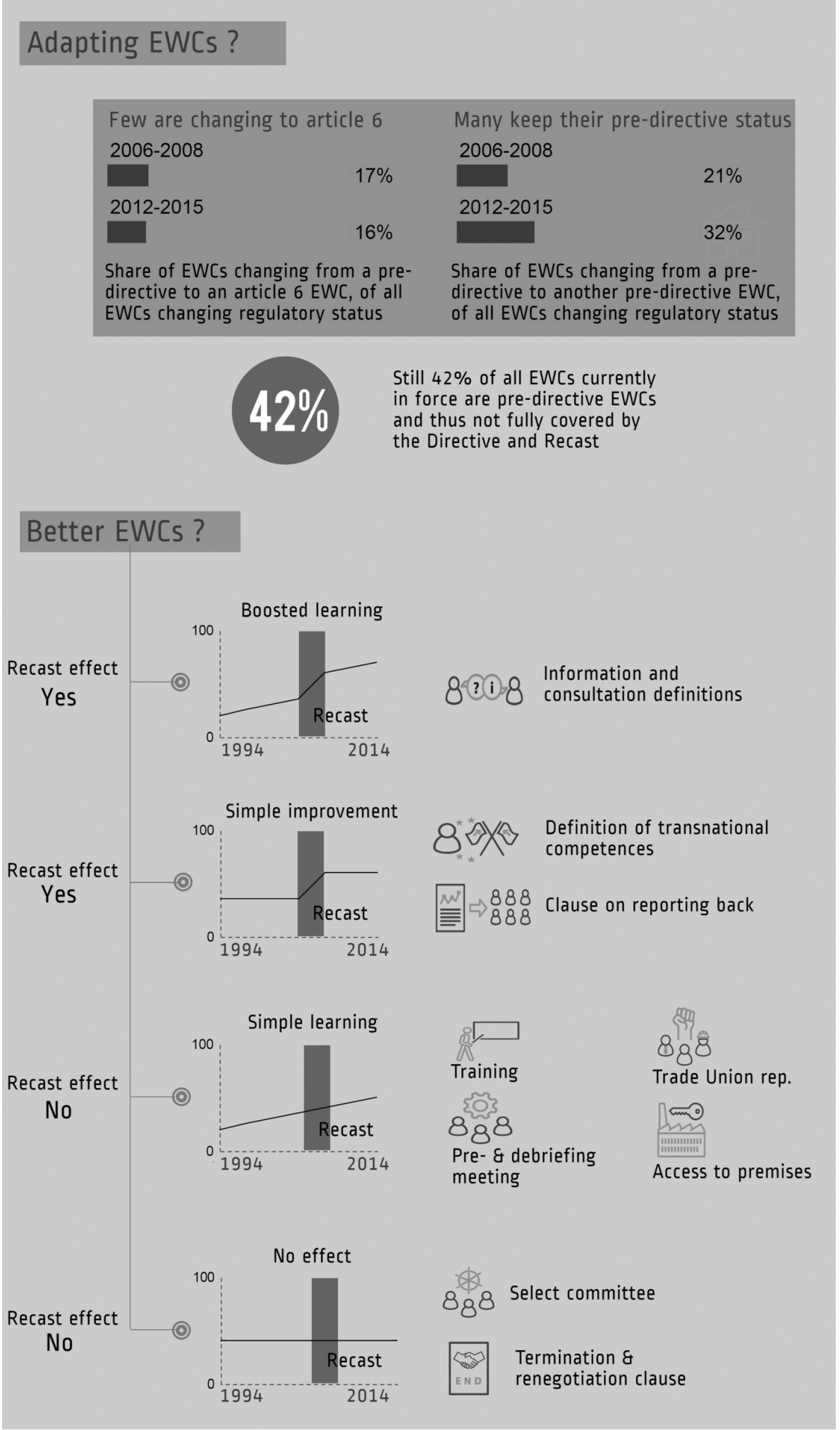




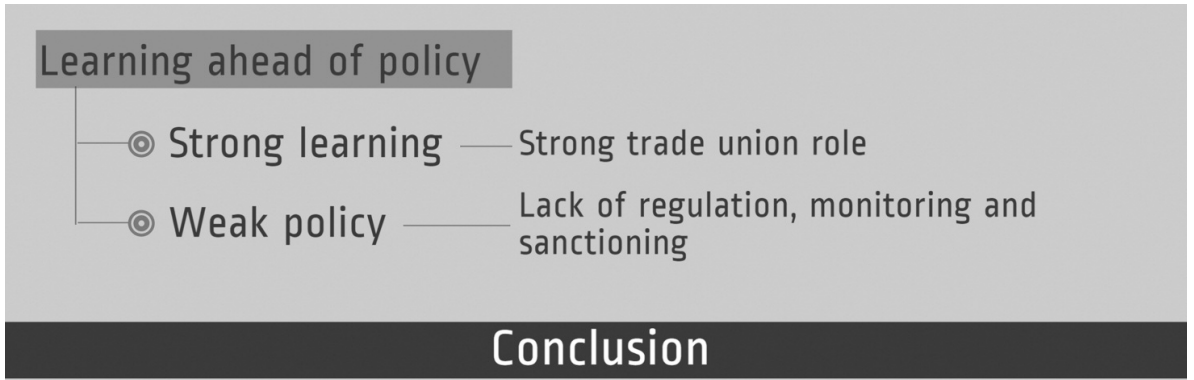

\section{Too little \& too late}

( ) Slowing growth rate

$\rightarrow$ Lack of incentives

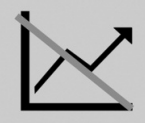

(?) Ineffective adaptation clause

$\rightarrow$ Lack of instruments to overcome obstacles

\section{Confirming, not forming reality}

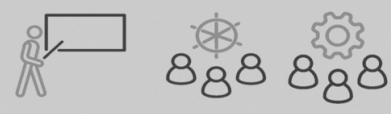

() No incentives for real innovation

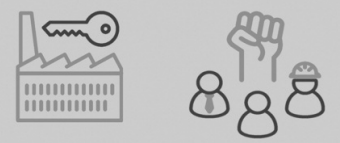

\section{Future}

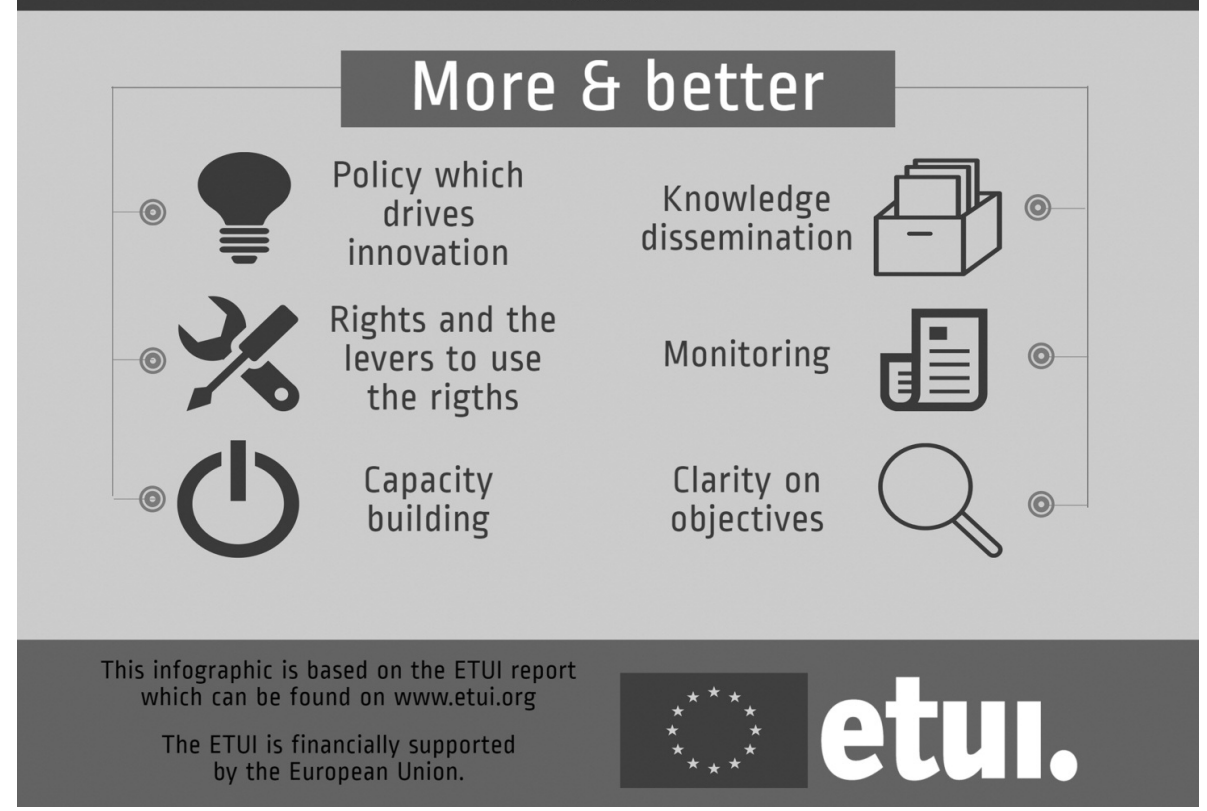





\section{Introduction}

2016 is the year in which Europe can engage in an in-depth evaluation of how the 2009 Recast of the original 1994 Directive on European Works Councils (EWCs) has been implemented. This evaluation promises to be a subject of contestation, triggering a discussion not only on the merits and limitations of the current legislation, but also on the desirability of further policy steps.

While most countries and social partners acknowledge the relevance, potential and added value of EWCs, there is no shared opinion on what the role of policy should be in this. Employee representatives and trade unions wish to bolster the functioning of the EWCs by establishing clearer rights and competences for representatives. In this approach, policy has a role to play. BusinessEurope, on the other hand, fears the mounting costs of EWCs and their impact on decision-making. They therefore support a more voluntary approach: if wished for, companies should be able to develop extensive EWCs, but they should not be forced to do so. Clearly, policy has only a restricted role in such a scenario.

Before a debate on future policy steps can take place, a thorough evaluation of the successes and failures of past policy is necessary. This report is the contribution of the European Trade Union Institute (ETUI) towards this evaluation exercise.

From the perspective of the ETUI, supporting the development of the EWCs has always been a priority. These councils form a unique platform for employee representatives from all over Europe to meet, exchange information and discuss matters that affect them all. It is the only forum in which they can be informed and consulted about the overarching strategy of the firm and how it affects the employees. An EWC also gives the employers the opportunity to consult employee representatives on planned policies and incorporate their views. Moreover, together with the later established SE (societas europaea) Works Councils, EWCs are the only policy-backed institutions that might lead to a much needed Europeanisation of industrial relations.

Because of this, the ETUI has long invested in researching and monitoring the development of EWCs. The EWC database ran by the ETUI (ewcdb.eu) is currently the most exhaustive database on available EWC agreements and also collects information on EWC evolutions, as well as relevant company information. The purpose of this database is to monitor developments in EWCs, provide access to information for practitioners and researchers, and enable a more in-depth analysis of evolutions over time. 


\section{European Works Councils}

Creating a single European market was one of the policy priorities of the EU in the last decade. In line with the deepening of this single market, multinationals and national companies tend to spread their activities over multiple Member States and thus 'Europeanise' their operations (Fligstein and Merand 2002). As these firms Europeanise, their management also moves to the transnational level. Crucial strategic decisions are no longer taken by national management, but in European or global headquarters.

At the same time, almost all European countries have developed systems of employee information and consultation. Mostly, these systems require the organization of local and national works councils. In these works councils, employee representatives are informed about the company situation, strategy and any upcoming changes, enabling them to voice their concerns about these decisions.

When company decisions are taken at a transnational level, the national systems of employee information and consultation no longer suffice. Employees in multinationals are unable to get the crucial transnational information and can no longer defend their interests to the real, transnational, decision-makers. In order to cope with this problem of levels, the European Union decided to install several regulatory frameworks on the transnational information and consultation of employees. As such, directives were developed regarding employee involvement in the case of collective redundancies, transfer of undertakings, cross-border mergers, and employee involvement in European companies, among others (ETUC and ETUI 2016).

One of the most important of these directives was the 1994 Directive on the European Works Councils (EWCs). This Directive covers a wide range of companies and led to the establishment of hundreds of EWCs, of which there were more than 1000 up and running in 2015 (De Spiegelaere and Jagodzinski 2015).

European works councils are bodies for employee information and consultation on transnational issues. They bring together representatives of the employees and employers to discuss the transnational company strategy and policy, and their potential consequences for employees.

\section{The EWC Directives}

The EWC Directives (both the 1994 original and 2009 Recast) regulate the establishment of European Works Councils in European multinationals that have at least 1000 employees in the countries covered by the Directive, of which at least 150 are employed in two different countries. In such companies, and after an initiative from the employee or employer side, an EWC is to be negotiated and installed. 


\subsection{Regulated self-regulation and EWC agreements}

The Directives provide general requirements on the procedures, competences, role and composition of an EWC; but in general the choice is left to the company employer and employee representatives to agree on the specifics. Almost all EWCs are therefore based on a negotiated agreement. If the parties are not able to reach such an agreement, pre-designed rules apply (the socalled 'subsidiary requirements'). The EWC regulation is hence an example of regulated self-regulation, as it gives the opportunity of self-regulation within certain limits and including some auxiliary rules (Platzer 2002).

An EWC is thus never created 'by default'. Employers and employees need to go through a (lengthy) process of negotiations before they can establish an EWC by agreement, or according to the subsidiary requirements when no agreement can be reached.

In the large majority of cases, an agreement is established and signed between the different parties. This EWC agreement forms the cornerstone of the EWC functioning, as it specifies the mutual rights, obligations, and procedures to be followed. The negotiation of an EWC agreement is done by an existing EWC or by a Special Negotiation Body (SNB). An SNB is a temporary body of employee representatives that enters into negotiations with the management on how to structure the functioning of the EWC.

The EWC agreement is also one of the primary interfaces in which the policy maker tries to affect the functioning of the EWC in practice. Both EWC Directives specified the need for the negotiating parties to discuss and mention a topic, rather than indicating a preferred outcome. In Article 6 of the original EWC Directive, clear indications are given on what the EWC agreement must discuss and mention. Examples include the composition of the EWC, its functions and procedures, the frequency of meetings, the financial means, and the duration of the agreement. In the Recast, this article was extended with more specifications. By extending this to-do list of EWC agreements, the policy makers aimed to (indirectly) influence the practical functioning of the EWCs in the field.

Beyond Article 6, however, both the EWC Directive and the Recast rely on the individual agreements to specify the details of how the EWC functions. The EWC Recast Directive clearly establishes several rights: in Article 10§4, the right to training; in Article 10§1, the obligation of management to provide the means required to apply these rights; and in Article 10\$2, the necessity to report back to the employees. An effective implementation of these specifications requires agreement on how they should be enacted but (strictly speaking) they do not have to be outlined in the specific agreement.

1. The negotiating partners can also decide not to establish an EWC but instead initiate a 'procedure for information and consultation of employees'. Such a procedure should guarantee the provision of equally qualitative information and consultation to employees. In practice, this option is used only rarely. 
To conclude, observations reveal that on various topics the policy makers aimed to influence the effectiveness of EWCs by extending (directly and indirectly) the scope of the EWC agreements. In other words, the Directives push the negotiation partners to talk and agree on many more topics and hope that this will boost the functioning of the EWC. Consequently, this report will focus on an evaluation of how this policy intervention (the Recast Directive) affected the content of EWC agreements.

\subsection{Transition periods}

In order to get the EWCs up and running, the 1994 EWC Directive included the infamous Article 13, which stressed the 'self-regulatory' aspect. This article stipulates that EWCs created before the EWC Directive came into force (on 22 September 1996) were exempted from the rules of the Directive and were therefore fully 'self-regulated' or voluntary. This article created a transition period which led to a record number of companies negotiating and agreeing swiftly on the establishment of EWCs. Since then, two kinds of EWCs exist: the pre-Directive Article 13 EWCs, which are exempt from the obligations arising from the Directive, and the post-Directive Article 6 EWCs, which are fully covered by the Directive and all its obligations.

With the Recast Directive, the European institutions wished to again incorporate a transition period in order to boost the negotiations and establishment of EWCs, and so included Article 14.1b. This article stipulates that agreements or renegotiations made between 5 June 2009 and 5 June 2011 are exempted from the new obligations arising from the Recast (e.g. training rights), but are not exempted from the rules and obligations of the first Directive.

From 2009 onwards then, we can distinguish between three types of EWC agreements, according to their regulatory status:

1. Pre-Directive EWCs: The first are the agreements made in EWCs established under Article 13 of the original Directive. This article specifies that the Directive shall not apply to EWC agreements made before $22^{\text {nd }}$ September 1996. Moreover, if such agreements are later renewed or renegotiated they continue to be exempted from the rules of the Directive. These agreements are sometimes called 'voluntary agreements', 'Article 13 agreements' or 'pre-Directive agreements'.

2. Article 6 EWCs: A second type are the agreements from EWCs established under Article 6 of either the original EWC or Recast Directive. These agreements are fully covered by the Directive and all its rights and obligations.

3. Article 14.1b EWCs: The third type are the Article 14.1b agreements, established under the regulation of Article 14.1b of the Recast Directive. This article stipulates that agreements (both original and renegotiations) 
made between 5 June 2009 and 5 June 2011 be given a special status. The definitions and principles of the Recast apply to those agreements, but not the 'new obligations' (Picard 2010).

In March 2016, of all the EWCs in force, 42\% (395) were still exempted from the rules of the Directive and the Recast (so-called pre-Directive EWCs), 53\% (495) were functioning as Article 6 EWCs, and 3\% (31) were functioning as Article 14.1b EWCs. Additionally, nine information and consultation procedures were registered, alongside twelve EWCs functioning under the subsidiary requirements.

\subsection{The Recasting process}

In the original EWC Directive an official 'review' of the Directive was envisaged after a period of five years. In 1999 it became clear that a possible revision of the Directive would not be a quick and simple process. While the European Parliament supported a revision, the visions of the social partners were not aligned.

The European Trade Union Confederation (ETUC) pushed the EU to move towards a revision. On its wish list were several changes that were to drastically improve the effectiveness of EWCs. More specifically, the ETUC sought to improve the definitions of information, consultation and transnational; improve rights for training, time off and meetings for EWC representatives; reduce the period over which special negotiating bodies (SNBs) could deliberate over the establishment of an EWC; reduce the workforce size thresholds, thereby increasing the coverage of the Directive; and introduce a clear and defined role for trade unions (Jagodzinski 2009).

BusinessEurope was openly opposed to a revision, on the grounds that the fiveyear period would be too short to make real conclusions about the (mal)functioning of the EWCs; furthermore, any additional burden on companies was to be avoided. BusinessEurope favoured a more voluntary approach to European industrial relations. Furthermore, BusinessEurope argued that a decrease of the threshold was undesirable and that the threeyear negotiation period was necessary.

The position of managers responsible for EWCs within multinational companies (MNCs) was different. They acknowledged deficiencies but also saw the added value of including an EWC in company decision-making processes, for the working of communication systems and for generating employee commitment (Lamers 1998).

Although the social partners declined to work towards a negotiated solution, they did publish a 'Joint Advice' in August 2008 describing their shared opinion (Jagodzinski 2010). 
In light of the differences in approach to the revision of the Directive, it is no surprise that both the ETUC and BusinessEurope saw the Recast as not entirely satisfactory. Through extensive lobbying, BusinessEurope was successful in excluding from the Recast the clauses on a reduction in the SNB negotiation period and on changes to the workforce-size thresholds, but was unable to prevent the revision per se. The ETUC secured amendments intended to improve the operation of EWCs.

\section{The evaluation of the Recast Directive}

Just as in the first EWC Directive, the Recast Directive includes an article envisaging a report on the implementation of the Recast by June 2016, together with the specification of appropriate proposals for change. This report contributes to this exercise by evaluating the effectiveness of the Recast in attaining its declared objectives. These objectives are reflected in Recital 7:

'It is necessary to modernise Community legislation on transnational information and consultation of employees with a view to ensuring the effectiveness of employees' transnational information and consultation rights, increasing the proportion of European Works Councils established while enabling the continuous functioning of existing agreements, resolving the problems encountered in the practical application of Directive 94/45/EC and remedying the lack of legal certainty resulting from some of its provisions or the absence of certain provisions, and ensuring that Community legislative instruments on information and consultation of employees are better linked.'

The Recast thus has a triple objective: (1) to promote the establishment of more EWCs, (2) to improve the functioning of existing EWCs, and (3) to provide legal certainty to EWCs (Kerckhofs 2010; European Commission 2016). In this report we assess and evaluate the efficacy of the Recast in bringing about more and better EWCs.

In doing so, this report draws largely on the data collected in the European Works Council Database. Using this database, this report presents an evaluation of the Recast Directive structured as follows:

- The first chapter discusses whether the Recast was successful in promoting the establishment of more EWCs.

- The second chapter studies whether the type of EWC agreements changed in the post-Recast period and whether or not the adaptation clause was effective.

- The third chapter considers whether the Recast was effective in contributing to better EWCs. 
- Following these three chapters, a general conclusion offers several specific policy recommendations. 


\title{
Chapter 1: More EWCs?
}

\begin{abstract}
The EWC Recast Directive aimed to stimulate the establishment of new EWCs in order to enlarge the coverage of the Directive. For this, some changes were introduced regarding the roles of the Special Negotiation Body and of the social partners; a transition period (a so-called 'window of opportunity') was also included. However, data shows that there was no increase in the amount of newly established EWCs; not during the transition period, nor in the post-Recast period. An estimation of the coverage rates suggests that saturation of the population cannot explain the lack of renewed momentum, nor can the availability of alternatives in organising transnational information and consultation. The conclusion is that the Recast was ineffective in stimulating the establishment of more EWCs because it does not address common obstacles to EWC establishment.
\end{abstract}

In line with the idea of 'regulated self-regulation', the establishment of a European Works Council is mandatory only after an initiative is taken by the employer or employee's side. If no initiative is taken, there is no obligation to set up an EWC, even if the company employs the requisite amount of employees in several European countries. The amount of EWCs thus depends on the number of employees or employers who know about the possibility and who see the value in organizing an EWC.

The European legislator tried to stimulate companies and employees to work towards the establishment of EWCs in several ways. The most well-known of these initiatives is the transition period (the so-called 'window of opportunity') included in the first EWC Directive. According to this, EWCs established before 22 September 1996 are exempted from the rules of the Directive as long as they fulfil some conditions. This rule led to a surge in the number of EWCs, with more than 400 EWCs created in 1996.

After this transition period ended, the pace of establishing EWCs dropped steeply and continued to decline over the years (Jagodzinski 2011). However, this is not a case of there being a saturated population of companies with EWCs; reports show that there continue to be a lot of multinational companies without a functioning EWC and thus lacking genuine information and consultation rights on transnational issues (Kerckhofs 2010).

Confronted with these developments, it was one of the main (declared) objectives of the 2009 Recast of the EWC Directive to give a new impetus to the creation of EWCs. For this, the Recast provided several instruments that were to lead to a new wave of establishment of EWCs, including a second transition period similar to the one included in the first Directive.

How an EWC is established is regulated by the EWC Directive and its Recast. In short, either employees or the employer can request that an EWC be established. Once this initiative is taken, a temporary Special Negotiation Body (SNB) is convened, comprising employee representatives from each Member 
State in which the company has employees. This SNB has up to three years to negotiate an EWC agreement with management which regulates the competences and functioning of the EWC. Once an agreement is reached, the EWC is established. If no agreement is reached before the end of the threeyear period, or if negotiations are not taken up as requested, fall-back rules apply. In this case, an EWC is created according to the subsidiary requirements laid out in the EWC Directive, in which the basic rules governing the EWC are defined. Therefore, in theory, every formal request to negotiate an EWC should lead to the establishment of an EWC; either by agreement or according to the subsidiary requirements.

This chapter will discuss whether or not the Recast was effective in stimulating the creation of new EWCs or not. It will first review the way in which the Recast aimed to create a new dynamic. The second part discusses the evolution of the establishment of EWCs and concludes that the Recast did not deliver on this objective. The next parts consequently search for possible explanations for this, such as the existence of alternatives to EWCs and compliance rates.

\section{The Recast's declared objectives and instruments}

The objectives of the EWC Recast Directive are clearly established in Recital 7. This recital includes a clear mention of the need to work towards the establishment of more EWCs:

'It is necessary to modernise Community legislation on transnational information and consultation of employees with a view to (...) increasing the proportion of European Works Councils established while enabling the continuous functioning of existing agreements (...).'

In order to boost the amount of EWCs, the Recast Directive worked along three lines of action.

First of all, it included a transition period similar to the one in the original EWC Directive (14.1b). EWCs which renegotiated their agreement or were established in the period between 5 June 2009 and 5 June 2011 are subject to a special exemption. While still covered by the original Directive, they would not fall under the Recast Directive; the new rules and obligations stemming from the Recast would not apply to them.

Second, the Recast Directive included an article (4§4) on the provision of information required to establish a Special Negotiation Body. Faced with unclear rules in the original Directive, some companies refused to give information on the amount of employees working for the company in the different European countries. Such refusals were serious obstacles to the creation of an EWC, most famously illustrated in the Kühne-Nagel case (Dribbusch 2004; Dorssemont and Blanke 2010). The Recast tried to solve this problem by clearly indicating the responsibilities of the different management levels. 
Finally, the Recast strengthened the role of the European workers' and employers' organizations by the inclusion of Article 5.2 and Recital 27. These clauses required information to be sent to the European workers' and employer's organizations about the start of the negotiations and the composition of the SNB. This rule aimed to further the involvement of, for example, the European Trade Union Federations, and consequently to increase the number (as well as the quality) of EWC agreements.

These three lines of action were to contribute to a new dynamic in the creation of EWCs, both during the transition period and afterwards.

\section{EWC growth rate}

Using the data of the European Works Council Database (www.ewcdb.eu), the question of whether the Recast was successful in boosting the establishment of new EWCs can be addressed. Figure 1 shows the evolution of the number of EWCs over time. The two shaded areas refer to the number of EWCs created and dissolved, and the full line reflects the total number of active EWCs between 1989 and 2015. The slope of this full line thus represents the net growth rate: the number of established EWCs minus the dissolved. EWCs dissolve for various reasons, but primarily because of mergers and acquisitions of firms (De Spiegelaere and Jagodzinski 2015).

\section{Figure 1 Establishment and dissolution of EWCs}

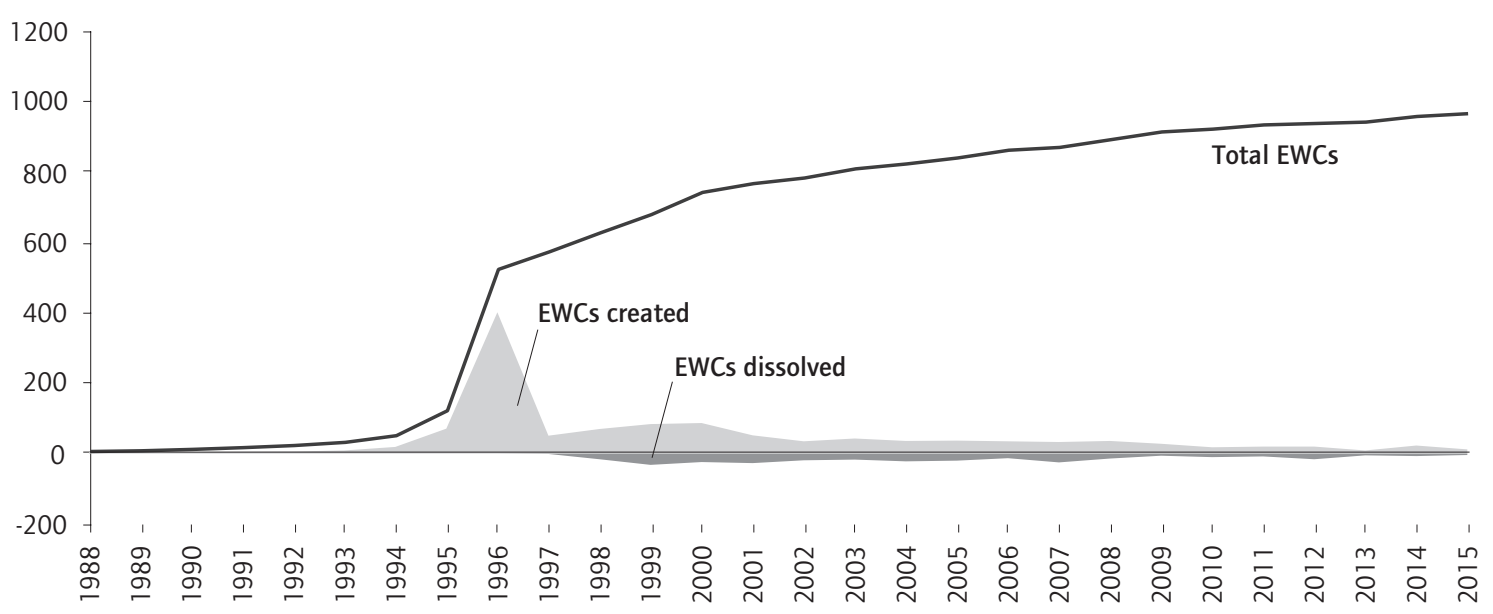

The evolution shows some interesting patterns. There is a slow growth of EWCs before the introduction of regulation. In the run up to the application of the first Directive (the first transition period), a record amount of EWCs were created, resulting in a net growth of about 400 EWCs in 1996. Immediately afterwards, the net growth rate declined to around 50 a year and, over time, it dropped even further to less than 20 in the years running up to the Recast. 
The main, if not the only, observable event in this evolution is the first transition period. The accession of the UK to the system in 1997 and the extension towards most Central and East European countries in 2004, and towards Bulgaria and Romania in 2006, did not significantly impact the establishment of new EWCs.

At first sight, the Recast does not seem to have impacted the net growth rate of EWCs. There is no visible change during the transition period, nor after the full implementation of the Recast in 2011. The net growth trend declines and continues to do so, independent of the Recast Directive.

A comparison between the period preceding the Recast, the transition period and the post-Recast period gives a more detailed insight into the trend over the last decade. Table 1 details the numbers of established and dissolved EWCs in these three periods, including also the net growth rate.

This table clearly shows that the second transition period (between 5 June 2009 and 5 June 2011) did not lead to a momentum equal to that of the first transition period. Between 2009 and 2011 only 66 new EWCs were created. In the three preceding years more than 100 were created and in the three following years, 52 .

Table 1 EWC growth rate before, during and after the Recast

\begin{tabular}{|l|r|r|r|}
\hline Period & Established & Dissolved & Net growth rate \\
\hline $2006-2008$ & 104 & -45 & 59 \\
\hline $2009-2011$ & 66 & -24 & 42 \\
\hline $2012-2014$ & 52 & -28 & 24 \\
\hline
\end{tabular}

This pattern is most likely related to the mixed experiences of EWCs and trade unions in the first transition period. This period led to a massive increase in the amount of EWCs, but a large proportion of those EWCs still function in a regulatory vacuum. Although their agreements tend to reflect the rules, obligations and definitions of the Directive, the legacy of this first transition period is still present (ETUC and ETUI 2016). This led the trade unions to resist the establishment of Article 14.1b EWCs in this transition period and to actively advise not to establish or renegotiate EWC agreements in this time frame (e.g. Picard 2010).

This resistance is also visible in the fact that only 31 of the EWCs which were established or which renegotiated their agreement in that period can be rightfully identified as functioning under Article $14.1 \mathrm{~b}$ of the Recast. All others have explicitly chosen in their agreements to establish themselves as Article 6 EWCs, or they were pre-Directive EWCs that wished to keep that status. Obviously, the second transition period did not succeed in boosting the establishment of new EWCs. 
The Recast aimed to stimulate the establishment of EWCs in, but also after, the transition period. In other words, it aimed to have a continuing effect on the growth of EWCs. Table 1 also clearly shows that in the post-Recast period, the growth rate did not recover to pre-Recast levels. Taking into account the amount of dissolved EWCs, we even observe a continuously decreasing net growth rate.

These results show that the Recast Directive was not effective in attaining its goal of 'increasing the proportion of European Works Councils established'; not during the second transition period, nor in the post-Recast period. Whether the Recast was instrumental in slowing down the growth rate of EWCs is, however, not certain either. Prior to the Recast Directive, a continuous decline in the growth rate was identified, which continued independent of the Recast.

\section{Box 1 The transition period}

Article $14.1 \mathrm{~b}$ of the EWC Recast Directive states:

'Without prejudice to Article 13, the obligations arising from this Directive shall not apply to Community-scale undertakings or Community-scale groups of undertakings in which (...)

(b) an agreement concluded pursuant to Article 6 of Directive 94/45/EC is signed or revised between 5 June 2009 and 5 June 2011.'

This article introduced a transition period between the Directive and the Recast. EWCs created or renegotiated in that transition period are exempted from the rules of the Recast, but remain fully covered by the rules of the original Directive (as transposed in national law). The objective of this transition period was to give an impetus to the creation of new EWCs, similar to that of the first transition period included in the original Directive. This first transition period saw the establishment of about 400 EWCs.

The second transition period, however, was markedly less successful. In this period, 83 agreements were signed, 28 of which were first agreements establishing an EWC, 9 were renegotiations and 46 were amendments or extensions. It should be noted that the trade unions actively advised against establishing an EWC or renegotiating an agreement in this period since this would result in EWCs being partly exempted from the new provisions of the Recast (Picard 2010).

In the end, only 31 EWCs can be rightly considered as Art. 14.1b EWCs, as the others explicitly ruled out that possibility in the agreements. Of those 31,22 were EWCs which were established for the first time in that period and 9 were already existing EWCs which transformed their legal status from a pre-Directive or Article 6 EWC into an Article 14.1 b EWC. 
Obviously, the transition period provided by the Recast did not duplicate the experience of the first transition period. Only a few EWCs were created or renegotiated in that period and some of them explicitly ruled out the possibility of falling under the rules of Art. 14.1b. What the transition period did produce, however, was an additional diversity in the legal frameworks of EWCs, adding to the general complexity of the issue.

\section{Compliance: are there still sufficient companies?}

One possible explanation for the small number of newly established EWCs in the last decade is a possible saturation of the population: of all the companies eligible to have an EWC, most might already have one. The fewer companies that can potentially establish an EWC, the slower the growth is likely to be.

In order to assess this hypothesis, a compliance rate needs to be calculated. Such a compliance rate reflects the share of companies - of all those companies covered by the Directive - which have an EWC. The amount of companies with an EWC is known but the amount of companies covered by the Directive is not, as there is no administrative obligation for multinationals to report the number of their employees in different Member States. There is consequently no reference population.

Up until 2009, the ETUI tried to assess the population of multinational corporations (MNCs) covered by the Directive by establishing a database on them (Kerckhofs 2010). While imperfect, this database was for a long time the only reference to calculate compliance rates. Due to the continuous restructuring of companies, this database has not been updated since 2009. The last available estimation of the overall compliance rate is therefore for 2009 (Kerckhofs 2010; Waddington 2010).

The information on the amount of companies covered by the EWC Directive over the years can, however, be instrumental in estimating the amount of companies covered by the Directive in the years after 2009. An extrapolation of the yearly growth rate in companies covered by the Directive, observed since 2004 (the moment the Central-East European countries were included in the scope of the Directive), provides us with an estimated amount of companies covered between 2010 and 2015. By combining this information with the known amount of established EWCs, an estimated compliance rate can be calculated for the 2010-2015 period (Figure 2).

This estimation illustrated in Figure 2 shows that the (relatively) slow net growth rate of EWCs was only instrumental in stabilizing the observed compliance rate of 2009. The estimated compliance rate of 2014 is less than $40 \%$. While this estimation is not perfect, the results show at least that an almost full compliance rate (saturation) cannot be the reason for the slowing growth rate of EWCs. 
Figure 2 (Estimated) compliance rates

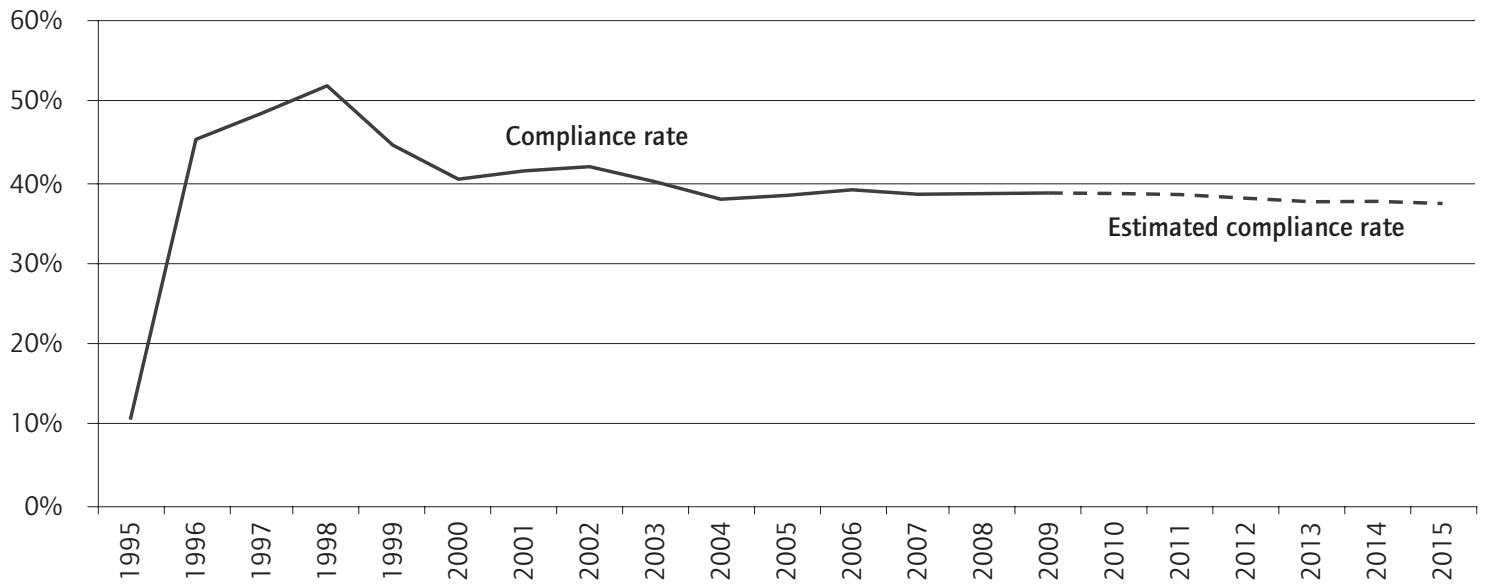

\section{Alternatives: are EWCs transforming into alternative legal frameworks?}

A second possible explanation for the few newly established EWCs in the last decade is the emergence of alternative solutions for transnational information and consultation. Since 2004, European multinationals can organize under the European Company (Societas Europaea, SE) legal structure. Companies adopting such a structure can, after negotiations, organize transnational information and consultation of employees through the establishment of an SE Works Council (SEWC). The rules on the establishment and function of an SEWC are very similar to those of the EWCs (Jagodzinski 2013).

Possibly, companies could increasingly establish SEWCs instead of EWCs to organise information and consultation on transnational issues. This would be reflected in a slowing down of the growth rate of EWCs, yet in an overall increase of bodies with principally the same function. Even though an SEWC can be used as an alternative to an EWC (if the company also changes its legal structure), SEWCs constitute more than an alternative. Companies not covered by the EWC Directive can become SEs and install an SEWC. The scope of the SEWCs is therefore potentially larger than that of the EWCs.

The European Works Council Database also collects information on established SEWCs. The information on both institutions is presented in Figure 3. This figure is identical to Figure 1 up until 2005. In 2005 the first SEWC was established, hence the divergence of the lines.

Even though the increase of SEWCs indeed leads to a higher growth rate in the years after the implementation of the SE Directive, it is not of such a size as to increase the overall net growth pace in the years after the Recast. 
Figure 3 Establishment of EWCs and SEWCS

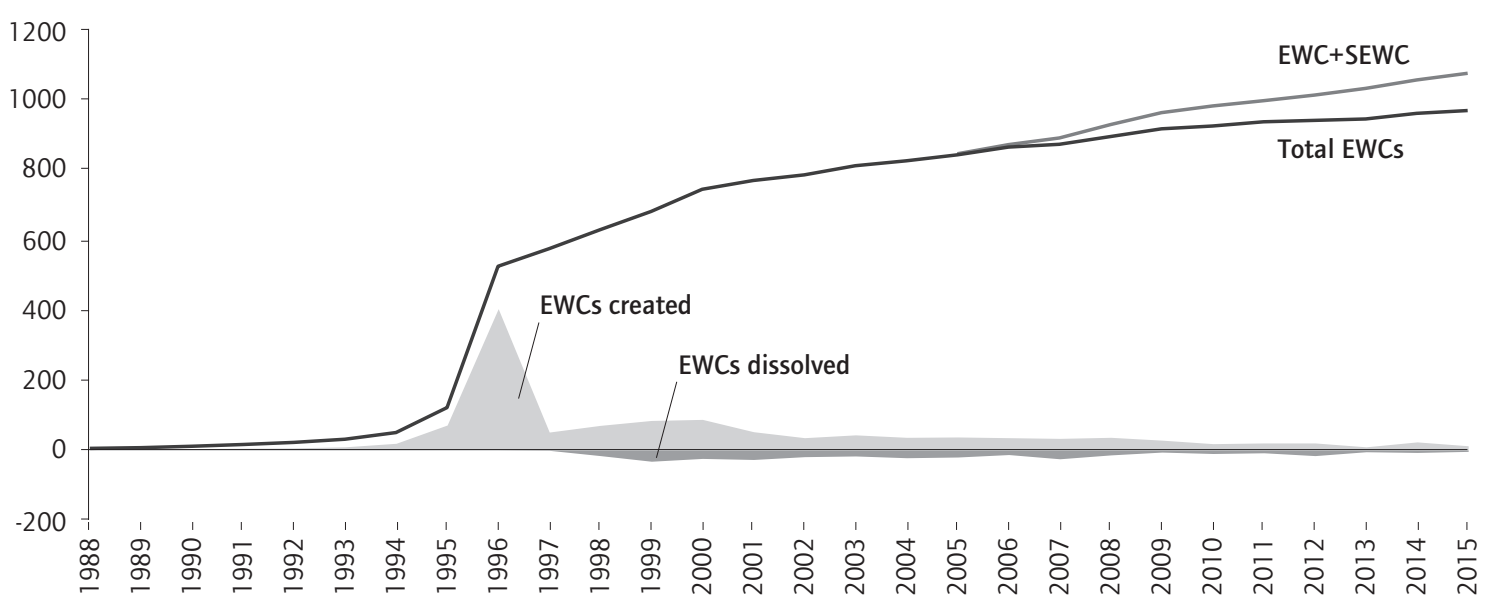

Table 2 details the numbers of established and dissolved EWCs and SEWCs, as well as the net common growth rate. As mentioned before, adding the SEWCs to the figures increases the overall growth rate but, in comparison with the pre-Recast period and the interim period, the net growth rate in the postRecast period is still lower. Adding the SEWCs to the amount of EWCs does not change the conclusion of a general slowing down of the growth rate of EWCs (or of the alternative frameworks). Moreover, the SEWCs are potentially established in firms that are not covered by the EWC Directive.

Table 2 EWC and SEWC growth before, during and after the Recast

\begin{tabular}{|l|r|r|r|}
\hline Period & Established & Dissolved & Net growth rate \\
\hline $2006-2008$ & 135 & -52 & 83 \\
\hline $2009-2011$ & 95 & -27 & 68 \\
\hline $2012-2014$ & 87 & -28 & 59 \\
\hline
\end{tabular}

Another way of looking at the SEWC as a potential alternative to the EWC is by studying the number of EWCs that dissolved and transformed into SEWCs because of a change of legal structure in the company. Over the years, only 15 EWCs have gone through such a transition. Of those 15,11 were pre-Directive EWCs and 4 were Article 6 EWCs.

Both results suggest that the existence of an alternative way of organizing information and consultation on transnational issues cannot explain the small number of EWCs created in the last decade. Only a few have transformed, and even if combined, the overall growth rate is still lower in the transition and post-Recast periods when compared to the pre-Recast period. 


\section{Changing company characteristics}

Focusing on the characteristics of the companies in which the new EWCs are established, some minor but significant trends are apparent. In the tables below, the characteristics of the newly established EWCs are given for successive five-year periods. From the first table we conclude that a higher share of the newly established EWCs is established in small multinationals $(<5000$ employees). In the last period (2010-2014) the (net) share has risen to about $50 \%$ of all EWCs created in that year.

Table 3 Company size of new EWCs

\begin{tabular}{|l|c|c|c|c|c|}
\hline Period & Unknown & $\begin{array}{c}\text { Small } \\
(<\mathbf{5 . 0 0 0 )}\end{array}$ & $\begin{array}{c}\text { Medium } \\
(\mathbf{5 . 0 0 0 - 1 0 . 0 0 0 )}\end{array}$ & $\begin{array}{c}\text { Large } \\
(>\mathbf{0 . 0 0 0 )}\end{array}$ \\
\hline $1995-1999$ & $4 \%$ & $40 \%(41 \%)$ & $16 \%(17 \%)$ & $40 \%(42 \%)$ & 642 \\
\hline $2000-2004$ & $6 \%$ & $37 \%(40 \%)$ & $21 \%(22 \%)$ & $36 \%(39 \%)$ & 224 \\
\hline $2005-2009$ & $26 \%$ & $31 \%(41 \%)$ & $18 \%(24 \%)$ & $26 \%(34 \%)$ & 133 \\
\hline $2010-2014$ & $39 \%$ & $31 \%(50 \%)$ & $10 \%(16 \%)$ & $21 \%(34 \%)$ & 67 \\
\hline
\end{tabular}

Note: Percentages in parentheses are the net percentages, not including the 'unknown' category. The proportional increase of the amount of companies with unknown data on their size is caused by a rupture in the systematic tracking of the company sizes.

Table 4 shows the distribution over the country clusters. This table shows that the share of EWCs established in mixed market economies (MMEs) is rising over time and accounts for more than one fourth of all newly established EWCs in the last five years. With regards to the other clusters, an overall trend is difficult to establish next to some minor fluctuations.

Table 4 Company HQ cluster of new EWCs

\begin{tabular}{|l|c|c|c|c|c|}
\hline Period & Nordic & CME & MME & LME & Total (N) \\
\hline $1995-1999$ & $17 \%$ & $39 \%$ & $10 \%$ & $35 \%$ & $29 \%$ \\
\hline $2000-2004$ & $15 \%$ & $33 \%$ & $23 \%$ & $35 \%$ & 224 \\
\hline $2005-2009$ & $15 \%$ & $31 \%$ & $19 \%$ & $21 \%$ & 67 \\
\hline
\end{tabular}

Note: Country clusters: Nordic (DE, NO, SE, FI, IS), Coordinated Market Economies (DE, BE,NL, AU, LU, CH), Mixed Market Economies (FR, IT, PO, ES, EL), Liberal Market Economies (UK, IE, US, CA, JP and all other countries).

Table 5 shows the sectoral distribution of the newly established EWCs. This table shows a minor decrease in the share of the chemical and metal sectors (in terms of newly established EWCs) in favour of the 'other/unknown' sector. In this cluster, textile, transport and public service sectors are grouped. 
Table 5 Sector of activity of new EWCs

\begin{tabular}{|c|c|c|c|c|c|c|}
\hline Period & Chemicals & Metal & Services & $\begin{array}{l}\text { Food and } \\
\text { horeca }\end{array}$ & Building & $\begin{array}{l}\text { Other / } \\
\text { unknown }\end{array}$ \\
\hline 1995-1999 & $22 \%$ & $32 \%$ & $15 \%$ & $12 \%$ & $7 \%$ & $12 \%$ \\
\hline $2000-2004$ & $15 \%$ & $40 \%$ & $19 \%$ & $8 \%$ & $8 \%$ & $9 \%$ \\
\hline $2005-2009$ & $12 \%$ & $34 \%$ & $29 \%$ & $7 \%$ & $6 \%$ & $13 \%$ \\
\hline $2010-2015$ & $18 \%$ & $31 \%$ & $21 \%$ & $6 \%$ & $8 \%$ & $16 \%$ \\
\hline
\end{tabular}

In conclusion, new EWCs are still predominantly created in companies where they are already traditionally prone to be established (large multinationals, companies headquartered in coordinated market economies (CMEs) and companies from the metal or chemical industry or the service sector). However, over time, relatively more EWCs are created in smaller companies, in companies from MMEs and in companies from such sectors as textile, transport and public services.

\section{Other possible explanations}

If the compliance rate and the existence of alternative models cannot explain the slowing growth rate, and if we see only a limited change in the type of companies establishing EWCs, what are the possible alternative explanations?

Based on the available literature and insights from practice, Figure 4 gives a graphical illustration of the various factors at play in the establishment of a European Works Council.

First of all, there are three major actors at play in the potential establishment of an EWC: (1) employees, (2) management and (3) trade unions. For the purpose of simplicity, these actors are considered as relatively unified groups. Based on Whittall et al.'s (2015) propositions, these actors all make a 'tradeoff' in considering whether or not to invest in the establishment of an EWC. This trade-off is based on the following considerations:

1. The perceived added value: Does the actor see a value in setting up an EWC? Can the EWC be an effective way to defend their interests?

2. The resources needed: How much effort and cost will the establishment and functioning of an EWC demand?

3. The resources at hand: How many resources (time, money, network etc.) does the actor have at its disposal?

4. Other priorities: Are there other more urgent priorities which place demand on the available resources? 
This trade-off is influenced by various contextual factors. First of all, the tradeoff can only be made if the actors have knowledge of the possibility to organize an EWC and have sufficient information about their company. This problem of knowledge and transparency is not to be underestimated; almost $20 \%$ of the respondents of German works councils in companies covered by the Directive did not know of the existence of EWCs, and another fifth thought (incorrectly) that their company was not covered by the Directive (Whittall et al. 2015).

Secondly, the variables in the trade-off are influenced by several structural factors. These relate to the characteristics of the country, sector and company involved. Starting with the country, different traditions in employee involvement at the company level affect the variables in the trade-off (Hertwig 2015). Employees, managers and trade unions from countries with strong information and consultation rights are more likely to take an interest in organizing an EWC and to have resources (work organisation, time off etc.) to invest in it. The sector also plays a role as it determines the degree to which companies have a limited amount of large establishments (e.g. automobile companies) or a large amount of small establishments internationally (e.g. construction companies) (Marginson et al. 2013). In the second case, the cost will be higher, as the internal networking will require more effort. In parallel, depending on the sector of activity, a different European Trade Union Federation will follow up on the activities of the EWC. Similarly, company characteristics play a role. In larger companies, the available resources and added value of an EWC are more likely to be higher than in relatively small multinational companies. Interrelated with the company, country and sector characteristics is, of course, the factor of trade union strength. Where trade unions are well-developed, well-resourced institutions with a broad member base, it is more likely that they will provide the necessary financial and nonfinancial resources for the development of an EWC.

Thirdly, the regulatory framework plays a role. Obviously, depending on the scope of the regulation (both geographically as well as content-wise), the actors will have a different perception of the costs, added value and resources needed for the establishment of an EWC. Clarity on who is responsible for what is another essential point. Legal vagueness can lead to actors not doing anything and perceiving the costs (for example, regarding uncertain legal action) as being very high. This brings us to the issue of sanctions. If there are no sanctions and regulatory enforcement, not following the rules of the Directive becomes very easy (and cheap). This, again, reduces the perceived added value in the minds of some actors and greatly increases the resources needed to establish an EWC.

Linking this framework to the instruments provided by the Recast to boost the amount of EWCs exposes a large discrepancy.

- The legal clarity on who is to provide the necessary information for the establishment of an EWC might have prevented legal cases, but it did not encourage management to inform employees about whether or not their 
Figure 4 Barriers to the establishment of EWCs

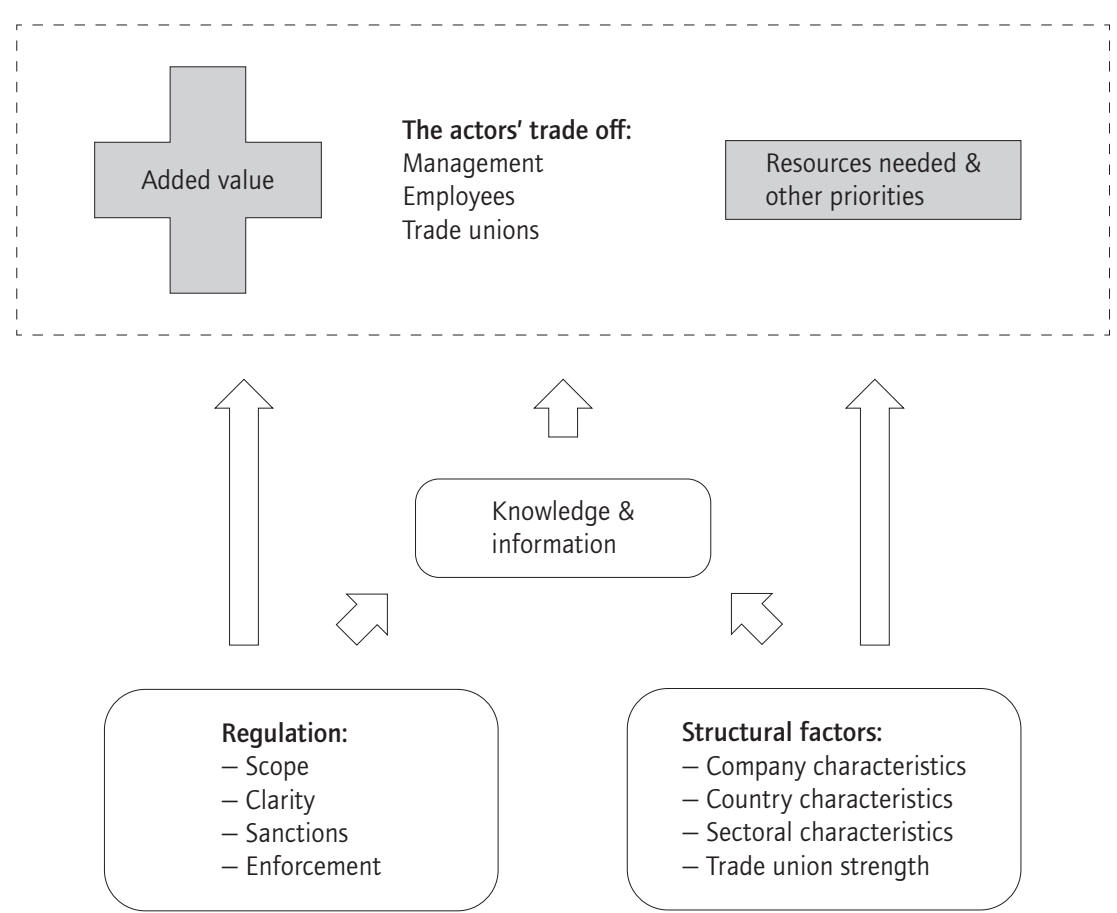

company was covered by the Directive. It did not, in essence, solve the problem of insufficient knowledge of the Directive.

- The possibility for an SNB to get training and external assistance might have upgraded the quality of the SNB's work, but it did not essentially change the estimation made by the employees of the resources needed to establish an EWC. Improving the functioning of an SNB does not necessarily lead to the establishment of more SNBs, and therefore EWCs.

- The requirement to inform the trade unions about the establishment of an SNB did not lead to the establishment of more SNBs or EWCs either. It might have increased the trade union involvement once an SNB was formed, but it did not give trade unions additional instruments to support the establishment of SNBs in companies without an EWC.

Fundamentally, the Recast Directive was not effective in stimulating the establishment of more EWCs as the instruments it provided did nothing to: make the case for EWCs, increase the awareness of the possibility of the establishment of an EWC, disseminate knowledge about which companies are eligible to establish an EWC, limit the resources needed for employee representatives to establish an EWC, increase the capacity of employee representatives and trade unions to establish EWCs, provide more clarity on mutual rights and obligations, provide sufficient sanctions and enforcement for non-compliance, or address some other structural obstacles to the 
establishment of EWCs in non-unionized settings with scattered employment in small multinationals.

\section{Conclusion}

One of the main objectives of the EWC Recast Directive was ' $($...) increasing the proportion of European Works Councils established.' While new EWCs are still being created every year, the net growth rate has significantly slowed down over the years, both during and after the Recast:

- during the Recast, as the transition period did not lead to a wave of new EWCs. In this period, the amount of newly established EWCs dropped. Moreover, several EWCs established in this period explicitly chose not to function under the provided exemption clause;

- after the Recast, as the establishment of new EWCs in the post-Recast period did not recover to pre-Recast levels. The EWC Recast could not reverse the long term trend of a declining net growth rate.

Neither of the following two explanations is able to account for this declining growth rate. First, the estimations of the compliance rate suggest that less than half of all eligible companies have an EWC. The declining growth rate cannot therefore be explained by a lack of companies that are eligible and still lacking an EWC.

Second, the existence of alternative ways of organizing transnational information and consultation, such as the SEWCs, cannot explain the declining net growth rate either. Even the combined growth of EWCs and SEWCs is declining and only a few EWCs have directly transformed into SEWCs.

These observations suggest that the legal changes made in the Recast were ineffective or insufficient to result in a new dynamic in the establishment of EWCs. Building on existing insights into the obstacles to the establishment of EWCs, and comparing these with the legal interventions of the Recast, leads to the conclusion that there is an ill fit. The Recast was ineffective in structurally stimulating the establishment of EWCs, as the instruments it included did not do enough to address the multiple obstacles and trade-offs involved in the establishment of an EWC. 


\title{
Chapter 2: Adapting EWCs
}

\begin{abstract}
One of the main objectives of the EWC Recast Directive was to improve the functioning of the existing EWCs. How an EWC functions is, however, negotiated and codified in EWC agreements. In order not to force all existing EWCs to start renegotiations, the EWC Recast explicitly mentioned that the new rights and obligations were directly applicable and therefore there was no obligation to renegotiate. At the same time, the Recast included a new stipulation enabling a full renegotiation of the agreement in the event of a significant structural change in the company (the adaptation clause). This clause was intended to give pre-Directive EWCs the option to be re-established as Article 6 EWCs, and it was expected to lead to a certain convergence. The evaluation presented in this chapter concludes that the Recast did increase the share of renegotiations in the post-Recast period and that the adaptation clause did not lead to the expected convergence.
\end{abstract}

According to Recital 7 of the Recast Directive, one of the objectives of the Recast is to improve the functioning of the currently existing EWCs:

'It is necessary to modernise Community legislation on transnational information and consultation of employees with a view to ensuring the effectiveness of employees' transnational information and consultation rights, increasing the proportion of European Works Councils established while enabling the continuous functioning of existing agreements (...).'

More particularly, the Recast establishes additional requirements for obligatory mentions in the EWC agreements, specifies definitions of some central concepts and establishes some rights and obligations for employee representatives. How these rights and obligations are to be applied is subject to negotiation between the employers and employee representatives and should be determined in the EWC agreement.

Negotiating an EWC agreement can, however, be a lengthy and complicated endeavour. The Recast therefore explicitly stresses that there is no formal obligation to start renegotiations. This is clearly mentioned in Recital 41: '(...) the agreements in force should be allowed to continue in order to avoid their obligatory renegotiation (...).' For the Article 6 EWCs, this does not mean that they are exempted from the rules and obligations stemming from the Recast. Although they are not forced to renegotiate, the Recast fully governs their operations, and the adapted rights, obligations and definitions directly apply to all Article 6 EWCs.

Although EWCs are not obliged to renegotiate, one could expect that some EWCs will be encouraged to amend or adapt their agreement to be in line with the Recast Directive. Even if they do not amend their agreement, the Article 6 EWCs are covered by the new rights and obligations that stem from the Recast. In order to operationalize these right and obligations, the practicalities should be organized in an EWC agreement. 
For pre-Directive or Article 14.1b EWCs, this is not the case (European Commission 2010: 55; Picard 2010). Pre-Directive EWCs and Article 14.1b EWCs are not obliged to renegotiate their agreements and the rights and (under certain conditions) obligations stemming from the Recast do not apply to them. For the pre-Directive EWCs this exemption relates both to the original and the Recast Directive. For the Article 14.1b EWCs, the exemption is limited to the rights and obligations of the Recast Directive.

Notwithstanding this general lack of obligation to renegotiate agreements, the EWC Recast does include some concrete situations in which a renegotiation is obligatory (if demanded by either the employer or employee side). This obligation is included in the so-called adaptation clause in Article 13 of the Recast. This clause states that EWC agreements can be fully renegotiated (including the establishment of a new Special Negotiation Body) when there is a significant change in the company structure. It is also clear that this clause applies to all EWCs, irrespective of whether they are pre-Directive, Article 6 or Article 14.1b EWCs (European Commission 2010).

In essence, this adaptation clause gives a potential exit option for pre-Directive EWCs in the event of mergers or acquisitions. If they invoke this clause, new negotiations will start, leading eventually to an Article 6 EWC. For this reason, Picard (2010) reasoned that 'the adaptation clause is therefore likely to play a unifying role in the future. As the business environment is constantly changing (...) one can logically expect that Article 14 will over time become obsolete. Agreements in force will have to be renegotiated under the terms of the new EWC directive, thereby unifying the regimes applying to EWCs throughout Europe.'

In this chapter both issues will be treated. In the first part, the evolution of the EWC renegotiations will be inspected to identify whether or not the Recast impelled EWCs to renegotiate or adapt their agreement. In the second part, the focus will be on the transformation of EWCs and whether or not the adaptation clause was effective in playing a 'unifying role'.

\section{Renegotiation of EWCs}

Ever since there were EWC agreements, EWCs engaged in renegotiations and amendments of the existing agreements. Although the Recast explicitly mentioned that EWCs were not expected to renegotiate their agreement, it is reasonable that a lot of EWCs would engage in such renegotiations in order to align their EWC with the new rights and obligations that apply to them (Eurofound 2015).

For this reason, a visible increase in the amount of changed agreements is expected in the aftermath of the Recast. Figure 5 shows the overall amount of yearly agreements and amendments on the right axis (shaded area). The lines and the left axis show the share of the types of agreements for each year. As can be expected, in the early years almost $100 \%$ of the agreements established 
a new EWC. Over the years, the share of renegotiations and amendments rose; yet important year-to-year fluctuations are present.

Figure 5 Original agreements, renegotiations and amendments

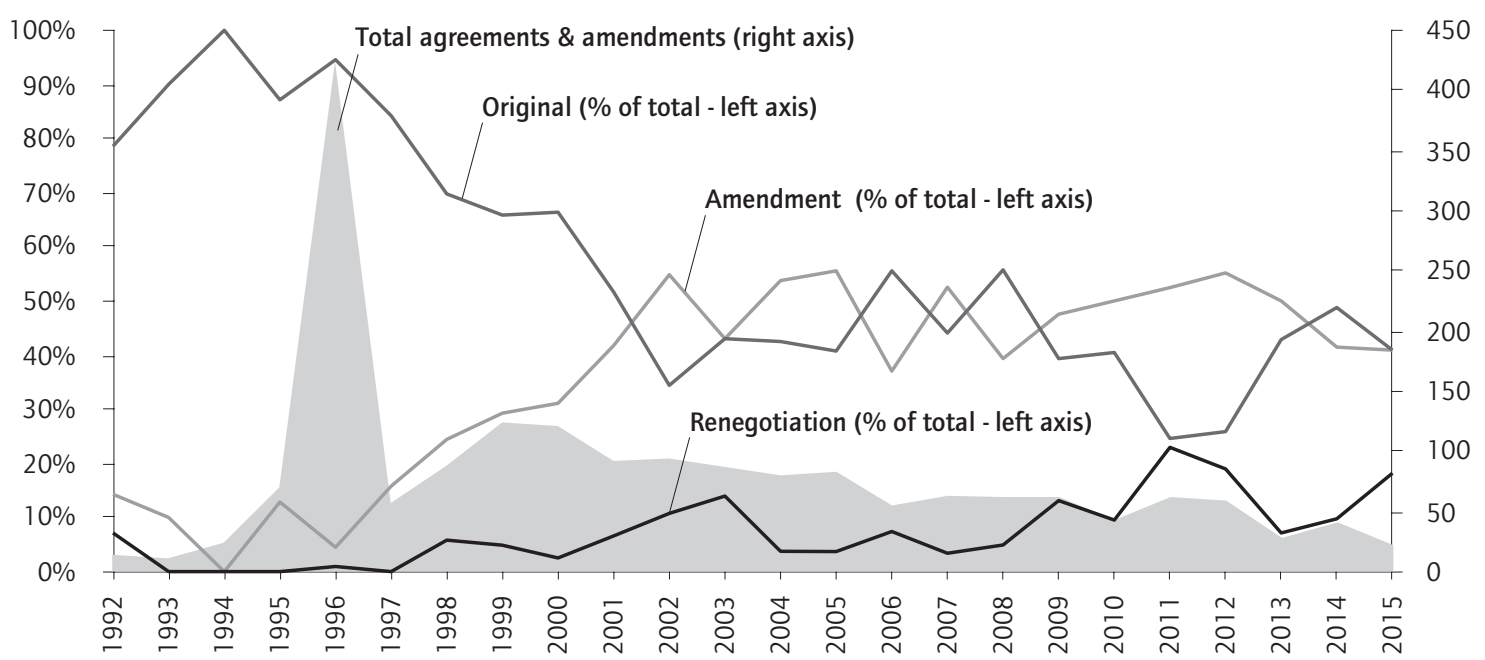

During and after the Recast Directive the figures show a relatively high share of amendments and renegotiations. Table 6 gives the averages of the period before the Recast (2006-2008), the transition period (2009-2011) and the post-Recast period (2012-2014). Clearly, the share of renegotiations and amendments has risen in the transition and post-Recast period, in comparison to the pre-Recast period.

In total, 43 renegotiated EWC agreements and 145 amendments were registered between 2009 and 2014. Compared to the amount of original agreements, this was more than could have been expected, so it seems that the Recast Directive did indeed lead to EWCs renegotiating or at least amending their EWC agreements. The effect is limited, however, and does not take the shape of a 'wave of renegotiations'.

Table 6 Share of original agreements, renegotiations and amendments before, during and after the Recast

\begin{tabular}{|l|r|r|r|c|}
\hline & Original & Renegotiations & Amendments & Total \\
\hline $2006-2008$ & $52 \%$ & $5 \%$ & $43 \%$ & 172 \\
\hline $2009-2011$ & $35 \%$ & $15 \%$ & $50 \%$ & 164 \\
\hline $2012-2014$ & $40 \%$ & $14 \%$ & $47 \%$ & 127 \\
\hline
\end{tabular}




\section{The use of the adaptation clause}

While the Recast did not include an obligation to renegotiate agreements, it did include a new and important article on renegotiations in the event of significant restructuring. Article 13 of the Recast Directive states that in the event of a significant change in structure, the EWC agreement can be renegotiated, via a Special Negotiation Body. This clause covers all EWCs, irrespective of whether they are pre-Directive, Article 6 or Article 14.1b EWCs (European Commission 2010).

\subsection{Transforming EWCs}

In total, the EWCdb registered 228 EWCs that transformed into other EWCs because of mergers, acquisitions or changes of legal status (Table 7). The last example refers to EWCs which changed because the company transformed into an SE, or to EWCs which decided to change the legal status of their operation. As can be seen in the table below, most that transformed into other EWCs are pre-Directive EWCs which keep this status (38\%) or Article 6 EWCs which remain as such. About 19\% change from a pre-Directive to an Article 6 EWC. Interestingly, about 8\% (19) of EWCs changed their status from an Article 6 into a pre-Directive EWC. These cases are generally take-overs in which a standing Article 6 EWC is integrated into an older Article 13 EWC of the buying company. In total, $4 \%$ (10) of EWCs changed their legal status from an Article 6 or pre-Directive EWC into an Art. 14.1b EWC during the second transition period. Another $7 \%$ of the transformed EWCs (16) are EWCs which transformed into SE Works councils. In five cases (2\%), EWCs working under the subsidiary requirements, or in companies that had an information and consultation procedure, transformed into fully operative EWCs.

Table 7 EWC transformed bodies

\begin{tabular}{|c|c|c|}
\hline Transformation & Amount & Share \\
\hline Pre - Pre & 86 & $38 \%$ \\
\hline Pre - Art. 6 & 49 & $21 \%$ \\
\hline Art. 6 - Pre & 19 & $8 \%$ \\
\hline Art. 6 - Art. 6 & 43 & $19 \%$ \\
\hline Pre - SE & 11 & $5 \%$ \\
\hline Art. 6 - SE & 5 & $2 \%$ \\
\hline Pre/Art. 6 - Art. 14.1b & 10 & $4 \%$ \\
\hline Other & 5 & $2 \%$ \\
\hline Total & 228 & \\
\hline
\end{tabular}




\subsection{Convergence of EWCs}

In theory, the inclusion of the adaptation clause in the Recast gives a potential 'exit option' for pre-Directive EWCs. In the event of a significant structural change, the EWC can demand a full renegotiation of the EWC agreement by an SNB. By definition, the resulting EWC will be an Art. 6 EWC and thus fully covered by the Directive. This is why some expected this adaptation clause to play a 'unifying role', with the idea that it would phase out the pre-Directive EWCs (Picard 2010).

If such convergence occurs, two patterns are likely to appear: (1) relatively less EWCs will transform from Article 6 or pre-Directive EWCs into pre-Directive EWCs and (2) relatively more EWCs will transform from pre-Directive EWCs into Article 6 EWCs. These assumptions are made based on the fact that the Recast allows the EWC to 'opt out' from the pre-Directive or Article 14.1b status to an Article 6 EWC.

Table 8 shows the share of transformed EWCs for the following periods: 20062008 (pre-Recast), 2009-2011 (transition period) and 2012-2014 (post-Recast). Knowing that the total number of transformations in the period between 2006 and 2014 is relatively low (48), the figures should be interpreted with some caution. Moreover, given that during the transition period, $42 \%$ of transformed EWCs became Article 14.1b EWCs, the pre- and post-Recast figures should be compared.

The table shows that relatively less EWCs transform from an Article 6 to a preDirective body. At the same time, there is no change in the proportion of bodies which change from pre-Directive EWCs into Article 6 EWCs. This proportion remains relatively low (16\%). Simultaneously, the amount of bodies transforming from pre-Directive EWCs into other pre-Directive EWCs remains very high (32\%), while most of these bodies are theoretically able to invoke the adaptation clause.

The predicted 'unifying role' of Article 13 of the Recast can therefore not be confirmed by the data. Although almost all transforming pre-Directive EWCs have the theoretical option of invoking Article 13 of the Recast to remake their EWCs (because the transformation is mostly related to a merger case), this option is ignored by many.

Table 8 Transforming EWCs before, during and after the Recast

\begin{tabular}{|c|c|c|c|c|c|c|}
\hline & $\begin{array}{c}\text { Pre-Directive to } \\
\text { pre-Directive }\end{array}$ & $\begin{array}{c}\text { Pre-Directive } \\
\text { to Art. 6 }\end{array}$ & $\begin{array}{c}\text { Art. 6 to pre- } \\
\text { Directive }\end{array}$ & Art. 6 to Art. 6 & $\begin{array}{c}\text { Pre/Art. } \mathbf{6} \text { to } \\
\text { Art. 14.1 b* }\end{array}$ & N \\
\hline $2006-2008$ & $21 \%$ & $17 \%$ & $17 \%$ & $46 \%$ & n.d. & 24 \\
\hline $2009-2011$ & $13 \%$ & $17 \%$ & $8 \%$ & $21 \%$ & $42 \%$ & 24 \\
\hline $2012-2014$ & $32 \%$ & $16 \%$ & $5 \%$ & $47 \%$ & n.d. & 19 \\
\hline
\end{tabular}

* A transformation of a body into an Art. 14.1b EWC was legally not possible before 2009. In theory it is possible in the post 2012 period; however, we have no examples of such transformations. 


\subsection{Possible explanations}

Although the adaptation clause gives EWCs the theoretical possibility to demand a full renegotiation of their EWC agreement, and might therefore serve as an 'exit option' for pre-Directive EWCs, the data on transformations shows that its effects are limited. Nevertheless, many pre-Directive EWCs which transform into other bodies (mostly at the event of a merger) retain a preDirective status.

While there is no systematic research into this question, some possible reasons for the lack of a 'unifying role' in the application of the adaptation clause are evident. For their explanation we can again use the framework presented in Chapter 1 (Figure 6).

1. Knowledge: the adaptation clause is inserted in the Directive and transposed into national law but might not be well known on the field.

2. Low perceived added value: Because the adaptation clause requires a full renegotiation including an SNB (on request), it gives an 'exit option' to pre-Directive EWCs. It does not, however, guarantee that the outcome will be more beneficial for the current EWC or employee representatives. Well-established pre-Directive EWCs with good agreements might therefore be wary of taking that risk.

3. High perceived costs: The use of the adaptation clause including the establishment of a new SNB might be perceived as a highly complicated, lengthy and resource-draining strategy.

4. Management pressure: Even if the EWCs would find it useful to go towards a full renegotiation, management pressures might obstruct this, with the insistence that managing the merger is more pressing than renegotiating the EWC agreement. Moreover, management pressure can also be focused on keeping the pre-Directive status of the EWC.

5. Power dynamics between employees: In the case of a take-over, power dynamics might be at play, obstructing a full use of the adaptation clause. Specifically, the EWC of an acquiring firm might be keen on also 'acquiring' the EWC of the other company, even if that one is fully covered by the Directive and the one of the acquiring firm is not.

6. Legal clarity: The demand for a full renegotiation of the EWC can be voiced in the event of a 'significant change of structure'. What is to be understood by this term is not entirely clear and greater specificity is currently unavailable. Recital 40 of the EWC Recast Directive explains that it might be a 'merger, acquisition or division.' However, the potential coverage of the clause goes beyond these three examples. Even when a company grows or shrinks excessively, extends towards different countries or changes its activities, a significant change of structure could be invoked. This might however be challenged by management. 
While the current adaptation clause allows for the theoretical possibility to fully renegotiate an EWC in the event of a significant structural change, a multitude of practical obstacles result in the limited use of this clause. The current legal framework does not provide sufficient instruments to overcome these obstacles.

Figure 6 EWC establishment

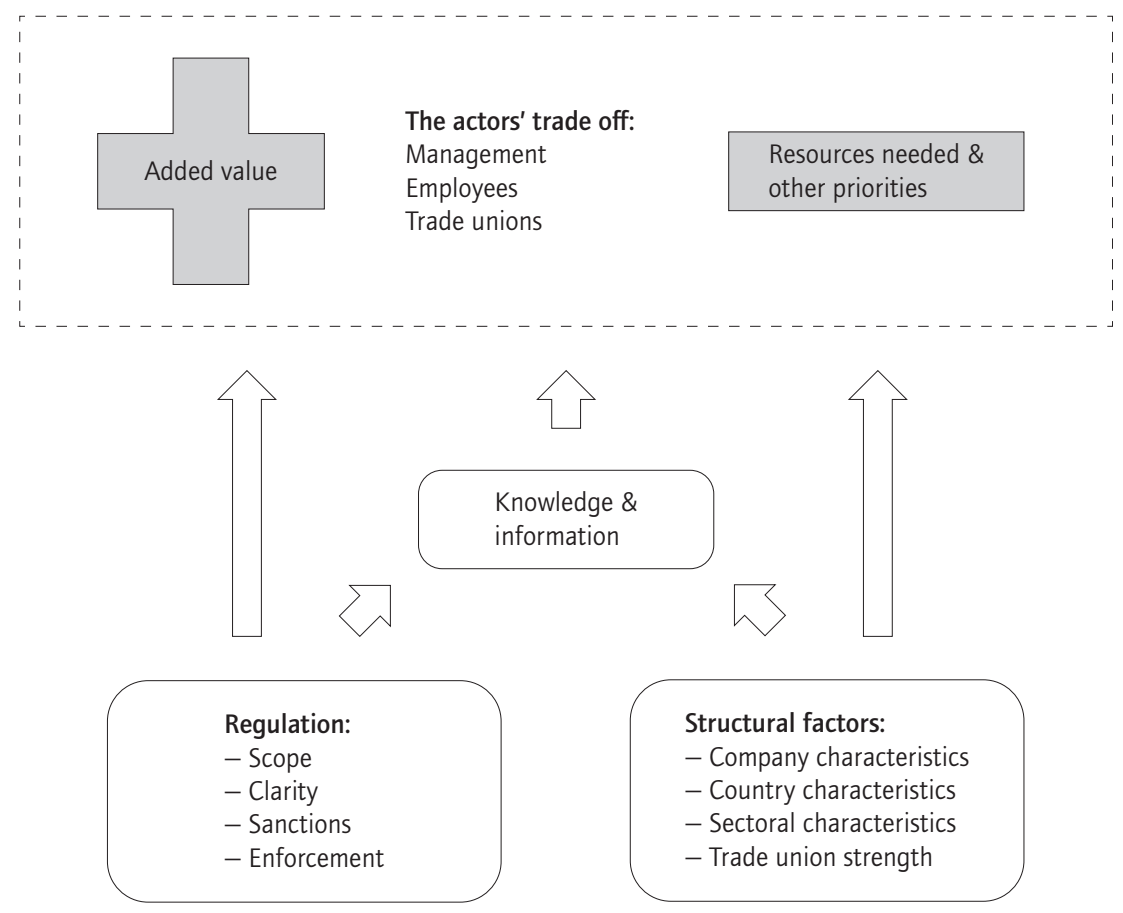

\section{Conclusion}

The EWC Recast Directive clearly excluded a general obligation to renegotiate agreements to align the existing EWCs with the new rights and obligations. Examination of the data shows the Recast did lead to a higher rate of renegotiations during and after the Recast, but that the effect is relatively small in scope and did not take the shape of a 'wave of renegotiations'.

Although in general the Recast did not demand renegotiation of the EWC agreements, in a specific case it does include an obligation (upon request from either the employer or employees) to fully renegotiate the agreement. In the event of significant changes in the company structure, the so-called 'adaptation clause' provides for an obligatory full renegotiation. This clause was expected to contribute to a certain convergence in the EWCs. This convergence, however, did not materialize. Only a few EWCs transformed from pre-Directive to Article 6 EWCs. Surprisingly, some transforming pre-Directive EWCs did not grasp the opportunity to renegotiate as an Article 6 EWC and retained their preDirective status. For the time being, the adaptation clause of the Recast has 
not been successful in supporting convergence. A multitude of obstacles to the use of the adaptation clause are identified which are not (or insufficiently) addressed by the current legal framework. 


\title{
Chapter 3: Better EWCs
}

\begin{abstract}
The key purpose of the EWC Recast Directive was to improve the functioning of the existing and future EWCs. For this, substantial revisions of the Recast included the right to training, reporting back to employees and the involvement of trade unions, together with amendments to the definitions of information, consultation and transnational. Using data from almost 1,100 EWC agreements, this chapter evaluates the effect of the Recast on the content of EWC agreements; it is expected the post-Recast agreements will be more likely to include these issues than their pre-Recast counterparts. The results show a combination of Recast effects with strong general learning effects in the negotiation and renegotiation of EWC agreements. In general, the learning effects surpassed the policy effects until policy caught up as a result of the Recast Directive.
\end{abstract}

\section{Notice}

The numbers reported in this chapter focus on EWC agreements. They are therefore fundamentally different from the figures reported in previous chapters or from those in the recent ETUI publication titled: European Works Councils and SE Works Councils in 2015: Facts and figures. These focused on the characteristics of EWCs themselves. In the Facts and figures publication, dissolved EWCs are excluded and the EWC characteristics are sourced only according to their last (active) agreement.

With the launch of the 1994 Directive on European Works Councils, the EU started an unprecedented experiment of developing a European policy on social dialogue in European multinationals. Facing an enormous variety in traditions and practices, the EU opted for a framework in which the company level social partners have considerable autonomy in organizing the process. Rules on minimum requirements and procedures were to guarantee good processes and optimal outcomes.

Following decades of experience with EWCs, case studies, surveys and court cases identified a number of best practices and major deficiencies (Lecher 1999; Lecher and Rub 1999; Weiler 2004; Marginson et al. 2013). After a long political process, a Recast of the original EWC Directive was adopted in 2009. One of its central objectives was to improve the functioning of the currently existing and future EWCs, as clearly stated in Recital 7:

'It is necessary to modernise Community legislation on transnational information and consultation of employees with a view to ensuring the effectiveness of employees' transnational information and consultation rights (...).'

To fulfil this goal, the Recast Directive included some minor and major changes regarding: the definitions of crucial concepts, rights and obligations of the EWC 
and its members, stipulations necessary in EWC agreements, and the relation between the EWC and other levels of employee participation.

This chapter evaluates the extent to which the Recast Directive brought about an 'ensured effectiveness' in EWCs. This evaluation builds on an extensive study of evolving EWC agreements and focuses both on general learning and policy effects. The chapter concludes that the Recast was only partially effective in bringing about change. The areas in which it was not effective are also the areas in which the Recast did not substantially outline measures and practices to support the rules. This observation underscores the need for clear language and instruments in legislation.

\section{Looking at agreements to evaluate the Recast}

The architecture of the EWC regulation concedes a lot of freedom to the employer and employee representatives to determine how their specific EWC functions. This type of 'regulated self-regulation' was seen as necessary to overcome the large differences in company-level social dialogue (Platzer 2002). The EWC Directive and its Recast do not determine directly how EWCs should function. They do determine the fundamental function of an EWC, some essential rights and obligations and what should be agreed upon in the EWC agreement.

The EWC agreement is the result of a negotiation process regulated by the Directive and the Recast and is to determine in detail the competences, composition and rules of operation of the EWC. By defining the process of negotiation and some required basic content of the EWC agreement, the Recast aims to have an impact on the functioning of the EWCs.

This indirect impact of the Recast through the EWC agreements on the functioning of the EWCs is clearly illustrated in Recital 19 of the Recast:

'In accordance with the principle of autonomy of the parties, it is for the representatives of employees and the management of the undertaking or the group's controlling undertaking to determine by agreement the nature, composition, the function, mode of operation, procedures and financial resources of European Works Councils or other information and consultation procedures so as to suit their own particular circumstances.'

Recitals 28, 29 and 30 specify further what the agreement should consist of and what issues must be treated.

Article 6 of the Recast Directive obliges the negotiating parties to agree on the procedural aspects of the EWC, the 'how'. This includes the composition of the EWC, when to meet, where, under which conditions, who is covered by the EWC etc. By altering the stipulations in Article 6, the Recast requires future agreements (in Art. 6 EWCs) to mention and organize these aspects. 
For some other issues, the Recast establishes the content of the EWC functioning and some mutual rights and obligations. More specifically, the Recast clearly defines what should be understood by 'information', 'consultation' and 'the transnational competence'. Also, it stresses that employees have a right to training and a right (and obligation) to inform the workforce about the process and outcome of the EWC's activities.

To be really effective, arrangements need to be made on the practical exercise of these rights, such as who is to pay for the expenses, how to go about it etc. In future agreements or renegotiations, EWCs may wish to include clauses on the practicalities related to the established rights. Similarly, although the definitions included in the Recast directly apply to Article 6 EWCs, it may be a good idea for agreements to mention them explicitly, in order to avoid confusion.

Figure 7 graphically illustrates the role of the EWC agreement in the relationship between the Directive or its Recast and the EWC practice. For the sake of completeness, this illustration also includes another step in the process: the national transposition or implementation of the rules of the EWC Directive. Because the EWC regulations are enforced through directives, they have to be transposed into national legislation to be applicable. In this transposition, the national legislator has the opportunity to further specify the rules of the directive. In practice, however, analysis shows that these transpositions are generally copy/paste exercises of the EWC Directive and rarely elaborate on the rights, duties or means of the EWCs. If the national legislation diverges from the EWC Directive it is generally because it omits certain clauses (Jagodzinski 2015).

Figure 7 The role of the EWC agreement

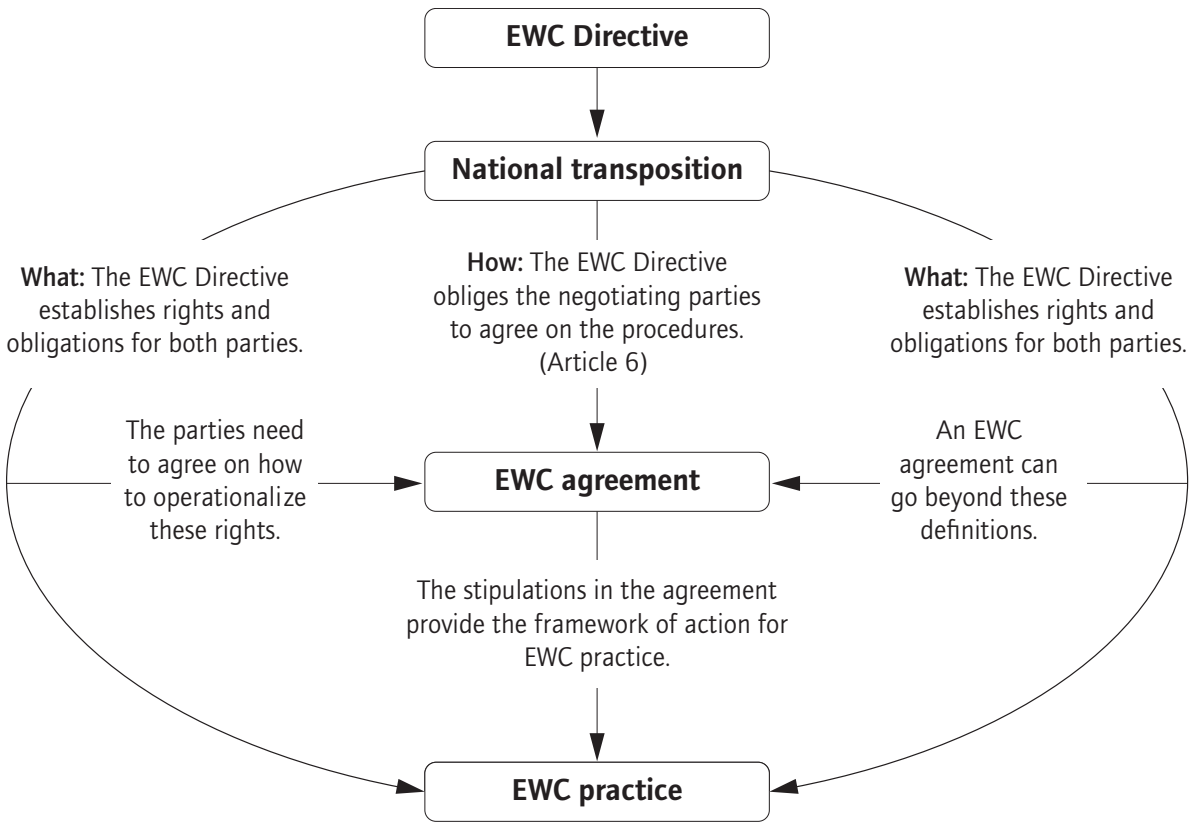


As the EWC agreement plays a central role in the interface between regulation and practice, one way of evaluating the effectiveness of the Recast is by looking at the content of EWC agreements. More specifically, if the Recast Directive had been effective, one could expect post-Recast agreements to be significantly different from pre-Recast agreements, particularly when it comes to Article 6 EWCs.

\section{Box 2 EWC agreements and EWC practice}

While an inspection of evolutions in EWC agreements is a valid policy evaluation strategy, it does not fully inform us of the impact of the Recast on the 'effectiveness' of EWCS. This effectiveness is dependent on how the EWC functions in practice and not only on how it should function according to the founding agreement.

In practice, divergence occurs between the codified rules and the reality. EWCs might meet more or less often, discuss issues not specified in the agreement or face a management denying some resources to the representatives. By only looking at the EWC agreements and all its clauses, one cannot obtain a full picture of the EWC operations. Nevertheless, the EWC agreements are used here as a proxy for EWC operations, as they outline the general framework in which an EWC should function. In the event of a conflict, it will be the signed agreement that will be used as an ultimate reference, rather than the developed practices. Moreover, in the event of a renegotiation such 'developed practices' are included in the agreements. Evolved practices are likely to be reflected in the agreements, taking into account a certain time lag.

Furthermore, as Cremers and Lorber (2015: 86) rightly mention, the effectiveness of an EWC is highly dependent on the relation of trust between the employee and employer representatives and the management attitudes towards the councils. As they argue, a clear agreement which specifies the mutual rights and obligations is essential in creating a supportive managerial climate for the EWC. Similarly, Gilman and Marginson (2002) concluded that 'the terms of the agreement will configure but not determine the actual practice of EWCs'. 


\section{EWC Recast Directive - Hypotheses}

The Recast Directive substantially altered some terms of the original Directive, with the objective of ensuring the effectiveness of the information and consultation rights on transnational issues. Some of these changes are discussed below and concrete hypotheses are developed on how they are likely to affect the content of EWC agreements.

\subsection{Information and consultation: definitions}

One of the clear changes implemented by the EWC Recast Directive is the inclusion of clear definitions of what should be understood by 'information' and 'consultation'. These definitions were included to respond to a lack of clarity on what should be understood by the two terms and also to the several court cases that resulted from this vagueness (Sachs-Durand 2010). The new definitions of information and consultation are mentioned in Article 2.1:

- Art. 2.1 (f): “information" means transmission of data by the employer to the employees' representatives in order to enable them to acquaint themselves with the subject matter and to examine it; information shall be given at such time, in such fashion and with such content as are appropriate to enable employees' representatives to undertake an indepth assessment of the possible impact and, where appropriate, prepare for consultations with the competent organ of the Communityscale undertaking or Community-scale group of undertakings'

- Art. 2.1 (g): “consultation" means the establishment of dialogue and exchange of views between employees' representatives and central management or any more appropriate level of management, at such time, in such fashion and with such content as enables employees' representatives to express an opinion on the basis of the information provided about the proposed measures to which the consultation is related, without prejudice to the responsibilities of the management, and within a reasonable time, which may be taken into account within the Community-scale undertaking or Community-scale group of undertakings'

An EWC is, however, free to specify a tailor-made definition of information and consultation. As long as this specific definition does not infringe on the rights of the employee representatives, EWC agreements might include more specificity about the timing and content of information and consultation. As a result of the EWC Recast, we thus expect more EWC agreements to mention and specify clearly what should be understood by information and consultation.

\section{Hypothesis 1:}

Post-Recast EWC agreements will be more likely to include information and consultation definitions than pre-Recast EWC agreements 


\subsection{Select committees}

A select committee mainly consists of a smaller group of EWC representatives which usually takes charge of some coordinating and organizing tasks. Depending on the agreement rules, they can also be given broader tasks of receiving information, dissemination, calling extraordinary meetings etc.

In the original EWC Directive, select committees were only mentioned indirectly. In the subsidiary requirements, the following mention was included: 'Where its size so warrants, it shall elect a select committee from among its members, comprising at most three members.'

The Recast Directive moved the requirement to decide about the establishment of a select committee to Article 6, which states: 'Without prejudice to the autonomy of the parties, the agreement (...) shall determine: (...) where necessary, the composition, the appointment procedure, the functions and the procedural rules of the select committee set up within the European Works Council'. Agreements made after the Recast are therefore, practically speaking, obliged to specify whether or not they are establishing a select committee. As a consequence, we can expect post-Recast agreements to be more likely to include a select committee than pre-Recast agreements.

\section{Hypothesis 2:}

Post-Recast EWC agreements will be more likely to have a select committee than pre-Recast EWC agreements

\subsection{Training}

As the EWCs often discuss complex financial and economic issues, the representatives need sufficient competences to realize the potential of an EWC (Waddington 2010: 216). For this, training is required. Acknowledging this point, the European Commission even opened budget lines for trade unioninitiated training activities. In the original Directive, no reference is made to the need or right to training for EWC members.

In the Recast, on the other hand, the need for training is expressed in both Recital 33 and Article 10§4, which clearly establish the right of employees to training without suffering any loss in earnings. According to the implementation report of the commissions' expert group, the costs of the training should, in principle, be borne by the management (European Commission 2010). In order to determine particular details, such as the types of training and the extent to which employees have access to training, the EWC agreements need to include some specifications. It is therefore assumed that post-Recast agreements will be more likely to include clauses on training than pre-Recast agreements.

\section{Hypothesis 3:}

Post-Recast EWC agreements will be more likely to establish a right to training than pre-Recast EWC agreements 


\subsection{Articulation}

For European-level employee involvement to be optimally effective, a certain communication and linkage must exist between the national and European levels of employee information and consultation. We here study three aspects of the issue of articulation: (1) the definition of the transnational competence of the EWC, (2) the right and duty to report back and (3) the right of employee representatives to visit the company premises.

\subsubsection{Transnational competence}

A first issue with regards to the relationship or articulation between the different levels is the material competence of each level. As experience showed that frequent discussion arose about what should be understood by 'transnational competence', the Recast Directive included a more specific definition of this matter.

According to Article 1.4, transnational competence is defined as follows:

'Matters shall be considered to be transnational where they concern the Community-scale undertaking or Community-scale group of undertakings as a whole, or at least two undertakings or establishments of the undertaking or group situated in two different Member States.'

While a similar definition was already included in the subsidiary requirements of the original Directive, the Recast moved this definition to the main body of the Directive. The definition should be interpreted together with Recitals 12 and 16. To this effect, the European Commission's evaluation roadmap (2016) states: 'The criterion used is that it is the potential effect of the subject that should determine whether this is a EU-level or national-level subject.'

Yet again, this definition is in essence a minimum requirement which does not affect the competence of the member states or the negotiating parties to provide more extensive or detailed specifications of what should be understood by 'transnational competence'. An analysis of the national transpositions nevertheless showed that the important recitals are often not transposed (Jagodzinski 2015).

Given that the Recast moved this definition to the core body of the text and that the interpretation might differ depending on whether or not the recitals are accounted for, post-Recast agreements are expected to be more likely to include a specific definition of the transnational competence than pre-Recast agreements.

\section{Hypothesis 4:}

Post-recast EWC agreements will be more likely include a definition of the

transnational competences than pre-recast EWC agreements

\subsubsection{Reporting back}

The second issue regarding articulation refers to the communication between employee representatives of the different levels. In this regard, the Recast 
Directive includes a right and obligation for the employee representatives to inform the local representatives and employees of the content and outcome of EWC operations in Article 10§2, and a mention of the importance of reporting back in Recital 33. The study of the national transposition laws has shown that this aspect of the Recast is not always reflected in national legislation (Jagodzinski 2015) and that only in Lithuania was the duty to report back further specified.

In other words, it is up to the negotiating parties to agree and implement procedures and practicalities on how to report back (De Spiegelaere and Jagodzinski 2016). In line with the Recast, it is the employee representative's duty to report back, but this could well be combined with a parallel or joint reporting from management. Post-Recast agreements may therefore be more impelled to include clear clauses on reporting back than pre-Recast agreements.

\section{Hypothesis 5:}

Post-Recast EWC agreements are more likely to include the right and obligation of employee representatives to report back than pre-Recast EWC agreements

\subsubsection{Access to premises}

An essential means of establishing a good connection between the different levels of employee representation is the right of EWC representatives to go and visit the employees they represent in their work context. This right to access the company premises is not mentioned explicitly in the Recast Directive, yet can be derived from the specified right and obligation to report back. As Picard (2010) mentions: 'The duty (...) to report back to the employees they represents implies that the management at all levels is under an obligation to provide EWC members with the appropriate means of communication with the workforce, including granting access to all company sites.' The 2010 Expert Report on the implementation of the Recast directive (European Commission 2010) made a similar evaluation: 'It (reporting back) could entail the need for EWC members to travel to local sites in order to report back to the workers'.

For such a right to be unequivocally established, an EWC report would need to call attention to it and organize it. Given the implicit mention of it in the Recast Directive, we expect to see more such clauses in post-Recast agreements than in pre-Recast agreements.

\section{Hypothesis 6:}

Post-Recast EWC agreements will be more likely to include the right to access the company premises than pre-Recast EWC agreements

\subsection{Preparatory and debriefing meetings}

For a qualitative information and consultation process, employees should be able to meet with management to ask questions, receive information and be consulted; but also to meet without management. Such internal meetings should enable the representatives to discuss the issues and develop positions. 
In the original Directive, an employee-only preparatory meeting was included in the subsidiary requirements. In the Recast Directive, this reference has not been altered. At the same time, Article $5 \S 4$ on the negotiation process envisages both a preparatory and debriefing meeting.

A spillover effect from the functioning of the SNB to that of the EWC can be expected, meaning that post-Recast agreements are more likely to include preparatory and debriefing meetings than pre-Recast agreements.

\section{Hypothesis 7:}

Post-Recast EWC agreements will be more likely to allow for employee only

preparatory and debriefing meetings than pre-Recast EWC agreements

\subsection{Trade union role}

Negotiating and running an EWC requires a certain level of expertise and experience. At the outset, this expertise is rarely available; experience with different issues only accumulates slowly. Trade unions have experience and expertise on these subjects and their positive role in the functioning of EWCs has been widely acknowledged (European Commission 2008). In the Recast Directive, the trade unions (and more specifically, the European Trade Union Federations (ETUFs)) were given a larger role in the negotiation and establishment of EWCs in four ways:

1. In Article $5 \S 4.3$, the Directive stipulates that the SNB may request the assistance of experts, which can include representatives of the ETUFs.

2. Article $5 \S 4.3$ gives the ETUF representatives the right to participate as an advisor in the negotiation meetings (at the request of the SNB).

3. Article $5 \S 2 . c$ states that the ETUF should be informed of the composition of an SNB and the commencement of negotiations. This should give them the opportunity to better monitor the developments in the field and approach the parties with their advice.

4. According to Article $4 \S 4$, management should communicate the required information for the negotiations to all 'parties concerned', which includes the trade unions (Picard 2010).

It is clear that the Recast indirectly aims to stimulate trade union involvement in EWCs. One way in which trade unions can be systematically involved in the EWC functioning is by taking a trade union representative as a permanent guest, member or expert in the EWC. The EWC Recast did not directly stimulate this kind of involvement, yet we assume that if trade unions participate more in the negotiations, they might at the same time develop their function as permanent advisors. It is therefore expected that post-Recast agreements will be more likely to include a permanent trade union guest in the EWC than pre-Recast agreements. 


\section{Hypothesis 8:}

Post-Recast EWC agreements will be more likely to allow trade union representatives to join the meetings than pre-Recast EWC agreements

\subsection{Renegotiation and termination clause}

In order to give employee representatives and management a way of regularly updating the EWC agreement to accommodate evolving practices, legislation, or company changes, the Recast included the following stipulation in Article $6.2(\mathrm{~g})$ :

'the date of entry into force of the agreement and its duration, the arrangements for amending or terminating the agreement and the cases in which the agreement shall be renegotiated and the procedure for its renegotiation, including, where necessary, where the structure of the Community-scale undertaking or Community-scale group of undertakings changes'.

Supported also by Recital 28 , this article requires agreements to be explicit on how they can be modified or terminated, and which rules will apply in the event of a renegotiation or termination. Accordingly, we expect to see relatively more of such clauses in post-Recast agreements than in pre-Recast agreements.

\section{Hypothesis 9:}

Post-Recast EWC agreements will be more likely to have a renegotiation and termination clause than pre-Recast EWC agreements

\section{Data and method}

\subsection{Data}

This chapter uses the EWC database, which is assembled by the European Trade Union Institute (ETUI) and is the most comprehensive source on EWCs. The EWC database comprises two elements: information on the number of EWCs and the full text of EWC agreements. While these two elements are clearly interlinked, the data does not always directly correspond. Each EWC may be attached to more than one agreement: for example, an agreement establishing the EWC as well as some renegotiated agreements. The research for this paper was undertaken in January 2016 when the number of active EWCs was 1,073, the number of EWC agreements was 2,003 and the number of agreements used for the study was 1,078 (of which 107 were signed in the post-Recast period). The agreements used for the analysis included complete agreements - irrespective of whether they were the original or a renegotiated document - signed between 1994 and 2014. EWC agreements based on the subsidiary requirements are excluded from the analysis. Agreements concluded before 1994 and after 2014 are also excluded as there are insufficient cases for a reliable analysis. Similarly, agreements which are known but of which no full- 
text version is available are excluded. Based on a coding scheme devised by the researchers, the full text of each EWC agreement has been coded, thus enabling an assessment of the changing content of EWC agreements ${ }^{2}$.

\subsection{Modelling time}

It is the objective of this article to study the effect of a policy intervention (the EWC Recast) on the content of EWC agreements. For this, we study whether post-Recast agreements are significantly different from pre-Recast agreements. Policy is, however, not the only time-related factor that influences the content of EWC agreements. As EWCs are designed according to the will (and agreement) of the negotiating parties, this institution should be seen as an 'institution in process' (Waddington 2010). Its development is a constant process and builds on internal EWC experience and the experience of other EWCs, as well as on changes in policy. In earlier studies of EWC agreements, strong learning effects were identified; learning effects which are partially independent of regulatory policy interventions (Waddington 2010:56). Also in longitudinal case studies of the EWCs, learning effects were observed (Eurofound 2015). When studying the evolution over time of EWC agreements, one therefore needs to account for both policy effects as well as general learning effects.

\subsection{Control variables}

In analysing the effect of the Recast on EWC agreements, several crucial control variables should be accounted for, as they are likely to influence the characteristics of the EWC agreements and equally related to our variable of interest. Gilman and Marginson (2002) already studied the determinants of EWC agreement content and distinguished between different influential factors:

- A statutory effect referring to the degree to which an agreement has to reflect the rules of the Directive. Here, the authors distinguished between Article 13 and Article 6 agreements.

- A learning effect referring to the overall tendency of some clauses to be replicated between agreements.

- A country effect referring to the idea that EWCs tend to partly resemble the industrial relations traditions of the home country.

- A sector effect referring to the tendency of similar companies (of the same sector) to agree on similar agreements.

The analysis presented here builds on these insights in the selection of the control variables, yet advances and extends this selection process:

2. For more details on the data used in this and other chapters, please refer to Annex 1. 
- As the regulatory framework differs, so the agreements may reflect this differentiation. Clearly, the legal obligations of Article 6 agreements are more extensive, making it more likely that these agreements will have more stipulations regarding such obligations as training, reporting back etc. Previous studies have already indicated such differences (Carley and Marginson 2000) and as there is a direct relation between the agreement period and the EWC type, including this control variable is indispensable.

- A second control variable is the sector in which the agreement is established. While the EWC Directive covers companies from a certain size in all sectors, most EWCs were first established in the metal and chemical sectors. While these sectors accounted for almost three quarters of all EWCs in 2002 (Kerckhofs 2002), they currently account for just over half of all currently active EWCs (De Spiegelaere and Jagodzinski 2015). The sector of establishment is most likely also related to the characteristics of the agreement. For one, depending on the sector, the EWCs are supported in their activities by different European Trade Union Federations which may differ in their policies and experiences (Waddington 2010). Secondly, as unionization and organization rates differ by sector, so does the power balance between the negotiating parties, which is likely to impact the negotiation outcomes.

- The third control variable is the company size. Again, this variable is related to both the outcomes of our analysis and to the independent variable (time). Over time, the proportion of EWCs established in large companies ( $>10.000$ employees in the EEA) tends to increase (Kerckhofs 2002, 2006; De Spiegelaere and Jagodzinski 2015). At the same time, company size tends to affect the EWC characteristics; a recent Eurofound report (2015) shows that larger companies are more likely to establish select committees.

- The last control variable included is the headquarters country of the company. EWCs tend to reflect national industrial relations traditions (Eurofound 2015; Hertwig 2015). Proportionally, a large part of the EWCs are established in companies headquartered in Germany, the US, the UK and France, with minor evolutions over time in terms of proportional spread. For this reason, four country clusters were employed to assess the impact of the home country on agreements, in relation to traditional differences in industrial relations regimes. First, a cluster of Nordic countries was identified comprising of Denmark, Norway, Sweden, Finland and Iceland. Next, a cluster named Coordinated Market Economies (CME) included Germany, Belgium, the Netherlands, Austria, Luxemburg and Switzerland. The Mixed Market Economies (MME) contained France, Italy, Portugal, Spain and Greece. The last cluster referred to Liberal Market Economies (LME) and included the United Kingdom, Ireland, the United States, Canada, Japan, the Central-East European countries and others. 
More details on these control variables and how they vary over time can be found in Annex 2.

\subsection{GEE modelling}

Building on the data and hypotheses, we have a series of binary dependent variables for which we want to estimate the effects of a series of mostly categorical independent variables. These independent variables include a continuous and a discrete time variable. The dataset has the following characteristics: (1) it has a hierarchical structure as some agreements are negotiated in the context of a single EWC (renegotiations) which violates the assumption of independent observations; (2) notwithstanding the hierarchical nature of the data, most observations are independent (only one agreement for an EWC), (3) we work with both continuous and discrete time effects to measure the overall learning effect and the policy effect and (4) the time intervals are unequally spaced.

Normal logistic regression analysis should not be used on this data given its hierarchical structure. Multilevel logistic regression could be used, but would provide us with subject-specific estimators. In this case, the estimates would relate to the effect of the independent variable on the dependent variable, in a specific EWC body. As EWC-level learning effects are not the focus of this study, we have to use marginal models which provide population average estimates, controlled for the correlation in the data because of the nonindependent character of some of the observations.

Generalized Estimating Equation (GEE) is such a method. In short, it calculates the estimates of interest, while correcting for the non-independence of the observations using working assumptions of how they correlate (Molenberghs and Verbeke 2005: 151-161). Yet, even when the correlation is misspecified (wrong working assumption), the estimates of the main effects are consistent, making it a very fit method to study the population average effect on longitudinal discrete data (Zeger and Liang 1986).

In this study we use GEE estimation to analyse the relation between the independent and dependent variables. The reported estimates use an exchangeable working assumption and the standard errors are empirically corrected, or socalled 'sandwich estimator' standard errors (Molenberghs and Verbeke 2005).

\section{Descriptive results}

Table 9 shows the share of agreements including a certain clause or definition and an illustration of the evolution of the yearly share of agreements over time. Of all 1078 agreements under study, a large majority include a provision on a select committee (88\%) and a provision on reporting back to the workforce (73\%), include a renegotiation and termination clause (68\%), and provide a definition of what should be understood by the transnational competence 
(66\%). More than half have a clause on training (58\%) while the other variables under study are overall less common. A guaranteed access to the company premises is introduced in $12 \%$ and a trade union representative in $12 \%$.

In Annex 2, the proportional difference is given depending on the headquarter country of the company, the company size, the EWC type and the sector of activity. The results in the annex show that the likelihood of an agreement (including different clauses) is related to the sector, country and company size. Some interesting patterns appear, yet any interpretation should take into account that these proportions are very rough and might include important composition effects (e.g. older agreements with specific characteristics are overrepresented in the metal sector).

For most variables there is a clear evolution over time. In Annex 2 and Table 3.1, the passage of time is illustrated using a graph plotting the yearly share of agreements including a certain clause. The interpretation should be as follows: of all agreements made in year $X, Y \%$ included a clause $Z$.

Regarding the information and consultation definitions, the share of agreements including both definitions rises slowly and then takes a leap around 2007. For the definition of the transnational competence, the 1994 level was already relatively high and rose rather erratically over time. For training, the 1994 share was very low, yet increased rapidly to about $60 \%$ and then even further in the run-up to the Recast. For reporting back, the trend is less clear; there seems to be a general yet erratic increase.

Just as with the training clauses, the 1994 share of agreements providing access to premises was very low but increased over time. However, the increase is much weaker than in the training case and only reaches about $30-40 \%$ in recent years.

The evolution with regards to the select committees is very different. Already in 1994 the share of agreements providing for them was higher than $50 \%$ and quickly increased to over $80 \%$. In recent years, virtually all concluded agreements have a select committee.

The inclusion of a trade union representative was not very widespread in the early years and does not seem to increase significantly over time. Finally, the inclusion of a renegotiation and termination clause increased in the first period, after which it stabilized at around $70 \%$. 


\section{Table 9 Overall presence and time-trend}

\begin{tabular}{l} 
Variable \\
\hline Information and consultation definitions \\
\hline 2 Select committee \\
\hline 4 Right to training \\
\hline 5 Refinition of the transnational competence \\
\hline 6 Access the company premises
\end{tabular}

\section{Multivariate results}

To identify specifically the effect of the Recast, a multivariate GEE analysis is performed for all the nine clauses which are likely to be stimulated by the Recast. Table 10 contains the results of the different models. In essence, these models aim to identify different possible patterns over time in order to establish whether or not the Recast had an observable effect on the content of agreements. These different patterns are illustrated in Figure 8.

- Boosted learning occurs when the Recast reinforces a pre-existing learning effect.

- Simple improvement occurs when there is a Recast effect but no general learning effect.

- Simple learning occurs when there is a learning effect and no Recast effect.

- No effect occurs when there is neither a learning effect nor a Recast effect. 
Figure 8 Different patterns

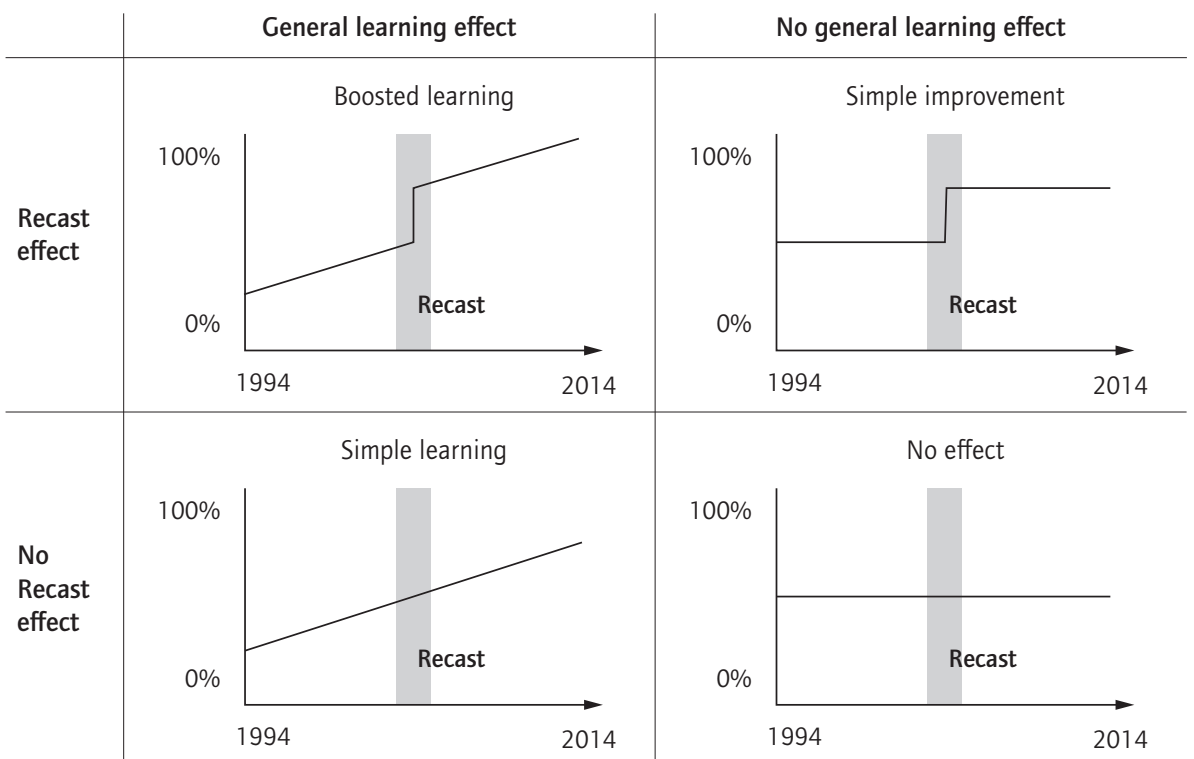

Table 10 gives the results of the multivariate GEE analysis. This analysis filters out the overall evolution in agreement characteristics, controlling for differences depending on company and EWC features. The table gives the odds ratios, the standard errors and significance levels for the different variables included in the model. The odds ratios measure the difference (increase/ decrease) in the odds (ratio of the probability that an event occurs, to the probability that it does not) of a particular clause being included in an agreement; depending on different variables and in comparison with a given reference group. An odds ratio of more than one signals that agreements with a certain characteristic are more likely to have, for example, a training clause than agreements from a reference group. An odds ratio of one signals that there is no difference and an odds ratio of less than one signals that agreements from that group have lower odds of inclusion than the reference group.

The results largely confirm the importance of the company- and EWC-related control variables. The odds of having a clause on reporting back, access to premises, trade union representatives and a preparatory and debriefing meeting differ significantly depending on the sector of activity. In general, agreements from the metal sector are more likely to include a clause on reporting back and providing access to premises, but also less likely to provide for preparatory and debriefing meetings or trade union representatives.

As for the country clusters, the model identifies significant differences for almost all variables except for the select committee. Without going into detail, agreements from companies headquartered in Coordinated Market Economies and Liberal Market Economies ${ }^{3}$ tend to diverge. Company size plays a minor

3. For a detailed list of countries allocated to those clusters, please see Annex 1: Data used. 


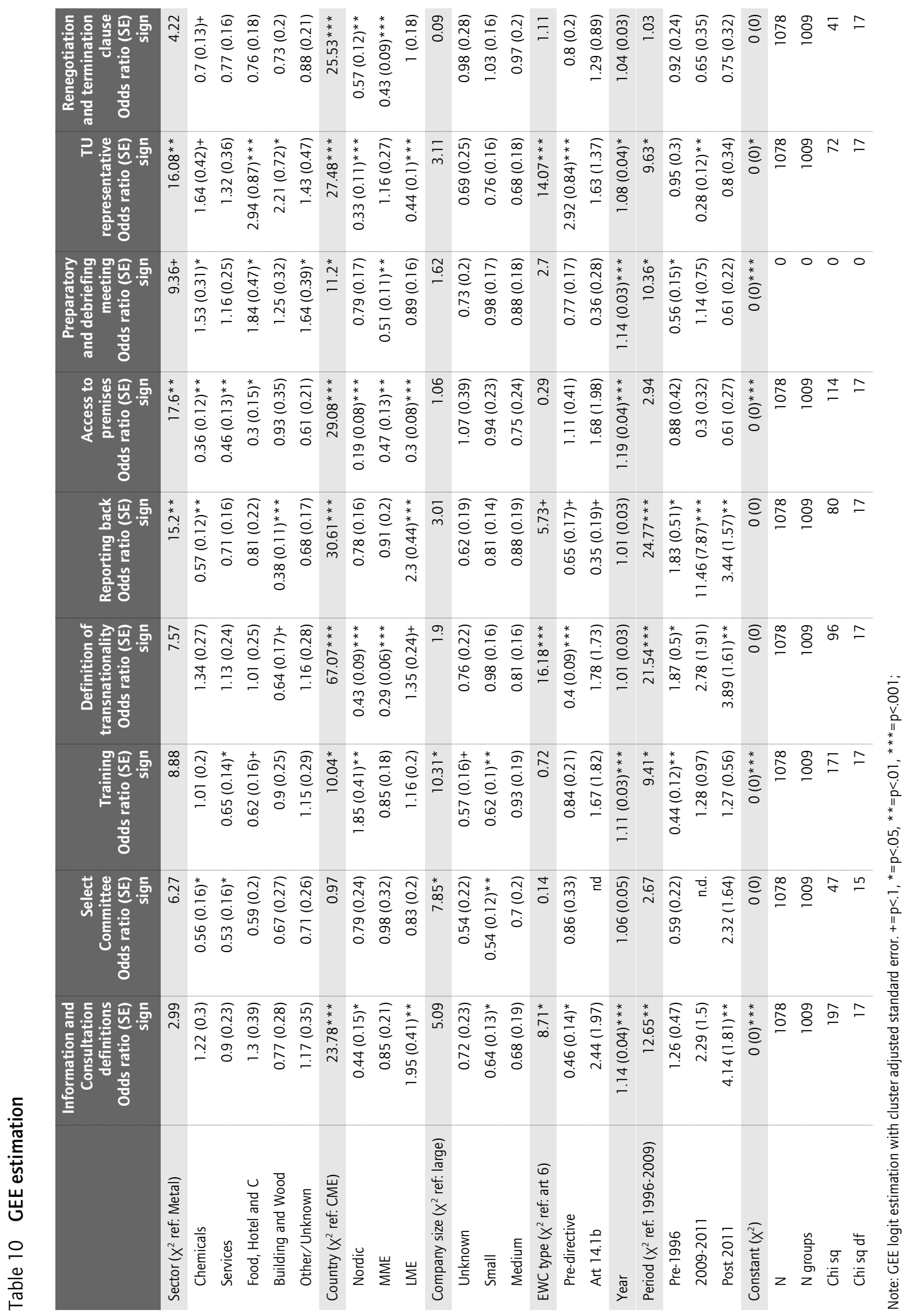


role, with agreements from large companies being more likely to have a training clause.

Of specific interest is the influence of the regulatory status of an EWC. Even when controlling for the country, cluster, date of establishment and company size, there are still significant differences between agreements made in preDirective, Article 6 and Article 14.1b EWCs. Compared to agreements made in Article 6 EWCs, those made in pre-Directive EWCs are significantly less likely to include definitions of information, consultation or the transnational competence, and are less likely to include clauses on reporting back. Conversely, they are more likely to provide for a trade union representative. The regulatory status of the EWCs is thus still an important issue and continuous to affect the quality of the EWC agreements.

To facilitate the interpretation of the two time-related variables of interest, Figure 9 shows the evolution over time of the predicted probabilities based on the model, as suggested by Agresti (2007) and Powers and Xie (1999). These figures neatly reflect the patterns discussed earlier.

Information and consultation definitions: boosted learning. According to the model, the probability that an agreement includes definitions of information and consultation is subject to a clear learning effect. With every passing year, the share of agreements including both definitions rises. At the time of the Recast, the probability further increases, reflecting a boosted learning pattern. The prior legal problems regarding the exact definition of information and consultation has probably contributed to the general learning effect, while the Recast effect can be explained by the up-front position of the new definitions in the Recast and the importance attached to the new definitions by trade unions. Currently, virtually all recently signed EWC agreements include such definitions.

Select committees: no effect. For select committees, the pattern is remarkable. From the outset, the establishment of a select committee was included in the original Directive's subsidiary requirement, leading to a high initial estimated probability of inclusion of over $80 \%$. Over the years, this probability increased further; yet, given the initially high probability, the increase is statistically insignificant. Moving this option to the core text in the Recast did not, either, lead to a significant increase of the probability of inclusion. There is, in summary, no effect.

Training clauses: simple learning. The pattern regarding training clauses is different as the model shows a clear learning effect, but no observable Recast effect. Although only few agreements included training rights in the beginning, the share of agreements providing training grew fast over the years to arrive at a (predicted) probability of about $85 \%$ in 2009. The Recast Directive, which established a right to training for all EWC representatives, did not affect this share in a significant way. This simple learning pattern can be explained by the fact that both employers and employees quickly recognized the added value of training and started including such a right in their agreements. At the time of 

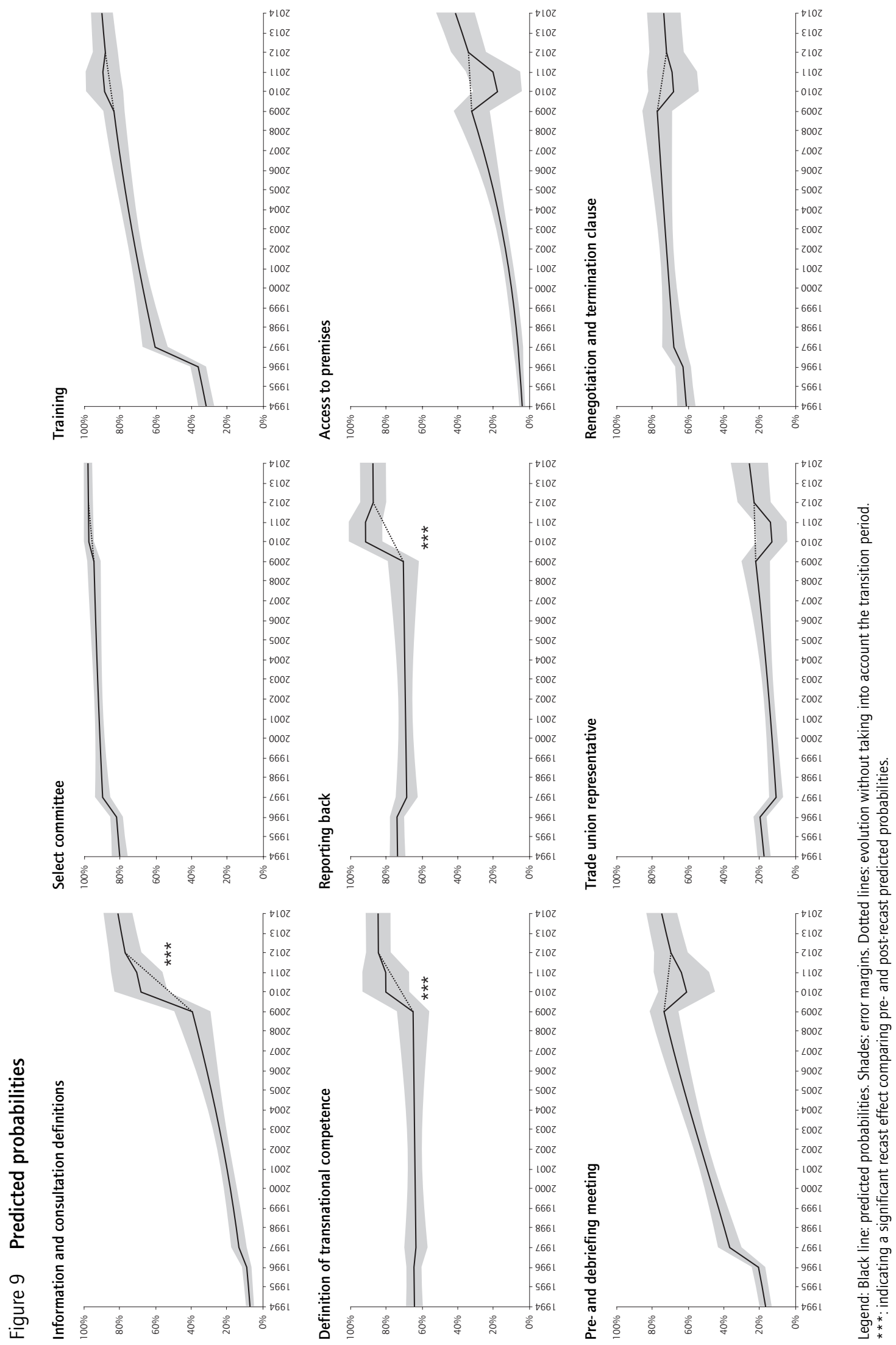
the Recast, the probability of inclusion was already high enough to make an additional increase difficult to realise. The Recast in this case merely affirmed existing practices, rather than changed them.

Definition of the transnational competence: simple improvement. For the definition of the transnational competence of the EWC, the model shows a clear effect of the Recast Directive, but no general learning effect. This pattern of simple improvement can be explained by the fact that a lot of agreements already included a definition of the transnational competence from the outset, as this concept is essential in defining the scope of activities of an EWC. Since the EWC Recast proposed a new definition, relatively more agreements started to include one in their agreements.

Reporting back: simple improvement. Regarding the inclusion of clauses on reporting back the pattern is one of simple improvement. Just as with the definitions of the transnational competence, the probability of inclusion was initially already relatively high. Over time, this probability did not change but increased with the Recast. Forging connections with the other levels of employee representation is essential for the good functioning of an EWC, and the need to inform the workforce was therefore included in the initial subsidiary requirement. Already in the early periods, therefore, this gave way to a relatively high probability of inclusion. The mention of this right in the core text further increased the probability of inclusion to almost $90 \%$ in new EWC agreements.

Access to premises: simple learning. As a guaranteed access to premises is not explicitly mentioned in either the original or the Recast Directive, the model shows that the initial probability of inclusion is rather low. There is, however, an overall increasing trend in the probability of inclusion which is unaffected by the Recast. This pattern of simple learning seems to be interrupted during the transition period (2009-2011) where the estimated probability decreases sharply. However, as the number of agreements in that period is relatively low, this decrease is only marginally statistically significant and is undone by the subsequent increase in the predicted probability in the post-2011 period. Obviously, the implicit means of including this right in the directives did not translate into a greater exercise of this right in practice. However, over time, the probability of inclusion increases, suggesting that the negotiating parties see such a right as instrumental for the effective and independent functioning of an EWC.

Preparatory and debriefing meeting: simple learning. The pattern with regards to the inclusion of preparatory and debriefing meetings is one of simple learning. With every passing year, the probability that an agreement includes the right to have both preparatory and debriefing meetings increases distinctly. With the Recast, the estimated probability changes, but the estimate is not statistically significant. There is, in other words, no significant difference in the probability of an agreement providing for preparatory and debriefing meeting between the pre-Recast and the transition or post-Recast period. The projected spillover of a practice established in the SNB to the EWC did not 
therefore occur. Part of the explanation might be that even before the Recast, the predicted probability was already relatively high, leaving only limited room for improvement.

Trade union representatives: simple learning. For the inclusion of trade union representatives the model shows a slow learning curve. In the transition period, the likelihood dropped significantly, but recovered afterwards. There is no Recast effect. The four ways in which the Recast tried to stimulate trade union involvement in EWCs did not result in more trade union representatives as permanent guests at EWC meetings.

Renegotiation and termination clauses: no effect. According to the model, the likelihood that an agreement includes a renegotiation and termination clause is not subject to a general learning effect nor a Recast effect. The modelled probability fluctuates at around 60-70\%. Already before the Recast, a majority of EWCs saw the use of including clauses on how to terminate and amend the agreement. The fact that the Recast added this as an official requirement for an EWC agreement did not significantly raise the number of EWC agreements including such clauses.

\section{Discussion}

The primary interest of this research is the question of whether or not the policy intervention of the EWC Recast had any observable effect on the agreement content. As we know from the literature and past research, policy is not the only time-related variable that is likely to affect the agreements' content. A general learning effect was already identified, as EWC agreements build on experiences and innovations of previous EWC agreements and incorporate them. These two effects have been modelled as a linear 'learning effect' and a discrete 'Recast effect', distinguishing between different relevant policy periods. Combining our two time-related variables, four patterns appear.

\section{$6.1 \quad$ Boosted learning}

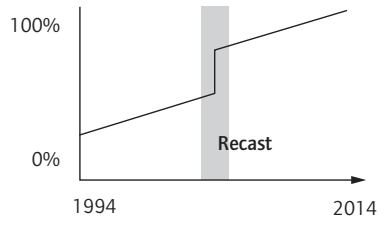

The Recast boosted the inclusion of information and consultation definitions in the EWC agreements.
For only one variable, a genuine boosting effect was identified in which both a learning as well as a Recast effect is present: this is the inclusion of definitions of information and consultation. The likelihood that agreements mention clear definitions of information and consultation is growing over time, but with the EWC Recast Directive this growth curve was given an extra boost. The need for clear definitions was clearly accepted as a best practice that was proliferating, but the fact that the Recast included clear definitions gave a serious boost to the likelihood of EWC agreements including such definitions. 


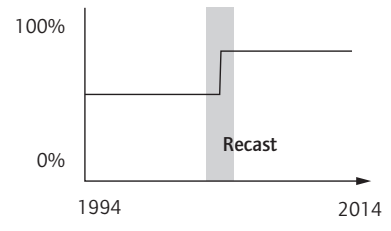

The Recast Directive increased the likelihood that definitions of transnationality and clauses on reporting back are included in EWC agreements; this likelihood didn't grow over time, independent of the Recast.

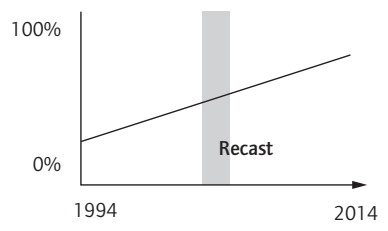

The Recast Directive only affirmed the already existing reality of omnipresent training rights and preparatory and debriefing meetings.

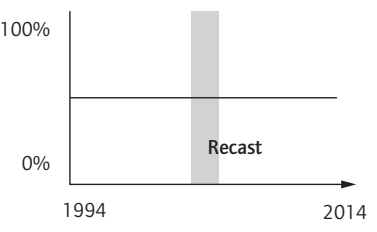

\subsection{Simple improvement}

For two other variables we observe a simple improvement effect; while there is no general learning effect, the Recast positively affected the likelihood of inclusion. This is the case for the inclusion of definitions of transnationality and the right and obligation of employee representatives to report back about the EWC activities. Regarding the reporting back, we observe that the probability of an agreement including such a clause was already an estimated $70 \%$; yet with the Recast, this probability increased to about $90 \%$. As for the definitions of transnationality, a similar pattern is observed. The probability was stable at around $65 \%$ and due to the Recast Directive, increased to about $85 \%$.

\subsection{Simple learning}

For most other variables the Recast did not affect a pre-existing learning trend and just affirmed an existing reality of proliferating best practices. This is the case for the existence of training rights, the provision of a right to visit the company premises, the possibility to hold preparatory and debriefing meetings and the inclusion of a trade union representative in the EWC meetings.

For training rights and preparatory and debriefing meetings, most agreements signed just before the Recast already included such clauses, leaving very little room for improvement.

For the inclusion of trade union representatives and the provision of guaranteed access to premises, there is still much room for improvement. However, the Recast did not affect the general learning effect, which just continues after the Recast.

\subsection{No effect}

For two variables - the inclusion of renegotiation and termination clauses and the presence of a select committee - we observed neither a general learning effect nor a policy effect.

Although the inclusion of such clauses was not mandatory in the pre-Recast period, many agreements did include them. In the post-Recast period, agreements are obligated to include them and yet there has been no substantial increase in the proportion of agreements that do so.

The same goes for the select committee. Even though the select committee was only mentioned in the subsidiary requirement in the original directive, this practice spread very quickly in all EWC agreements. Even long before the Recast, virtually all (re)negotiated agreements included a select committee. Also on this point, the Recast only affirmed existing practices. 


\subsection{Recast vs. self-regulation}

An EWC agreement defines the contours in which the EWC will function. It defines a set of procedures, engagements, rights and obligations within the framework of the law. The EWC regulation is an example of 'regulated selfregulation'. Our analysis of EWC agreements' content over time shows the clear presence of a strong learning effect in the content. Through experience and copying best practices, providing training to employee representatives quickly spread, just as providing definitions of information and consultation and giving the employee representatives the opportunity to have employee-only preparatory and debriefing meetings did.

One major group of actors in this learning process are the European Trade Union Federations (ETUFs). Through their policy of assigning national or European trade union coordinators to EWCs, they enable and stimulate mutual learning. These coordinators are frequently responsible for more than one EWC and organize through coordinator network meetings (Waddington 2010; Rüb and Platzer 2015). This, together with the centrally developed guidelines, guidebooks and toolboxes for EWCs, is most likely one of the major explanations for the observed strong learning effect.

As a consequence of this strong learning effect, some practices were relatively widespread in EWC agreements, even before there was any discussion of a recast of the Directive. There was accordingly little room for improvement and therefore the Recast did not affect the share of agreements that included a select committee or training rights. Here, the changes of the Recast reflected an already omnipresent reality.

The Recast introduced some different requirements for EWC agreements. As a result, EWC agreements did start to include more definitions of information, consultation and the transnational competence of the EWC, as well as specifications on the right to report back. Here the Recast was a realitychanging policy. It either strengthened existing learning curves (e.g. regarding the inclusion of information and consultation definitions) or simply increased the likelihood of inclusion (transnational competence definition and reporting back).

Both the regulatory and the self-regulatory aspect are thus effective in some fields. At the same time, both aspects are equally ineffective in stimulating the spread of some other practices. The clearest example is the possibility for a trade union representative to join the EWC meetings as a permanent guest. Although trade union involvement is considered positive for the functioning of an EWC, a limited learning effect is observed. Despite the Recast declaring it as an objective to stimulate trade union involvement, there is no significant increase in the amount of agreements providing for such a permanent representation. The same goes for employee access to premises. Although there is a small learning effect with more and more agreements providing for such a guaranteed access, the Recast did not manage to encourage the spread of this practice. 
The explanation is probably related to the way in which the Recast tried to boost trade union involvement and guarantee access to premises. In both cases, the rules are not clear or significant. For union involvement, the Recast only demanded that they would be informed about the start of negotiations. Regarding access to premises, this option was not even mentioned in the Recast but was considered a logical consequence of the duty to inform the local representatives and the need for the managers to provide sufficient means to the EWC representatives to fulfil their obligations. This implicit inclusion in the regulatory framework is evidently not a game changer and does not lead to a significant shift in the content of EWC agreements.

\subsection{Continuing legacy of the first transition period}

In comparing EWC agreements, this study also controlled for possible differences between agreements made in EWCs functioning under different legal frameworks. As pre-Directive EWCs are exempted from the rules of the Directive, agreements made in such EWCs are likely to be less affected. The model presented confirms this. With regard to the inclusion of definitions of information and consultation, the definition of transnational matters and clauses on reporting back, there is a marked difference. Agreements from preDirective EWCs are less likely to include such clauses. However, when it comes to trade union representatives, pre-Directive agreements are more likely to provide for them. This last observation can be explained by the need for such a pre-Directive EWC to cover the whole workforce. One frequent way of doing so (in the absence of a formally organised SNB) was by negotiating with the present trade unions, rather than with an ad-hoc negotiation committee.

\subsection{Non-observable Recast effects}

This chapter focused on the observable Recast effects by comparing EWC agreements from different periods. In this exercise it is assumed that the changes made in the Recast should be reflected in proportionally more EWC agreements that include certain clauses, rights or definitions. This study found only a few observable Recast effects. However, for several reasons, this does not entirely exclude the possibility that the Recast had an effect.

First of all, some agreements negotiated just before the Recast was concluded and implemented might have renegotiated their agreement in the shadow of the law. In this case they would have already taken into account upcoming legal changes in their current agreement. Such anticipated alignment might mask some of the Recast effects.

Second, and more importantly, this study is focused on EWC agreements, with the recognition that many EWCs have never renegotiated their agreements; for these, the effect of the Recast is therefore by definition non-observable. However, the rights and obligations stemming from the Recast directly apply 
to these EWCs (if they are Article 6 EWCs) even when they haven't renegotiated their agreement.

\section{Conclusion}

This chapter focused on the question of whether or not the Recast led to the development of better EWCs. In evaluating this question, it searched for observable effects of the Recast regarding the changing content of EWC agreements. In doing so, this study controlled for possible intervening effects (country, sector etc.) and also included a general learning effect.

The results show that for most included variables which the Recast aimed to affect, no observable Recast effect could be established. For some variables, this was mostly due to the presence of strong learning effects, which resulted in very limited room for improvement at the time of the Recast. In these areas (training, select committee and preparatory and debriefing meetings) the Recast merely affirmed existing practices.

On some other points, the Recast did have an observable effect: namely, the inclusions of definitions of information, consultation and transnational matters, and clauses on reporting back to the employees. Elsewhere, there was no such effect but still clear room for improvement. More specifically, the inclusion of trade union representatives in the EWC meetings and the guaranteed access to company premises is unaffected by the Recast but not yet very widespread. The absence of clear instruments in the Recast to promote these aspects can be identified as the major cause.

Overall, the Recast reflected the lowest common denominator more than the best practices. This observation is shared by various other studies using different methodologies. Kerckhofs (2015), for example, presented a similar conclusion based on several longitudinal case studies. Waddington et al. (2016), meanwhile, interviewed managers, similarly demonstrating how the Recast introduced rights and practices which were already common and therefore did not affect the functioning of the EWCs. 


\section{General conclusion}

This report aimed to evaluate the EWC Recast Directive. In doing so, the report focused on the two main objectives of the Recast, namely: (1) to stimulate the creation of more EWCs and (2) to enhance the effectiveness of existing and future EWCs. By building on data from the most comprehensive database of EWC agreements, an evaluation was made of how effective the Recast has been in delivering on its declared objectives.

While the Recast Directive was a clear improvement on the previous Directive and contributed to the legal certainty in several ways, the overall conclusion of this evaluation exercise is that the Recast was in most respects too little, too late for enabling the establishment of more and better EWCs.

\section{More EWCs}

Based on results of this research, the Recast Directive was found to be ineffective in stimulating the creation of more EWCs. Both during the second transition period and in the post-Recast period, the number of newly created EWCs declined and continues to do so. This decline in the growth rate is unlikely to be caused by a saturated population or by the presence of alternative ways of organizing transnational information and consultation.

The legal instruments provided by the Recast to boost the establishment of new EWCs (a transition period, information to trade unions and clarification on who should give the necessary information for the negotiations) can be rightly considered ineffective and insufficient.

Future policy interventions should focus on increasing the overall awareness of the possibility to establish EWCs, spreading information on which companies are eligible to organize an EWC, and providing resources for the initial phases of negotiation. Capacity building of trade unions and (national) employee-representation structures could help to boost the creation of new EWCs, as could the establishment of an EU-level database on companies.

\section{Adapting EWCs}

Although the Recast aimed to affect the functioning of both present and future EWCs, it explicitly ruled out an obligation for EWCs to renegotiate their agreements. The figures show that there was a slight increase in renegotiations 
and amendments in the post-Recast period but that there was no great 'wave' of renegotiations as had been expected.

One possible explanation is the fact that the new rules applied directly to all (Art. 6) EWCs. Another is that a lot of the changes introduced by the Recast were already present in most of the recently established or renegotiated agreements. In these cases there was no clear need for a renegotiation or amendment.

The Recast also provides for an obligation to fully renegotiate the EWC agreement in the event of 'significant structural changes' in the company. If demanded by the employees, the renegotiation should entail the creation of a new SNB and thus lead to a brand new EWC. This so-called adaptation clause was expected to serve as a converging factor and an opportunity of transformation for pre-Directive EWCs which are still not covered by the rules of the initial Directive or the Recast. Such a convergence, however, did not materialize. Few EWCs have transformed from pre-Directive into normal Article 6 EWCs.

The ineffectiveness of the adaptation clause could have been caused by a multitude of reasons, such as: little knowledge of the existence of this clause, limited legal clarity on what 'significant change of structure' means, other priorities for employee representatives and management in the event of a merger, power dynamics, high perceived costs and low perceived added value.

These obstacles are in no way addressed by the Recast or the national implementation laws, leading to a limited use of the adaptation clause. Future policy interventions should focus on making the adaptation clause fit the reality of constant restructuring.

A consequence of the limited effectiveness of the adaptation clause is the fact that a considerable number of the EWCs continue to be pre-Directive EWCs and thus not fully covered by the Recast. This undermines the ability of any regulation to influence the content of EWC agreements. Our study indeed shows that agreements made in pre-Directive EWCs remain less complete and advanced than in the others.

Future legislation should avoid creating even more exemptions and transition periods and instead work towards a unified framework for all employee rights to transnational information and consultation.

\section{Better EWCs}

Through the comparison of agreements from different periods, this report studied the contribution of the Recast to creating better EWCs. The report focused on the following agreement characteristics: information and consultation definitions, presence of a select committee, training clauses, definition of the transnational competence, clause on reporting back, access to company 
premises, preparatory and debriefing meetings, presence of a trade union representative and the inclusion of renegotiation and termination clauses.

The results of the study show that a Recast effect was observed for only three of these characteristics: information and consultation definitions, definition of the transnational competence and the presence of a clause on reporting back. In the case of the first characteristic, the Recast boosted an existing general learning effect; while for the other two, there was no observable learning effect and the Recast therefore played a role in improving the situation.

For all the other variables, a Recast effect could not be observed. In most cases there was, however, a strong learning effect. In the case of the select committee and the training clauses the limited room for improvement explains the absence of a Recast effect. On these topics the Recast merely affirmed the fact that in virtually all recent EWC agreements these aspects are already included.

For the inclusion of clauses on trade union representatives and giving employees access to the company premises, no Recast effect was observed (although there remains great potential for improvement). Clearly, the implicit way in which they were included in the Recast was not effective in boosting their inclusion in EWC agreements.

\section{Learning and policy}

One of the major explanations for the limited effect of the Recast Directive on the content of EWC agreements is the observed strong learning effects which left only limited room for improvement. Learning effects in many ways surpassed policy effects, which only caught up by means of the Recast. This can be explained in two ways.

One the one hand, learning in EWCs was particularly strong. Thanks to the efforts of the European Trade Union Federations in providing coordination for EWCs' negotiation and practice, and for the development of specialized training courses, some practices proliferated very quickly.

On the other hand, policy is particularly weak. In many cases, the Recast only stipulates what should be regulated but does not prescribe the content or specific solutions. There are very little monitoring and even less administrative sanctioning policies organized to enforce compliance. This, together with a policy that mostly reflects the most common and already accepted practices, reduces the potential for strong policy effects.

\section{The future}

Future policy intervention should provide real resources and incentives for the creation of more and better EWCs. From this evaluation study we identify five areas of progress to be made: 
1. Policy which drives proactive innovation: instead of reflecting commonly accepted practices, policy should stimulate less commonly employed good practices to really upgrade the functioning of the average EWC.

2. Rights and levers to use them: establishing a certain right (e.g. renegotiation in case of structural change) without providing the necessary instruments to make these rights effective in practice should be avoided. Rights should be combined with effective resources to overcome common obstacles.

3. Focus on capacity building: if policy aims to promote the establishment of more EWCs, it should focus on building up the capacity of the partners to make good use of the EWC (added value), but also ensure their capacity to negotiate an agreement. Here, investment in trade union organization and local information and consultation institutions is essential.

4. Knowledge and information: another major obstacle to the establishment of more EWCs and the effective use of the rights at hand is the limited knowledge of existing rules, and insufficient information on which companies are covered by the Directive (i.e. lack of a company registry).

5. Monitoring of formal compliance of EWC agreements could be developed in order to reduce the legal uncertainty arising from the diversity in legal arrangements, itself being a consequence of the policy of regulated self-regulation.

6. Clarity in objectives: certain objectives of the Recast (e.g. stimulating trade union involvement) were included implicitly. Naturally, the effectiveness of these policy interventions is very limited. If policy aims to stimulate certain practices, these objectives should be clearly included in the legal texts and backed by robust provisions.

Beyond the potential areas of progress identified by this evaluation exercise, improvements in other fields (not included in this study) might still be required. These involve, among others: clarifying the legal obligations of the employers when the subsidiary requirements apply; further clarifying the cooperation and coordination between different levels of employee involvement (articulation); regulating the scope and limits of confidentiality arrangements; guaranteeing effective enforcement of rules, including provisions for sanctioning; regulating the access of EWCs to courts; and many more. 
Table 11 Relation to the European Commission's roadmap (European Commission 2016)

\section{Question from the European Commission's roadmap \\ For the compliance: \\ To what extent is the transposition of the new rules correct at national level? \\ What are the main issues/aspects of the Directive that remain or have emerged as recurrent problematic or contentious issues at national and European levels or in their articulation? \\ For the effectiveness \\ In what respect/to what extent does the Directive - the ' new rules' - bring a new impetus to consultation and dialogue in transnational companies, in particular as regards the opening and process of the negotiations ...}

... the enhanced role of trade unions and employers' organisations,

the new concepts of information and consultation?

How many agreements [EWCs in ETUI's vocabulary] are still not ruled by the Recast Directive because of the derogations foreseen in its Article 14?

How many agreements apply the subsidiary requirements?

How is the new right for employees' representatives to benefit from training without loss of salary implemented in practice?

To what extent has the role of EWCs increased in the negotiation implementation and monitoring of transnational company agreements?

What is the specific effect of the recast against the prevailing economic context?

Against the baseline situation (2009), what is the impact of the Directive on the creation or the absence of EWCs in their various contexts (companies/ sectors/ countries) as well as the reasons for this?

How many EWC agreements were concluded or renegotiated during the reference period (5 June 2009 - 5 June 2011)?

What are the current main characteristics of the EWCs: composition number of meetings, existence of select committees and of working groups?
Not provided

Not provided

Not provided

Not provided

The Recast did not lead to a new wave in the establishment of EWCs. The declining growth rate persisted

The Recast did not lead to a significant increase in the representation of members of European or national trade unions in EWCs.

The Recast did significantly increase the probability that an EWC agreement includes specific definitions of Information and Consultation.

$42 \%$ (395) of all active EWCs are still functioning as pre-directive EWCs. An additional 3\% (31) are functioning as article $14.1 \mathrm{~b}$ EWCs.

12 EWCs are currently registered as functioning under the subsidiary requirements. Some more might not be registered in the database and it is unclear whether they function well.

The Recast did not significantly change the probability that an EWC agreement will include a clause on training. Over time, however, this probability increased significantly and in the period preceding the Recast it reached almost 100\%

Not provided

Not provided

The Recast did not lead to a new wave in the establishment of EWCs. Essentially, the Recast did not provide sufficient instruments and levers to overcome known obstacles.

In the second transition period, 83 agreements were signed. 46 were small amendments or extensions of existing agreements. 28 created new EWCs and 9 were renegotiations. However, only 31 EWCs can be considered as art 14.1b EWCs as the other explicitly ruled out that possibility.

The main characteristics of the currently active EWCs are discussed in the 2015 Facts and Figures publication
Not provided

Not provided

Chapter 1

Chapter 3,

part 2.6 and 5

Chapter 3,

part 2.1 and 5

Introduction, part 2.2

Introduction, part 2.2

Chapter 3,

part 2.3 and 5

Chapter 1

ntroduction, part 2.2 
Too little, too late? Evaluating the European Works Councils Recast Directive

\begin{tabular}{|c|c|c|}
\hline Question from the European Commission's roadmap & Answer based on this report & Part \\
\hline \multicolumn{3}{|l|}{ For the efficiency: } \\
\hline $\begin{array}{l}\text { How did the transposition of the new rules of the Directive, including } \\
\text { the new right for training, affect the benefits and costs for workers and } \\
\text { for companies? }\end{array}$ & Not provided & Not provided \\
\hline How did the recast simplify administrative burden? & Not provided & Not provided \\
\hline \multicolumn{3}{|l|}{ For the relevance : } \\
\hline $\begin{array}{l}\text { To what extent do national laws reflect similar or provide for more } \\
\text { protective conditions for workers than the Directive' s improved } \\
\text { information and consultation rights for employees? }\end{array}$ & Not provided & Not provided \\
\hline $\begin{array}{l}\text { What are the effects on legal certainty and clarity resulting from some } \\
\text { of its provisions, like the adaptation clause or the definition of } \\
\text { transnationality, or the absence of certain provisions, like on a clear } \\
\text { articulation between national and European information and } \\
\text { consultation procedures? }\end{array}$ & Not provided & Not provided \\
\hline $\begin{array}{l}\text { In particular how does it impact on the enforcement of rights by the } \\
\text { courts? What is the quantitative and qualitative dimension of litigation } \\
\text { or complaints and debates in the Member States? What is the impact of } \\
\text { the new competence of the members representing the employees on } \\
\text { the EWC to represent the employees of the undertaking or group of } \\
\text { undertakings? }\end{array}$ & Not provided & Not provided \\
\hline \multicolumn{3}{|l|}{ For the coherence : } \\
\hline $\begin{array}{l}\text { To what extent is the Directive coherent with other EU legislation } \\
\text { addressing workers' information and consultation rights, notably with } \\
\text { the Article } 27 \text { of the EU Charter of Fundamental Rights? }\end{array}$ & Not provided & Not provided \\
\hline \multicolumn{3}{|l|}{ For the EU added value } \\
\hline $\begin{array}{l}\text { The Directive } 2009 / 38 \text { on the establishment of European Works } \\
\text { Council has a genuine EU specificity as } 6 \text { EWCs are transnational bodies } \\
\text { representing employees of companies established in at least two } \\
\text { Members States. Based on the assessment of the above criteria, } \\
\text { conclusions will be made notably on the coordination gains, legal } \\
\text { certainty and ensuring minimum rights of the workers in terms of } \\
\text { information and consultation of employees via the EWCs. }\end{array}$ & Not provided & Not provided \\
\hline
\end{tabular}




\section{Annex 1: Data used}

\section{Data}

The data used in this study is taken from the EWC database (EWCdb), managed by the ETUI (European Trade Union Institute). The database includes information on EWCs, EWC agreements and multinational companies with EWCs. In the general absence of an exhaustive dataset of all EWCs, the EWCdb has the most comprehensive set of EWC agreements to be found.

\subsection{Level of analysis}

When studying EWCs, one can focus on different levels of analysis, depending on the research question of interest. If one is to describe the current situation with regard to EWCs (as is typically done in the EWC Facts and Figures series (Kerckhofs 2002, 2006; De Spiegelaere and Jagodzinski 2015), the level of analysis constitutes the EWCs that are currently active.

In Chapters 1 and 2 of this report, we do not focus on the current population of EWCs but on the population of all EWCs (active and dissolved). For Chapter 3 , the level of analysis is the individual EWC agreement.

\subsection{EWC agreement population selection}

In January 2016, a total of 2003 agreements were registered in the EWCdb. Not all these agreements are used in the subsequent analysis. The analyses in Chapter 3 are based on a sub-section of the whole population.

The criteria for the identification of this sub-population are:

- Full agreements: original installation agreements, extensive renegotiations and post-merger agreements

- Negotiated EWCs: excluding EWCs established on the subsidiary requirements because of a lacking agreement

- Post-1993 agreements: excluding agreements made between 1985 and 1993 (n: 36)

- Pre-2015 agreements: excluding agreements signed in 2015 and 2016. 
This selection is guided by computational and conceptual criteria. Conceptually, Chapter 3 focuses on evaluating the Recast. We are therefore interested in fundamental changes to EWC agreements and not cosmetic changes (as with amendments), nor in EWCs established because of a lack of agreement (as when the subsidiary requirements apply). Furthermore, the pre1993 agreements are not essential in this analysis as the major focus lies on comparing the pre- and post-Recast period.

Computationally, amendments and extensions are mostly empty agreements leading to a multitude of missing values; this influences the estimation. Pre1993 agreements are particularly significant outliers which influence our estimates due to the fact that they are completely 'voluntary' and hardly influenced by any (upcoming) regulation.

The 2015 agreements were deleted from the analysis because the database does not yet have a complete set of EWC agreements made in the last year. EWC agreements tend to be registered in the EWCdb with a certain delay. The ones registered quickly might not be a perfectly representative sample of all EWC agreements made. The fact that 2015 was in certain areas an outlier, led to the decision to exclude this year from the analysis.

Our full dataset for the following report thus represents 1078 EWC agreements of which $\mathbf{1 0 7}$ were signed in the post-recast period.

\section{Variables}

\subsection{Grouping variable}

Our level of analysis for Chapter 3 is the individual EWC agreement. Not all these individual EWC agreements are independent of each other. Some agreements are likely to resemble each other because they belong to the same EWC. For example, a renegotiation of a certain agreement is very likely to resemble the original agreement in various ways. For this reason, we use the EWC as a second level grouping variable.

\subsection{Control variables}

Four control variables are used in the analysis of Chapter 3 :

Sector: The sector of activity of the company in which the EWC is based. Distinction is made between six sectors:

- Chemical

- Metal

- Services

- Food, hotel and catering

- Building and woodwork 
- Other: taking in together EWCs from companies based in the textile, transport and public service sectors, together with EWC agreements for which the sector of activity is unknown.

Country cluster: This variable is based on the country in which the company of the EWC is headquartered. As EWCs can be installed in multinational companies based in any country of the world, we grouped the headquarter countries into four clusters:

- Nordic countries: Denmark, Norway, Sweden, Finland and Iceland.

- Coordinated Market Economies (CME): Germany, Belgium, the Netherlands, Austria, Luxemburg and Switzerland.

- Mixed Market Economies (MME): France, Italy, Portugal, Spain and Greece.

- Liberal Market Economies (LME): the United Kingdom, Ireland, the United States, Canada, Japan, the Central-East European countries and others.

Company size: This variable reflects the employment in the European Economic Area and distinguishes between relatively small multinationals ( $<5$.000 employees), medium sized multinationals (5.000-10.000 employees) and large multinationals (>10.000 employees).

EWC type: The EWC type refers to the overall regulatory framework which applies to the EWC in which the EWC agreement is made. Due to some specific articles in the original EWC and Recast Directive, distinction should be made between three types of EWC types:

1. Pre-Directive EWCs: The first are the agreements made in EWCs established under Article 13 of the original Directive. This article specifies that the Directive shall not apply to EWC agreements made before the $22^{\text {nd }}$ September 1996. Moreover, if such agreements are later renewed or renegotiated they continue to be exempted by the rules of the Directive. An agreement made in 2015 can therefore still be exempt from the Directive's rules and obligations. The agreements are sometimes called 'voluntary agreements', 'Article 13 agreements' or 'pre-Directive agreements'.

2. Article 6 EWCs: A second type are the agreements from EWCs established under Article 6 of the original EWC or Recast Directive. These agreements are fully covered by the Directive and all its rights and obligations which stem from it.

3. Article 14.1b EWCs: The third type are the Article 14.1b agreements, established under the regulation of Article 14.1b of the Recast Directive. This article stipulates that agreements (both original and renegotiations) made between 5 June 2009 and 5 June 2011 are given a special status. The definitions and principles of the Recast apply to those agreements, but not the 'new obligations' (Picard 2010). 
In identifying the legal basis of the signature date is an important, but not the only variable. Even if an EWC is established in the period that would enable it to be a pre-Directive EWC or an Article 14.1b EWC, the negotiating parties can still decide to reject that status and consider themselves fully covered by the directive. In that case, an EWC will be considered an Article 6 EWC.

\subsection{Time-related variables}

Depending on the signature date of the EWC agreement, two time-related variables are employed.

A first variable simply refers to the year in which the agreement was signed. The second variable refers to the policy period in which the agreement was signed. This variable contains four categories:

- Pre-1996, containing all agreements signed before 22 September 1996.

- 1996-2009, containing all agreements signed between 22 September 1996 and 5 June 2009.

- 2009-2011, containing all agreements signed between 5 June 1996 and 5 June 2011.

- Post-2011, containing all agreements signed after 5 June 2011.

\subsection{Dependent variables}

All dependent variables in this study are dummy variables (o/1), measuring whether or not a certain clause, right or information is present in an agreement. The data for these variables are source from a content analysis performed on all available agreements.

- Information and consultation definitions (o/1): Dummy variable indicating whether an agreement explicitly specifies a definition for information and consultation.

- Select committee (o/1): Dummy variable of whether or not the agreements specifies that a Select Committee is or will be installed for the EWC.

- Training clause (o/1): Dummy variable of whether the agreement specifies that EWC representatives have a right to training paid for by the management.

- Definition of the transnational competence (o/1): Dummy variable indicating whether an agreement explicitly specifies a definition for transnational matters.

- Clause on reporting back (o/1): Dummy variable indicating whether or not the agreement includes a clause on reporting back on EWC activities.

- Access to premises (o/1): Dummy variable indicating whether or not a clause is included guaranteeing the right of employee representatives to visit the company premises. 
- Employee-only preparatory and debriefing meetings (o/1): Dummy variable indicating whether or not the employee representatives can have a preparatory and debriefing meeting.

- Trade union representative (o/1): Dummy variable indicating whether or not the agreement allows representatives of a trade union to join the EWC meetings.

- Renegotiation and termination clause (o/1): Dummy variable indicating whether or not the agreement has a clause on the termination and renegotiation of the agreement.

\section{Data quality}

The data used for this study is based on a content analysis of the available EWC agreements in the ETUI's EWC database. Although this database is by far the most comprehensive dataset on EWC agreements and is the only one including a thorough and consistent analysis of the agreements' content, some data quality issues might occur. As such, there might be a coverage error if certain agreements are systematically not registered or a measuring error if there are systematic coding mistakes. To assess, correct and prevent such issues, the ETUI reviews regularly the database on errors and inconsistencies. While errors cannot be excluded, the results of these quality checks indicate that with the inclusion of the correct control variables, a significant bias in the estimates is unlikely.

\section{Robustness test of the GEE models}

\subsection{Non-linear time effects}

In Chapter 3 of this report several models are presented, including time as a linear effect. When working with GEE estimations, linear effects mean a constant change in the odds over time, which is actually a non-linear growth effect. However, one could also model the continuous time variable as a quadratic variable, which would model whether the change in the odds is changing over time or not. Training, for example, could experience a slow start, but once this 'best practice' is taken up, the growth rate increases. Analysis of the different models including such a quadratic learning effect nevertheless revealed no such significant effect.

\subsection{Interactions}

Chapter 3 of this report concentrated on the learning effect and a discrete policy effect which immediately influences the likelihood of a clause to be included in an agreement. One could, however, also conceive a different policy effect; one that increases the learning curve and thus the general learning effect. Alternative models including such an interaction term were fitted. These models did not provide indications for an effect in which the Recast affected the general learning curve. 


\section{Annex 2 \\ EWC agreement content: evolutions and bivariate relations}

This annex gives a descriptive overview of the evolution over time of the several dependent variables included in Chapter 3 .

\section{EWC agreement demographics}

\subsection{Agreements over time}

The amount of EWC agreements signed each year follows a very particular pattern (Figure A.1). Initiated in the 80s, the EWC agreements got off to a rather slow start with less than 10 agreements signed each year. This nevertheless radically changes in 1994 with the publication of the first EWC Directive. This Directive included a clause specifying that EWCs created before 22 September 1996 were exempted from the rules of the Directive if they met certain criteria. As a result, a record amount of 427 EWC agreements were signed, of which 403 established a new EWC.

Following the implementation of this Directive, the amount of agreements signed each year declined to less than 100. After a slight increase in the amount of agreements around 1998-2000, the overall pattern has since been one of constant decline in the amount of EWC agreements signed.

There are, however, different types of EWC agreements. As such, distinction is made between:

- Original installation agreements: first EWC agreements which establish a new EWC

- Renegotiations: fundamental changes to the functioning of the EWC

- Amendment/ extension: agreements on small changes to the existing agreement or simple extension of the current agreement for a new period.

As can be expected, in the first few years the EWC agreements are almost exclusively original agreements establishing an EWC. Over the years, the share of renegotiations, amendments and extensions increases. From 2002 onwards, the changes to existing agreements (amendment, extension and renegotiation) represent about half of all EWC agreements made in a given year. 
Figure A.1 EWC agreements over time

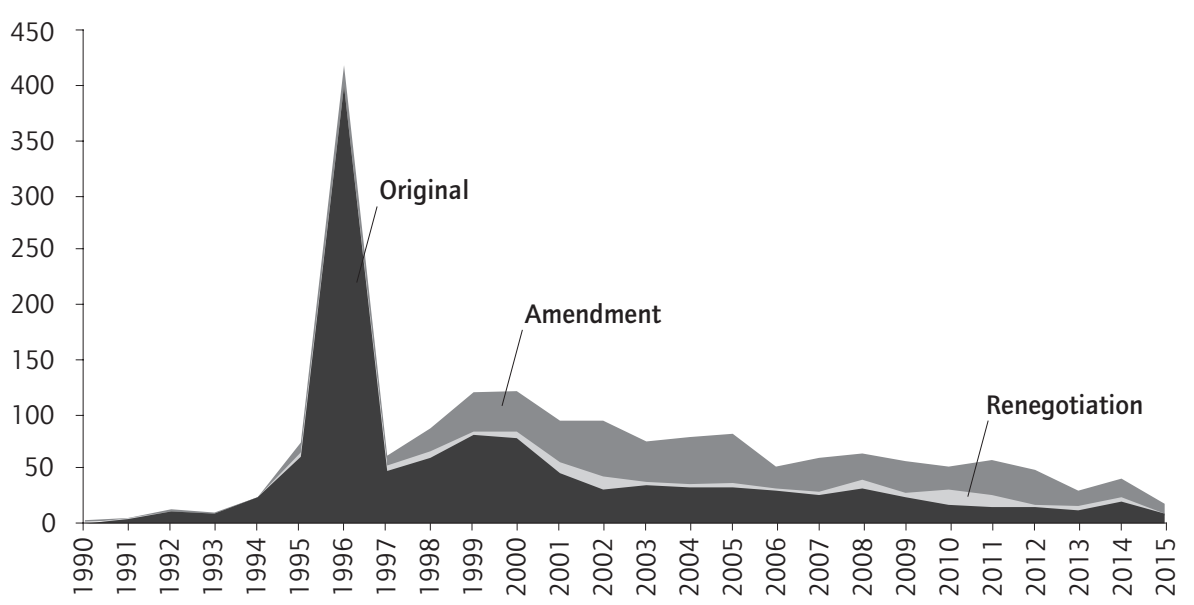

\subsection{EWC agreements across sectors}

Next to an unequal distribution over time, the EWC agreements are also unequally distributed over sectors. Figure A.2 shows the amount of EWC agreements per sector. Evidently, the bulk of the EWC agreements are made in the metal, chemical and services sectors.

Figure A.2 EWC agreements across sectors

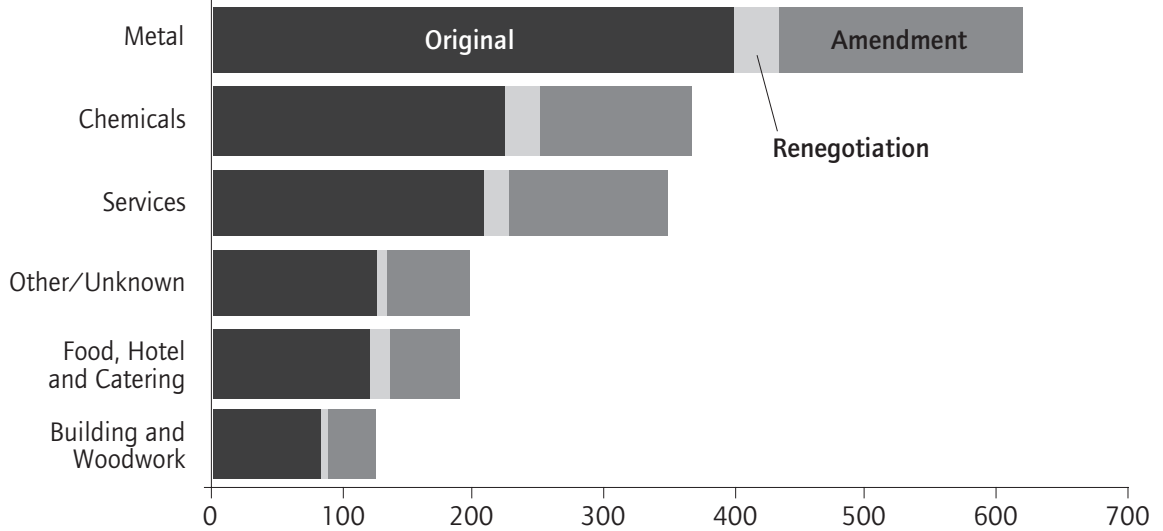


Focusing only on the 'full agreements' (original agreements and full renegotiations), an uneven distribution over time is also observed. Table A.1 shows the proportion of agreements per sector for subsequent five-year periods. These results show that the metal and chemical sectors continue to account for the largest share of EWC agreements, but that the other sectors are growing relatively more important over time.

Table A.1 Sectoral distribution over time

\begin{tabular}{|c|c|c|c|c|c|c|}
\hline & Chemicals & Metal & Services & Horeca & Building & Other/Unknown \\
\hline 1995-1999 & $23 \%$ & $32 \%$ & $13 \%$ & $13 \%$ & $8 \%$ & $11 \%$ \\
\hline $2000-2004$ & $18 \%$ & $37 \%$ & $20 \%$ & $8 \%$ & $9 \%$ & $8 \%$ \\
\hline 2005-2009 & $15 \%$ & $33 \%$ & $28 \%$ & $4 \%$ & $6 \%$ & $14 \%$ \\
\hline $2010-2014$ & $16 \%$ & $27 \%$ & $22 \%$ & $12 \%$ & $10 \%$ & $13 \%$ \\
\hline
\end{tabular}

\subsection{EWC agreements across company size}

Figure A.3 shows the distribution of agreements across different company sizes. Most EWC agreements are signed in (relatively) small multinationals $(<5$.000 employees in the EEA) and large multinationals ( $>10.000$ employees in the EEA). Moreover, in large companies, a relatively higher number of the EWC agreements are full renegotiations.

Figure A.3 EWC agreements across company size

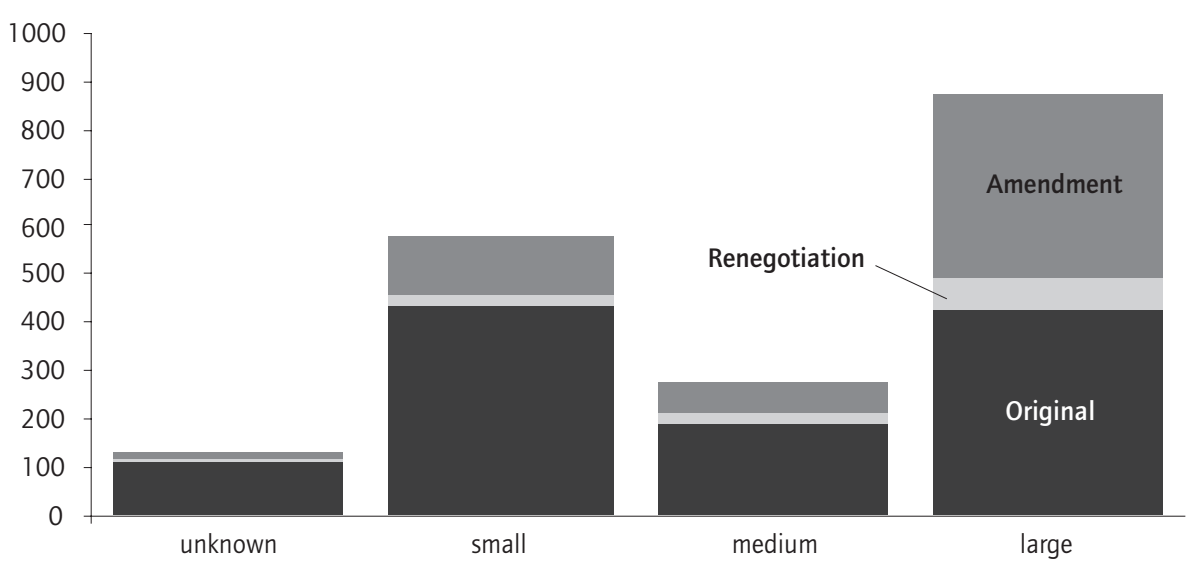


Focusing only on the 'full agreements' (original agreements and full renegotiations), Table A.2 shows a shifting pattern in terms of the size of the companies in which agreements are made. Obviously, the share of agreements made in companies of which the size is unknown increases. This is related to the decision to stop updating the database with multinationals covered by the Directive and focus exclusively on companies with EWCs.

Table A.2 Company size distribution over time

\begin{tabular}{|c|c|c|c|c|}
\hline & Unknown & Small & Medium & Large \\
\hline 1995-1999 & $4 \%$ & $37 \%$ & $16 \%$ & $43 \%$ \\
\hline 2000-2004 & $5 \%$ & $35 \%$ & $21 \%$ & $38 \%$ \\
\hline 2005-2009 & $22 \%$ & $29 \%$ & $19 \%$ & $30 \%$ \\
\hline $2010-2014$ & $27 \%$ & $30 \%$ & $11 \%$ & $32 \%$ \\
\hline
\end{tabular}

\subsection{EWC agreements across country cluster}

The amount of EWC agreements also differs depending on the headquarter country of the company. As can be seen in Figure A.4, most EWC agreements are signed in companies from CMEs.

Figure A.4 EWC agreements across countries

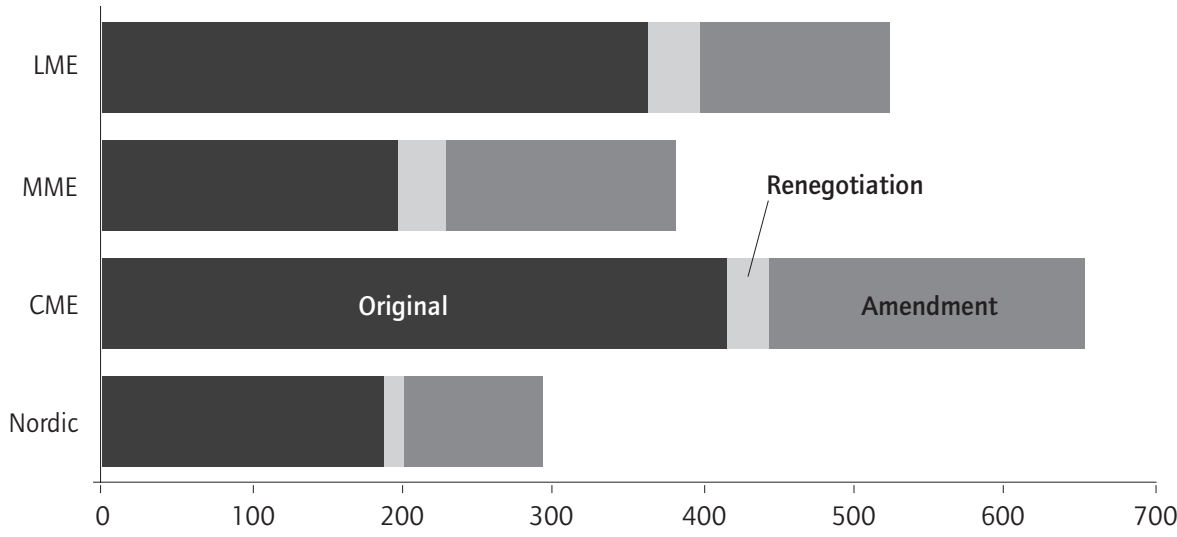

Considering only the full agreements (original, renegotiation and post-merger), Table A.3 demonstrates a change in the pattern. The relative weight of CME countries in the total amount of EWC agreements made is diminishing in favour of agreements made in MME headquartered companies. 
Table A.3 EWC agreements across country clusters, per five-year period

\begin{tabular}{|c|c|c|c|c|}
\hline & Nordic & CME & MME & LME \\
\hline 1995-1999 & $16 \%$ & $39 \%$ & $11 \%$ & $35 \%$ \\
\hline $2000-2004$ & $14 \%$ & $31 \%$ & $25 \%$ & $30 \%$ \\
\hline $2005-2009$ & $13 \%$ & $29 \%$ & $24 \%$ & $35 \%$ \\
\hline $2010-2014$ & $16 \%$ & $26 \%$ & $37 \%$ & $21 \%$ \\
\hline
\end{tabular}

\subsection{EWC agreements across type}

Finally, the distribution of EWC agreements over the type of EWC is examined. As discussed above, EWC can fall under different regulatory frameworks depending on the year of establishment and the will of the negotiating partners (Figure A.5). As many EWCs still function as 'pre-Directive EWCs' (De Spiegelaere and Jagodzinski 2015), a lot of EWC agreements are negotiated in such bodies. These EWCs are older, which explains the higher share of renegotiations and extensions. Next, we see that only 56 agreements are made in Article 14 EWCs. Of those 56, only 35 can be considered as full agreements (original installation agreements or full renegotiations).

Figure A.5 EWC agreements across EWC type

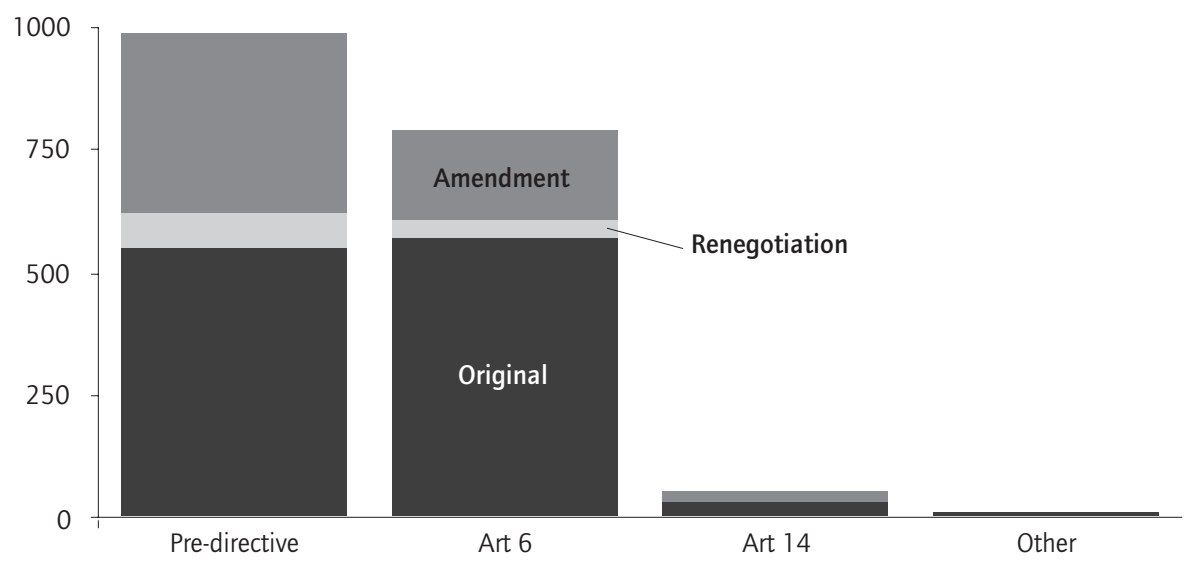

Table A.4 demonstrates the evolution of the shares over subsequent five-year periods. Obviously, in the first period ('95-'99) the majority of agreements are made in pre-Directive EWCs. However, this quickly changes; in all subsequent periods most agreements are made in Article 6 EWCs. 
Table A.4 EWC agreements across EWC type, per five-year period

\begin{tabular}{|c|c|c|c|c|}
\hline & Pre-Directive & Art. 6 & Art. 14 & Other \\
\hline $1995-1999$ & $68 \%$ & $20 \%$ & $0 \%$ & $12 \%$ \\
\hline $2000-2004$ & $17 \%$ & $75 \%$ & $0 \%$ & $7 \%$ \\
\hline $2005-2009$ & $10 \%$ & $81 \%$ & $5 \%$ & $4 \%$ \\
\hline $2010-2014$ & $11 \%$ & $66 \%$ & $13 \%$ & $11 \%$ \\
\hline
\end{tabular}

\subsection{Conclusion}

Looking at the EWC agreement demographics, some remarkable and uneven patterns are apparent. The EWC agreements are not evenly distributed over time, with 1996 being a huge outlier with more than 400 agreements signed. Over the years, the proportion of renegotiations tends to increase over time. Also, with regard to sector, company size and headquarter country of the firm, the distribution of EWC agreements is uneven. Proportionally more EWC agreements are signed in the metal and chemical sector, in large companies and in companies from CMEs.

Moreover, if we focus on the proportional distribution of these agreement characteristics in each year, we see both considerable year-to-year fluctuations and some more consistent evolutions, such as:

- An overall decline in the share of EWC agreements signed in the chemical sector over time and a parallel increase of the share of agreements signed in the service sector.

- An overall decline in the share of EWC agreements signed in large firms.

- An overall decline in the share of EWC agreements signed in companies headquartered in CMEs and an overall increase in MMEs.

- The share of agreements signed in pre-Directive EWCs falls sharply after 1996 and declines further over time.

\section{Agreement content and characteristics: bivariate relations}

Table A.5 contains shares of agreements containing a certain clause or definitions for each sector, country-cluster, company size, EWC type and period.

Sector: The agreement company differs significantly according to the sector of occupation on three variables. For clauses on reporting back we see that they are more common than average in the metal sector and less common in agreements from the building and woodwork sectors. The opposite pattern is observable for clauses on trade union representatives, which are also more present in agreements from the food, hotel and catering sector. Clauses on access to premises, on the other hand, are less present in the food, hotel and catering sector. 
Country: The headquarter country of the company is important for all but two variables: the presence of a select committee and preparatory and debriefing meetings. For all others there are significant country cluster differences. Interestingly, agreements from LMEs are more likely than average to have clauses on definition of the transnational competence and reporting back.

Company size: The company size plays a less important role and the patterns are not always clear. Clauses on trade union representatives, however, are more present in agreements from large companies than in others.

EWC type: The EWC type plays an important role for almost all variables except for clauses on reporting back and the presence of a trade union representative. In general, agreements made in Article 6 EWCs are more likely to have any of the included variables.

Period: As expected, the policy period plays a significant role for all variables and mostly because more recent agreements are more likely to have definitions and specific clauses then older agreements. One interesting exception is the presence of trade union representatives, which seems higher in pre-1996 agreements than in more recent ones.

\section{Trends over time}

The share of yearly agreements including information and consultation definitions has increased over time and has been about $80 \%$ in the last few years. The share of agreements including a select committee was already quite high in the ' 90 s yet continued to increase and now virtually all EWC agreements made in the last 10 years include a select committee. Training clauses were not so common in the period before 1996, yet this practice proliferated quite quickly until stabilizing at around $70 \%$ of the yearly agreements between 1997 and 2004. The share further increased over time and now close to $90 \%$ of all agreements signed in the last five years includes such a clause.

With regards to aspects of articulation, a definition of the transnational competence was already present in about half or more of the agreements until around 2005. Over the past ten years the share further increased, reaching about $80 \%$ in the last couple of years. The same can be said about clauses on reporting back. They were already quite common in early agreements yet stabilized for a long time at around $60 \%$ of agreements. In recent years, the share increased to more than $80 \%$. The last aspect of articulation, access to premises, is a lot less common. In the early years, virtually none of the agreements included such a right. Apart from year-to-year fluctuations, the share of agreements increased over time to about $25 \%$ in the last years. 


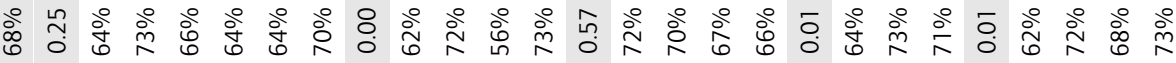

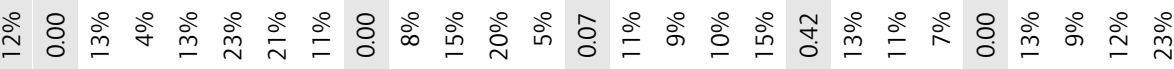

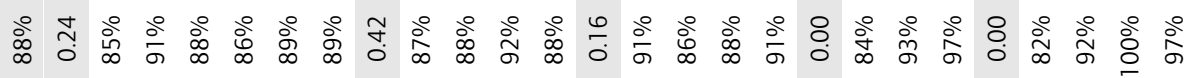

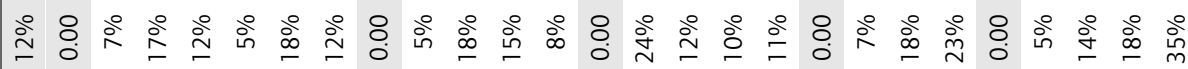

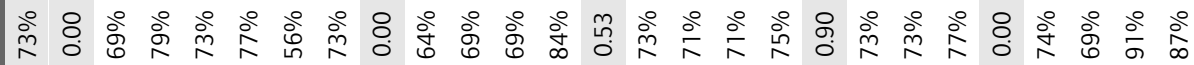

产

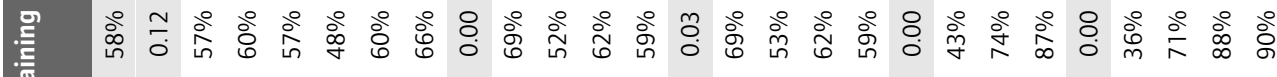

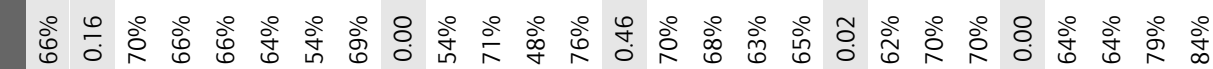

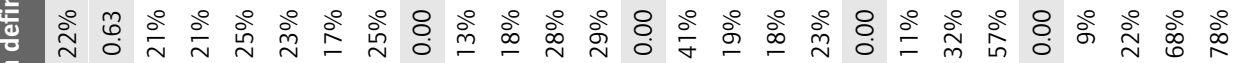

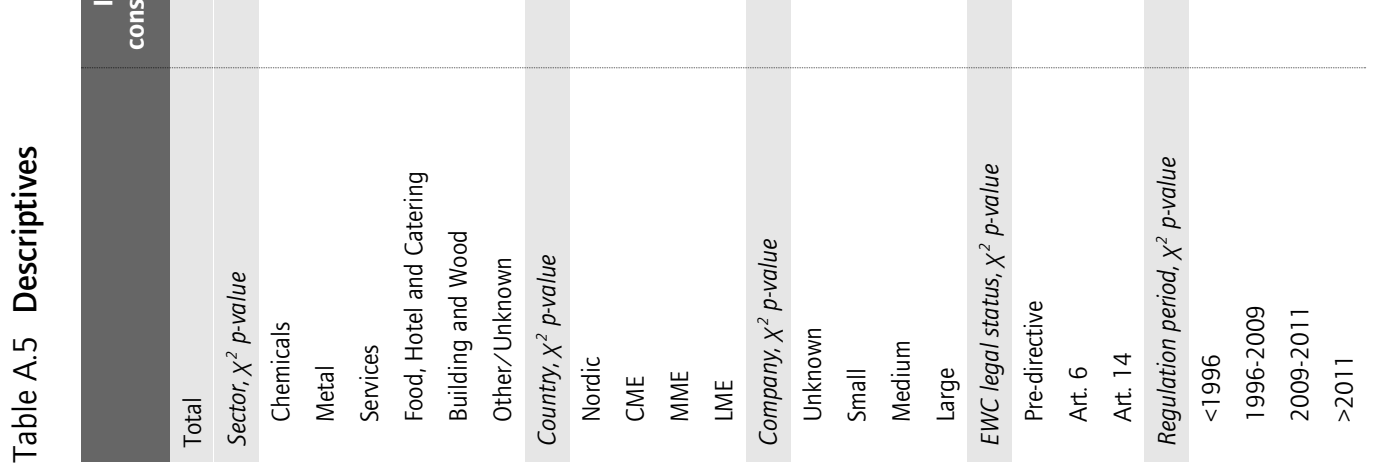


With regard to preparatory and debriefing meetings, we equally see a very low share providing for those in the early years and, again, the share rose to about $70 \%$ in the last years.

The inclusion of a trade union representative clearly follows different trends. First of all, the overall share of agreements providing for such representatives is quite low. Additionally, the tendency over time is not clear. The overall share of agreements does not seem to follow a growing trend.

With regard to the inclusion of both a renegotiation and termination clause, the observed pattern shows a rather quick initial learning phase, with an increase in the proportion of agreements including both clauses from $30 \%$ to over $50 \%$. Afterwards, the proportion seemed to stabilize at around $70 \%$. 

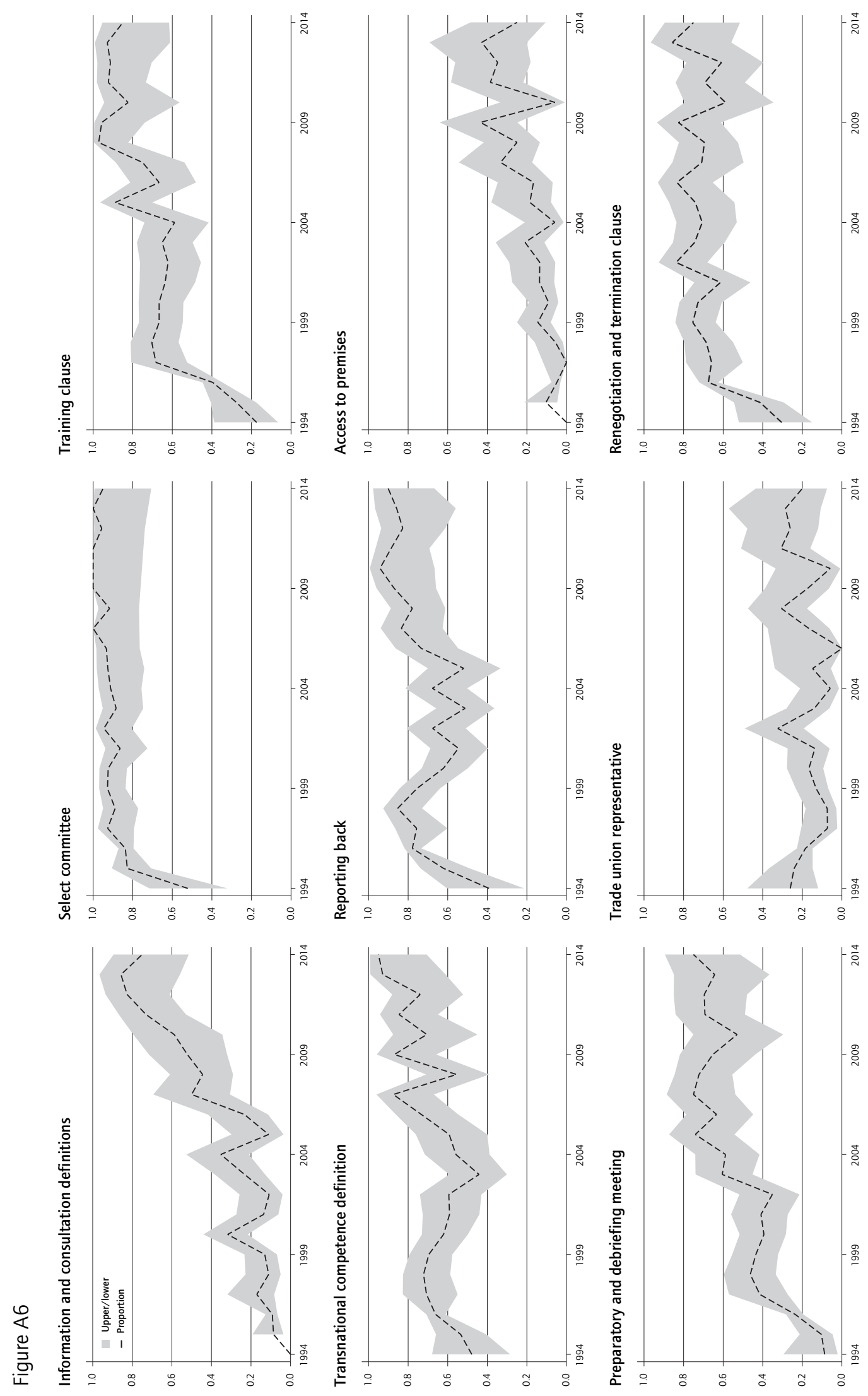


\section{References}

Carley M. and Marginson P. (2000) Negotiating European Works Councils: a comparative study of Article 6 and Article 13 agreements, Luxembourg, Office for Official Publications of the European Communities.

Cremers J. and Lorber P. (2015) Transposition of provisions of the Recast Directive on the functioning of the European Works Council, in Jagodzinski R. (ed.) Variations on a theme: the implementation of the EWC Recast Directive, Brussels, ETUI, 85-107.

De Spiegelaere S. and Jagodzinski R. (2015) European Works Councils and SE Works Councils in 2015: facts and figures, Brussels, ETUI.

De Spiegelaere S. and Jagodzinski R. (2016) The right and duty of European Works Councils to report back to the workforce: broad uptake, little specificity, Policy Brief 2/2016, Brussels, ETUI.

Dribbusch H. (2004) ECJ rules on German EWCs case, in EurWORK. European Observatory of Working Life. http://www.eurofound.europa.eu/observatories/ eurwork/articles/ecj-rules-on-german-ewcs-case

ETUC and ETUI (2016) Benchmarking working Europe 2016, Brussels, ETUI.

Eurofound (2015) European Works Council developments before, during and after the crisis, Luxembourg, Publications Office of the European Union.

European Commission (2008) European Works Councils: consultation of the European social partners on the revision of Council Directive 94/45/EC of 22 September 1994 on the establishment of a European Works Council or a procedure in Communityscale undertakings and Community-scale groups of undertakings for the purposes of informing and consulting employees, Brussels, European Commission.

European Commission (2010) Implementation of Recast Directive 2009/38/EC on European Works Councils - Report of the Group of Experts, Brussels, European Commission.

European Commission (2016) Evaluation on the implementation of Directive 2009/38/EC on the establishment of a European Works Council or a procedure in Community-scale undertakings and Community-scale groups of undertakings for the purposes of informing and consulting employees. http://ec.europa.eu/smartregulation/roadmaps/docs/2016_empl_011_evaluation_european_works_council_ en.pdf

Fligstein N. and Merand F. (2002) Globalization or Europeanization? Evidence on the European economy since 1980, Acta Sociologica, 45 (1), 7-22.

Gilman M.W. and Marginson P. (2002) Negotiating European Works Councils: contours of constrained choice, Industrial Relations Journal, 33 (1), 36-51.

Hertwig M. (2015) European Works Councils and the crisis: change and resistance in cross-border employee representation at Honda and Toyota, British Journal of Industrial Relations, 53 (2), 326-349.

Jagodzinski R. (2009) Recast directive on European works councils: cosmetic surgery or substantial progress?, Industrial Relations Journal, 40 (6), 534-545.

Jagodzinski R. (2010) Review, revision or recast? The quest for an amended EWC Directive, in Dorssemont F. and Blanke T. (eds.) The recast of the European Works Council Directive, Antwerp, Intersentia, 293-311.

Jagodzinski R. (2011) The EWC landscape on the eve of the transposition deadline of the recast directive 2009/38/EC, Brussels, ETUI. 
Jagodzinski R. (2013) The EWC directives and the SE legal framework: symbiosis and mutual reinforcement brought to a halt?, in Cremers J, Stollt M. and Vitols S. (eds.) A decade of experience with the European Company, Brussels, ETUI, 273-289.

Kerckhofs P. (2002) European Works Councils: fact and figures, Brussels, ETUI.

Kerckhofs P. (2006) European Works Councils: facts and figures 2006, Brussels, ETUI. Kerckhofs P. (2010) Can the Recast Directive bring more and more effictive EWCs?, in Dorssemont F. and Blanke T. (eds.) The recast of the European Works Council Directive, Antwerp, Intersentia, 399-419.

Lamers J. (1998) The added value of European Works Councils, Haarlem, AWVN. Lecher W. (1999) Resources of the European Works Council - empirical knowledge and prospects, Transfer: European Review of Labour and Research, 5 (3), 278-301.

Lecher W. and Rub S. (1999) The constitution of European Works Councils: from information forum to social actor?, European Journal of Industrial Relations, 5 (1), $7-25$.

Marginson P., Lavelle J., Quintanilla J., Adam D. and Sánchez-Mangas R. (2013) Variation in approaches to European Works Councils in multinational companies, ILR Review, 66 (3), 618-644.

Molenberghs G. and Verbeke G. (2005) Models for discrete longitudinal, New York, Springer.

Picard S. (2010) European Works Councils: a trade union guide to Directive 2009/38/EC, Report 114, Brussels, ETUI.

Platzer H.-W. (2002) Europäisierung und Transnationalisierung der Arbeitsbeziehungen in der EU, Internationale Politik und Gesellschaft, 2, 103-121.

Rüb S. and Platzer H.-W. (2015) The Europeanization of industrial relations in the service sector: problems and perspectives in a heterogeneous field, Bern, Peter Lang.

Sachs-Durand C. (2010) Information and consultation in the Recast Directive, in Dorssemont F. and Blanke T. (eds.) The recast of the European Works Council Directive, Antwerp, Intersentia, 313-326.

Waddington J. (2010) European Works Councils: a transnational industrial relations institution in the making, London, Routledge.

Waddington J., Pulignano V., Turk J. and Swerts T. (2016) Managers, BusinessEurope and the development of European Works Councils, Working Paper 06, Brussels, ETUI.

Weiler A. (2004) European works councils in practice, Luxembourg, Office for Official Publications of the European Communities.

Whittall M., Lücking S., Trinczek R. and Gunkel J. (2015) Closed frontiers: why German multinationals don't utilise the European Works Council Directive, Düsseldorf, HansBöckler-Stiftung.

Zeger S.L. and Liang K.Y. (1986) Longitudinal data analysis for discrete and continuous outcomes, Biometrics, 42 (1), 121-130. 